\title{
Evaluating the Approach of Using NOx Control Performance Tracking for On-Board Diagnostics of Heavy-Duty Diesel Vehicles
}

\author{
Renata Castiglioni \\ West Virginia University, recastiglionialveste@mix.wvu.edu
}

Follow this and additional works at: https://researchrepository.wvu.edu/etd

Part of the Other Mechanical Engineering Commons

\section{Recommended Citation \\ Castiglioni, Renata, "Evaluating the Approach of Using NOx Control Performance Tracking for On-Board Diagnostics of Heavy-Duty Diesel Vehicles" (2019). Graduate Theses, Dissertations, and Problem Reports. 3777.}

https://researchrepository.wvu.edu/etd/3777

This Thesis is protected by copyright and/or related rights. It has been brought to you by the The Research Repository @ WVU with permission from the rights-holder(s). You are free to use this Thesis in any way that is permitted by the copyright and related rights legislation that applies to your use. For other uses you must obtain permission from the rights-holder(s) directly, unless additional rights are indicated by a Creative Commons license in the record and/ or on the work itself. This Thesis has been accepted for inclusion in WVU Graduate Theses, Dissertations, and Problem Reports collection by an authorized administrator of The Research Repository @ WVU. For more information, please contact researchrepository@mail.wvu.edu. 
Evaluating the Approach of Using NOx Control Performance Tracking for On-Board Diagnostics of Heavy-Duty Diesel Vehicles

\title{
Renata Castiglioni
}

\author{
Thesis submitted \\ to the Benjamin M. Statler College of \\ Engineering and Mineral Resources \\ at West Virginia University
}
in partial fulfillment of the requirements for the degree of
Master of Science in
Mechanical Engineering

\author{
Arvind Thiruvengadam, Ph.D., Chair \\ Marc Besch, Ph.D. \\ V'yacheslav Akkerman, Ph.D. \\ Department of Mechanical and Aerospace Engineering \\ West Virginia University
}

\author{
Morgantown, West Virginia \\ 2019
}

Keywords: Diesel Exhaust Emissions, Nitrogen Oxides, Onboard Diagnostic, Onroad Testing

Copyright 2019 Renata Castiglioni 


\section{ABSTRACT \\ Evaluating the Approach of Using NOx Control Performance Tracking for On-Board Diagnostics of Heavy-Duty Diesel Vehicles}

\section{Renata Castiglioni}

Regulatory agencies have taken several measures to ensure proper regulation of engine exhaust in response to a yearly rise in urban pollution levels. This is due in no small part to vehicular traffic and resulting air pollution from exhaust.

This study evaluates the NOx Control Performance Tracking (NCPT) Onboard Diagnostic (OBD) parameter proposed by the California Air Resources Board (CARB) as a tool to assess inuse heavy-duty vehicle performance. It also assesses the various criteria prescribed in the NCPT approach for applicability to real-world vehicle data.

In order to analyze the data, the study also investigated the effect of various filter constants values over the cumulative values binned into the various categories. The study also illustrates the differences in the bin statistics as a function of vehicle activity and it evaluates the applicability of the NCPT approach for evaluating Not-to-Exceed (NTE) operation. The collected data displayed abnormalities which could be attributed to sensor limitations. This project proposes two options to reduce the noise in the sensor's data. In the first, it uses the NOx stable channel - if available and the second is the exponentially weighted moving average (EWMA). Both reducing methods were then compared to the original raw dataset to ensure no over smoothing of the data occurred. Once these datasets were finalized, they went through the Moving-Average Window (MAW) method proposed by EURO VI regulations before they could be binned.

The results indicate that despite applying different methods for NOx data reduction, the final binning product only displayed small change in value for certain bins while some remained intact. In addition, the vehicle displayed very few values inside the NTE zone, accounting at the most for $17 \%$ of the engine's operation. 


\section{Acknowledgements}

First and foremost, I would like to thank my Committee Chairperson Dr. Arvind Thiruvengadam for providing me with the opportunity to perform research in the field of my interest in addition to his teaching and guidance throughout the program. Your mentorship and patience were fundamental to my completion of this program. Additionally, I would like to thank my other committee members, Dr. Marc Besch and Dr. V'yacheslav Akkerman, for their time and consideration of my thesis.

I would also like to thank my friends and coworkers for their support and friendship. To Rasik, I genuinely appreciate all you've done for me. Without your mentorship and instructions, I would have struggled greatly through the program; you really were a mentor to me. I would also like to thank Sarah for always supporting me, and her companionship when I needed to spend time with a friend. Thanks are also due to Chakri and Sam for being outstanding office-mates; you were there when I needed a break from work and always provided me with the support to spur ideas when I thought I was at a dead end.

Additionally, I owe a debt of gratitude to my Morgantown family, the Martins, and especially Kimberly. You took me in and made me a part of your family and supported me through the rough times. I am very fortunate to have met you all and I can't thank you enough for the help and support you've provided.

Finally, I must thank my husband Caleb for his unfailing support despite the long days and hours of this program. You are my best friend and my favorite person. Lastly, I'd like to thank my puppies Luci and Bell, without whom this project would have been completed much sooner. 


\section{Table of Contents}

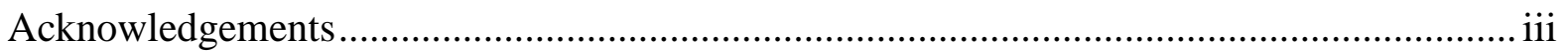

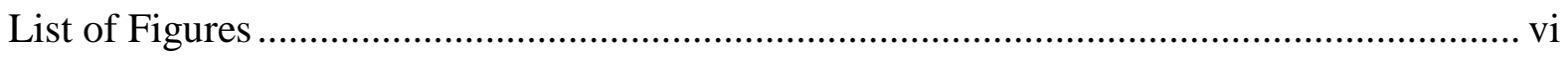

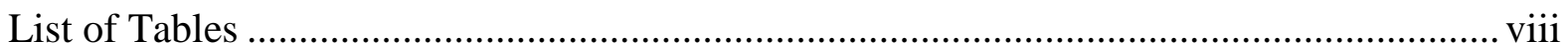

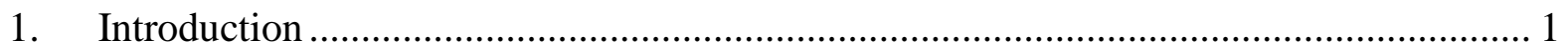

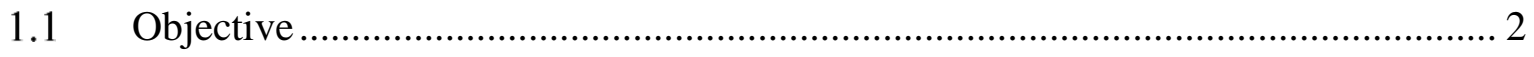

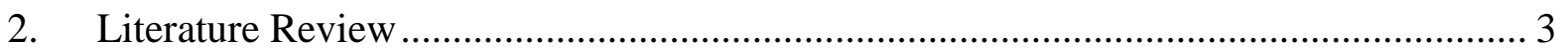

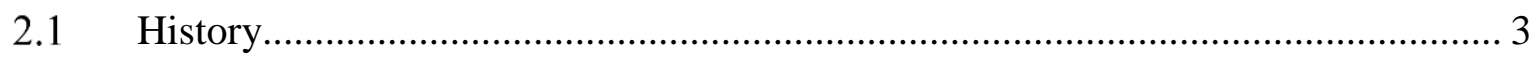

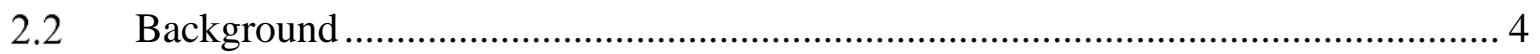

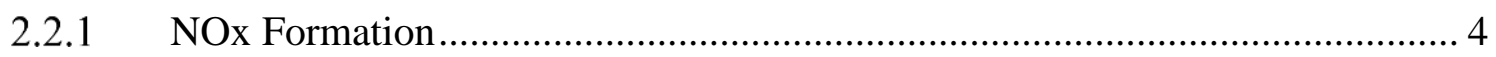

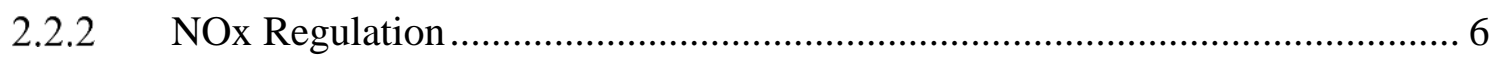

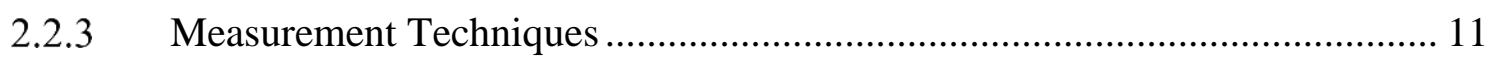

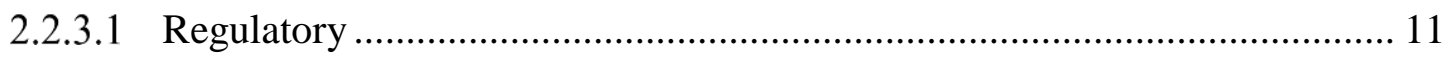

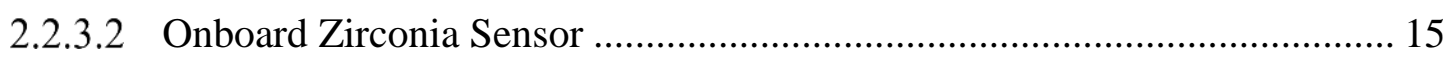

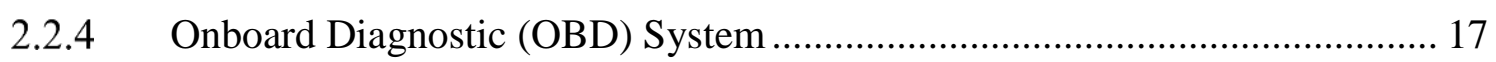

2.2.5 Moving-Average Windows (MAW) .......................................................... 17

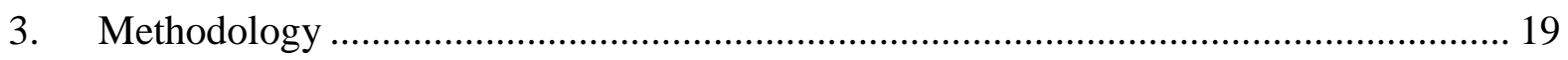

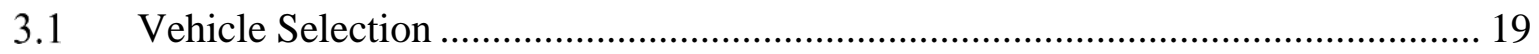

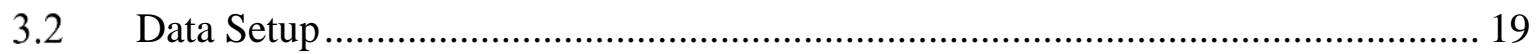

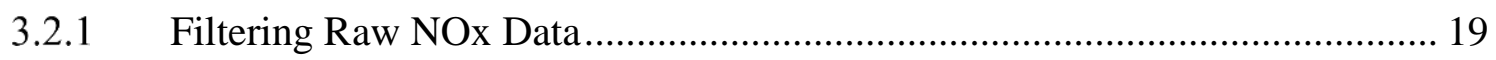

3.2.1.1 NOx Stable ................................................................................... 20

3.2.1.2 Exponentially Weighted Moving Average (EWMA) .................................. 20

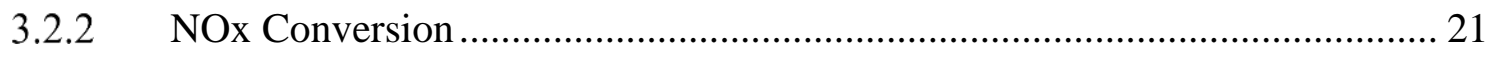

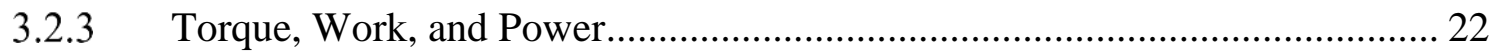

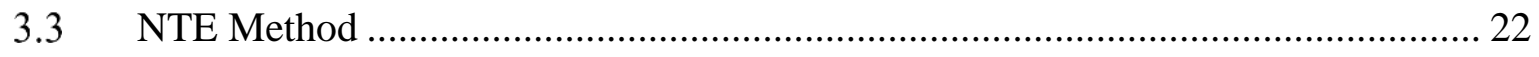

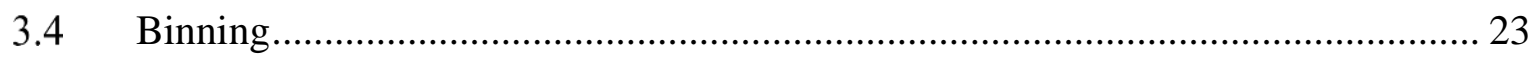

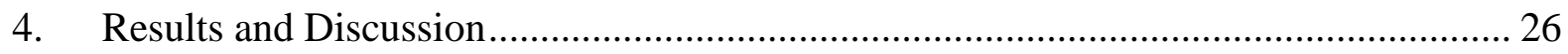

4.1 Lug Curve and NTE Zone............................................................................. 26

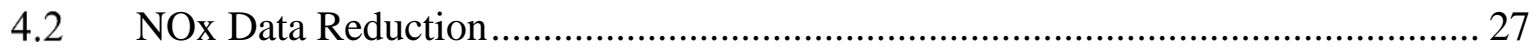

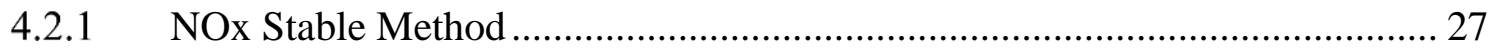

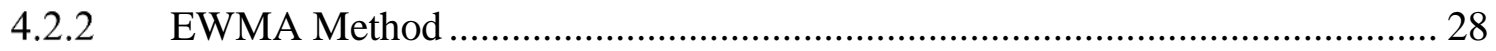

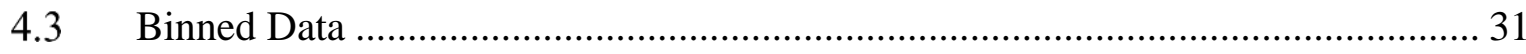

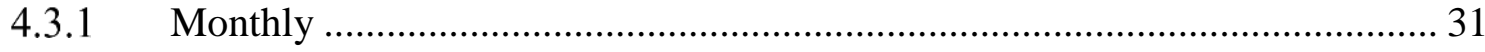

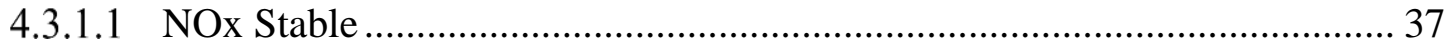




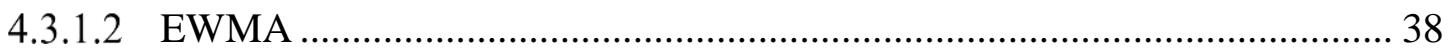

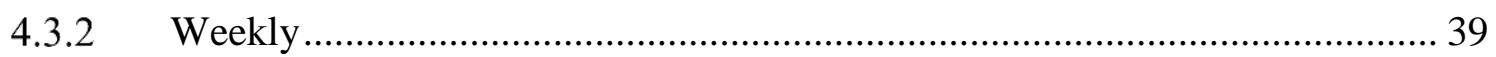

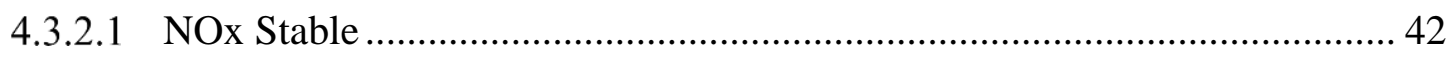

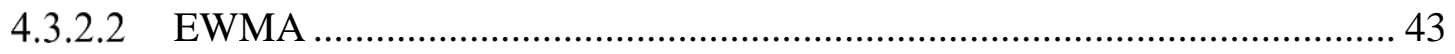

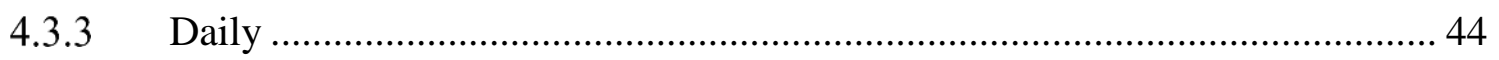

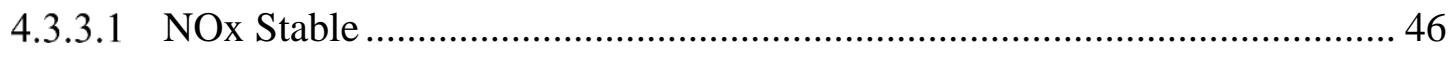

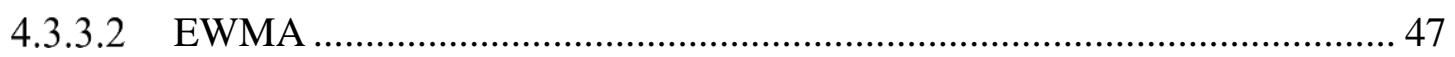

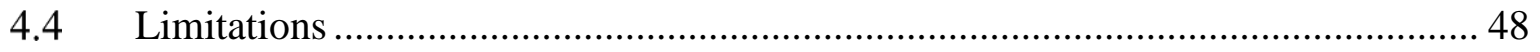

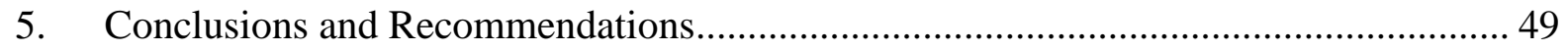

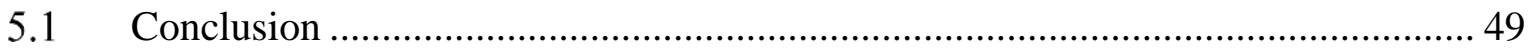

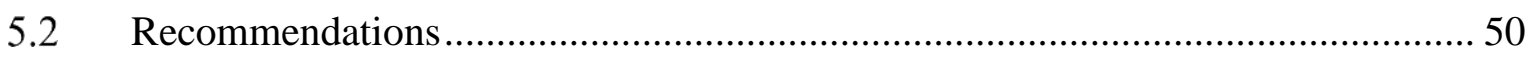

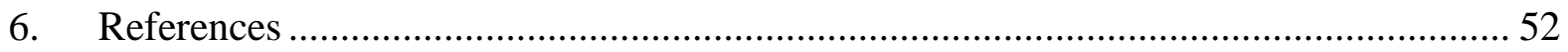

Appendix A: Bin Plots for Week Dataset .................................................................... 56

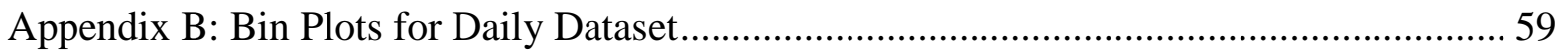




\section{List of Figures}

Figure 1 - NOx Emissions Standards for Heavy-Duty Diesel Vehicles Timeline [44] ............ 7

Figure 2 - NTE Zone Representation for a Generic Engine Torque Curve [18] .................... 10

Figure 3 - Chemiluminescent Detector Working Principle [20] ........................................... 12

Figure 4- Electrochemical Sensor Representation [46] ...................................................... 13

Figure 5 - PEMS Flow Diagram [25] ....................................................................... 14

Figure 6 - Zirconia Based NOx Sensor Representation [3] ................................................. 15

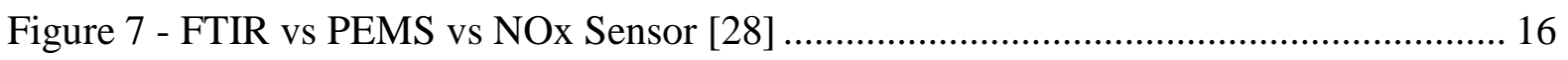

Figure 8 - NOx Tracking Binning Proposal [45] .............................................................. 24

Figure 9 - Lug Curve and NTE Zone for the Desired Vehicle …………………………...... 26

Figure 10 - NOx data filtered with NOx Stable vs Original Data ......................................... 28

Figure 11 - Amplified NOx data filtered with NOx Stable vs Original Data ....................... 28

Figure 12 - Filtered NOx EWF=0.1 vs Original data ...................................................... 29

Figure 13 - Amplified Filtered NOx EWF=0.1 vs Original data ......................................... 29

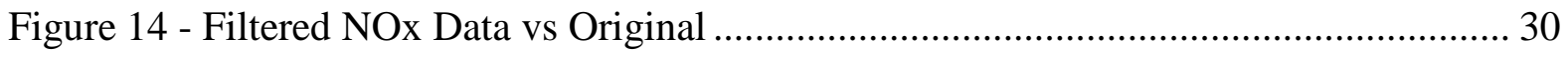

Figure 15 - Amplified Point 1: Filtered NOx Data vs Original ........................................... 30

Figure 16 - Amplified Point 2: Filtered NOx Data Peaks vs Original Data ........................... 31

Figure 17 - Original Data NOx (g/bhp-hr) Bin - Monthly ..................................................... 32

Figure 18 - Original Data NTE Bin - Monthly …………................................................... 33

Figure 19 - Original Data Bin Count - Monthly ............................................................... 33

Figure 20 - Original Data Post-SCR Exhaust Temperature $\left({ }^{\circ} \mathrm{C}\right)$ Bin - Monthly ..................... 34

Figure 21 - Original Data Power (bhp) Bin - Monthly …….................................................... 35

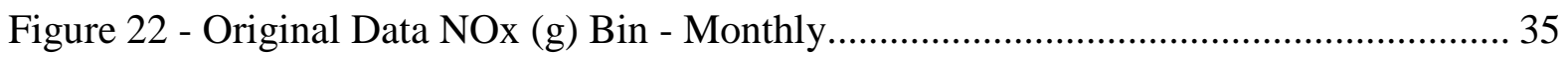

Figure 23 - Original Data Distance (miles) Bin - Monthly................................................... 36

Figure 24 - Stable Reduction Method NOx Data (g/bhp-hr) Bin - Monthly ........................... 37

Figure 25 - EWMA Method (EWF=0.1) NOx Data (g/bhp-hr) Bin - Monthly ....................... 38

Figure 26 - EWMA Method (EWF=0.25) NOx Data (g/bhp-hr) Bin - Monthly.................... 38

Figure 27 - EWMA Method (EWF=0.35) NOx Data (g/bhp-hr) Bin - Monthly.................... 39

Figure 28 - Original Data NOx (g/bhp-hr) Bin - Weekly ..................................................... 40

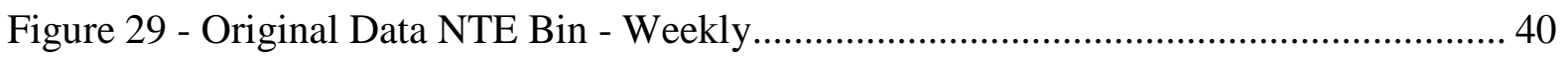

Figure 30 - Stable Reduction Method NOx Data (g/bhp-hr) Bin - Weekly............................. 42 vi 
Figure 31 - EWMA Method (EWF=0.1) NOx Data (g/bhp-hr) Bin - Weekly ..................... 43

Figure 32 - EWMA Method $(E W F=0.25)$ NOx Data (g/bhp-hr) Bin - Weekly ................... 43

Figure 33 - EWMA Method $(E W F=0.35)$ NOx Data (g/bhp-hr) Bin - Weekly ................... 44

Figure 34 - Original Data NOx (g/bhp-hr) Bin - Daily.................................................. 45

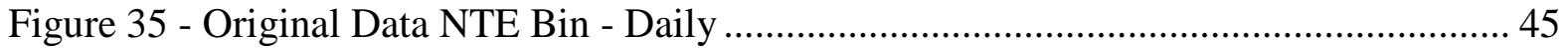

Figure 36 - Stable Reduction Method NOx Data (g/bhp-hr) Bin - Daily ............................. 46

Figure 37 - EWMA Method (EWF=0.1) NOx Data (g/bhp-hr) Bin - Daily........................ 47

Figure 38 - EWMA Method (EWF=0.25) NOx Data (g/bhp-hr) Bin - Daily...................... 47

Figure 39 - EWMA Method (EWF=0.35) NOx Data (g/bhp-hr) Bin - Daily....................... 48

Figure 40 - Original Data Post-SCR Exhaust Temperature $\left({ }^{\circ} \mathrm{C}\right)$ Bin - Weekly.................... 56

Figure 41 - Original Data Power (bhp) Bin - Weekly ................................................... 56

Figure 42 - Original Data Distance (miles) Bin - Weekly ............................................... 57

Figure 43 - Original Data NOx (g) Bin - Weekly ….................................................... 57

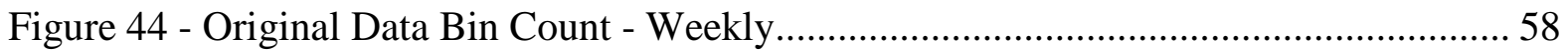

Figure 45 - Original Data Post-SCR Exhaust Temperature $\left({ }^{\circ} \mathrm{C}\right)$ Bin - Daily ........................ 59

Figure 46 - Original Data Power (bhp) Bin - Daily ....................................................... 59

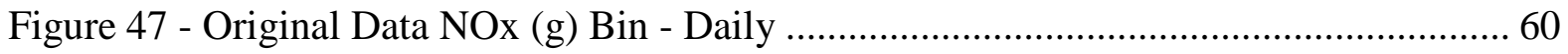

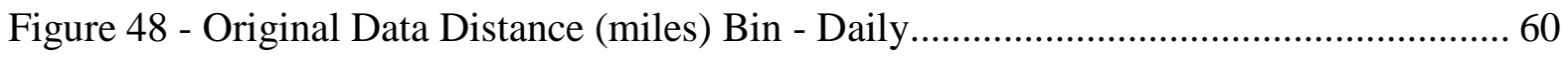

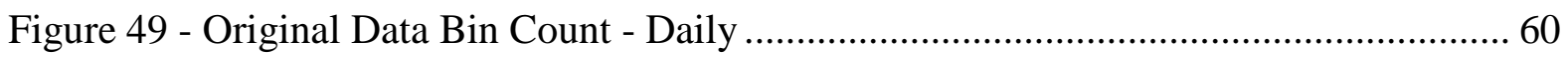




\section{List of Tables}

Table 1 - Nitrous Oxides Types and Properties [12] .................................................. 5

Table 2 - Heavy-Duty Highway Diesel Engines EPA Emissions Standards [47] ................. 9

Table 3 - Proposed Bin Structure According to CARB as of 2018 .................................... 25

Table 4 - WBW and Binning Analysis Method .......................................................... 25

Table 5 - Boundary Conditions for NTE Zone .............................................................. 27

Table 6 - Total Duration Summary - Monthly ......................................................... 32

Table 7 - Total Duration Summary - Weekly ............................................................. 41

Table 8 - Total Duration Summary - Daily ...................................................................... 44 


\section{Introduction}

Air pollution as a result of vehicle exhaust, has been a concern to human health world over for decades. It's well established that heavy-duty diesel (HDD) engines produce more oxides of nitrogen (NOx) than similar gasoline engines [1]. Several studies have been conducted to reduce emissions by studying the effects of different after treatment systems when added to the exhaust system. Despite continuous progress in emission technologies, overall emissions still continue to rise due to an increase in both number of vehicles and average yearly mileage traveled by vehicles within the United States [2]. In response, the United States government has committed to regulating emissions in conjunction with the engine manufacturers in order to minimize the emission profiles of these engines. However, as exhaust aftertreatment systems (EATS) become more complex there has been a growing need to determine appropriate means to ensure the proper working of the complex EATS. The current federal test procedure (FTP) cycle is not the most accurate representation of real-world vehicle activity [3]. There exists significant difference in real-world emissions rates and certification data [4]. In response, the California Air Resources Board (CARB) is in the process of introducing the window-averaging method to bin NOx data for standard evaluations of emission data regardless of route or driving cycle. This method is referred as the NOx Control Performance Tracking (NCPT) or Real Emissions Assessment Logging (REAL). This program has been recently implemented as part of the OBD regulations, which emphasize the use of current technology to analyze current onroad emission [5].

As part an effort to improve analysis of vehicular emissions profile and inform meaningful regulations, West Virginia University (WVU) was selected to conduct a study in California where researchers collected onroad data for multiple makes and models of heavy-duty vehicles. Sensors were attached to these vehicles before returning the vehicles to their usual schedule. Data was recorded for at least three months for each of the vehicles tested. The resulting datasets were then evaluated to better inform understanding of the emissions profile. 


\subsection{Objective}

The goal of this study was to analyze real-world data using a binning approach to characterize vehicle activity and in-use emissions for the purposes of OBD. The specific objective of the study included the analysis of real-world telemetry data in accordance to a binning method proposed by CARB. The main objective was to investigate the on-road emission data for a better understanding of the engine operation condition beyond test cycles. To do so, data was analyzed daily, weekly, and monthly in order to create consistent frames of reference when analyzing data sets. 


\section{Literature Review}

\subsection{History}

The first petroleum-based automobile was invented in Germany in the late 1800s. By the end of the first half of the twentieth century, the United States had become a major manufacturer of automobiles due to the perfection of mass production techniques first developed by Henry Ford. With the exception of a short stall in vehicle sales in 1927, the automotive industry has continued to grow yearly and accounts for vehicles from vocational cars to heavy duty vehicles [6].

The increase in vehicles sales and supporting infrastructure via highway building projects has also led to an increase in air pollution across the United States. This problem is specifically pronounced in cities due to the high volumes of vehicle traffic confined to a smaller area. In 1943, Los Angeles reported the first ever smog cloud which resulted in multiple health problems for residents. This first ever smog cloud incident was so pronounced that some residents were led to believe it was the result of a Japanese chemical weapons attack. It wasn't until 1948 that scientists discovered that smog was the result of vehicle exhaust and industrial pollution [7]. By 1955, in response to a growing concern for the health hazard caused by air pollution, the Department of Health, Education, and Welfare authorized the first air pollution program. This was the first instance of government's attempt to legislate air pollution and conduct research on the sources of pollution through the Air Pollution Control Act [8]. As an improvement to prior legislation, the Clean Air Act (CAA) of 1963 was passed. The CAA was intended to reduce pollution by holding each state responsible for its own control activities. In turn, the Department of Health, Education, and Welfare would conduct research into air pollution using federal funds. In 1965, the CAA was improved when amendments were passed to create national standards for motor vehicle pollution. However, it wasn't until 1967 when President Johnson asked Congress to pass new legislation that would enhance research and control efforts. As a result, Congress passed the Air Quality Act near the end of 1967. This new legislation aimed to expand funds for pollution research, air quality monitoring, and emissions control strategies [9].

By 1970, amendments were made to the 1963 CAA despite a decrease in air pollution across the United States. The 1970 amendments allowed both state and federal government to regulate emissions at both the industrial and individual level. It also established the National Emission Standards for Hazardous Air Pollutants (NESHAP), the National Ambient Air Quality Standards 
(NAAQS), and required individual states to plan for a means of meeting these standards. It was during this same period that the Environmental Protection Agency (EPA) was established to implement the requirements of this new legislation. The EPA is still a major government agency responsible for pollution regulation in the United States. In 1977 and 1990, additional amendments were passed to the $1963 \mathrm{CAA}$ to increase the authority of the federal government to regulate pollution and maintain air quality standards [8]. Throughout the years the regulations have gone from nonexistent in early 1950s to extremely strict. For instance, currently the NOx standard for HDD vehicles is $0.2 \mathrm{~g} / \mathrm{bhp}-\mathrm{hr}$ and California even offers an optional low NOx standard of 0.02 g/bhp-hr [10].

\subsection{Background}

\subsubsection{NOx Formation}

In compression ignition (CI) engines - Diesel engines - fuel and air are not mixed until both are injected into the cylinder and the ignition process starts. In CI engines, combustion follows the diffusion combustion pattern, whereby the fuel and oxidizer mix during the combustion process. When comparing engines, engines utilizing the CI combustion process produce a higher compression ratio and therefore increased efficiency in relation to spark ignition (gasoline) engines. However, this increased efficiency comes at the cost of higher particulate matter and NOx emissions [11].

Nitrogen oxides (NOx) is a family composed of multiple compounds. Table 1 displays the list of compounds within the NOx family. However, the EPA only regulates nitrogen oxide (NO) and nitrogen dioxide $\left(\mathrm{NO}_{2}\right)$, which are the most common $\mathrm{NOx}$ compounds present in engine exhaust gas. Therefore, for the purpose of this project, $\mathrm{NO}$ and $\mathrm{NO}_{2}$ are the only $\mathrm{NOx}$ family compounds referenced when the author uses the term NOx [12]. 
Table 1 - Nitrous Oxides Types and Properties [12]

\begin{tabular}{|l|l|l|l|}
\hline Formula & Name & $\begin{array}{l}\text { Nitrogen } \\
\text { Valence }\end{array}$ & Properties \\
\hline $\mathrm{N}_{2} \mathrm{O}$ & nitrous oxide & 1 & $\begin{array}{l}\text { colorless gas } \\
\text { water soluble }\end{array}$ \\
\hline $\begin{array}{l}\mathrm{NO} \\
\mathrm{N}_{2} \mathrm{O}_{2}\end{array}$ & $\begin{array}{l}\text { nitric oxide } \\
\text { dinitrogen dioxide }\end{array}$ & 2 & $\begin{array}{l}\text { colorless gas } \\
\text { slightly water soluble }\end{array}$ \\
\hline $\mathrm{N}_{2} \mathrm{O}_{3}$ & dinitrogen trioxide & 3 & $\begin{array}{l}\text { black solid } \\
\text { water soluble, decomposes in water }\end{array}$ \\
\hline $\begin{array}{l}\mathrm{NO}_{2} \\
\mathrm{~N}_{2} \mathrm{O}_{4}\end{array}$ & $\begin{array}{l}\text { nitrogen dioxide } \\
\text { dinitrogen tetroxide }\end{array}$ & 4 & $\begin{array}{l}\text { red-brown gas } \\
\text { very water soluble, decomposes in water }\end{array}$ \\
\hline $\mathrm{N}_{2} \mathrm{O}_{5}$ & dinitrogen pentoxide & 5 & $\begin{array}{l}\text { white solid } \\
\text { very water soluble, decomposes in water }\end{array}$ \\
\hline
\end{tabular}

$\mathrm{NO}$ is a common compound formed in the atmosphere; however, a percentage of NO present is the result of fuel combustion. The governing equations that summarize the formation of NO can be described in the following manner, which is often referred to as the Zeldovich mechanism [1].

$$
\begin{aligned}
& \mathrm{O}+\mathrm{N}_{2} \rightarrow \mathrm{NO}+\mathrm{N} \\
& \mathrm{N}+\mathrm{O}_{2} \rightarrow \mathrm{NO}+\mathrm{O} \\
& \mathrm{N}+\mathrm{OH} \rightarrow \mathrm{NO}+\mathrm{H}
\end{aligned}
$$

The formation of NO can occur at both the flame front as well as the end of combustion gases. In fact, during normal engine function the majority of $\mathrm{NO}$ is formed at the end of the combustion cycle. The formation of NO is mostly dependent on temperature. Higher temperatures combined with high oxygen concentrations will result in the formation of more NO relative to lower temperatures. Additionally, at the flame zone, $\mathrm{NO}$ can convert into $\mathrm{NO}_{2}$ and $\mathrm{NO}_{2}$ can convert into NO by the following processes described by equations ( 4 and (5. The latter process won't occur if the flame is mixed with a cooler fluid meaning that the highest $\mathrm{NO}_{2}$ to $\mathrm{NO}$ conversion occurs at light loads when the cylinders still contain cooler sections that could quench the flame [1]. The primary emitter from the engines is known to be NO [12]. 


$$
\begin{gathered}
\mathrm{NO}+\mathrm{HO}_{2} \rightarrow \mathrm{NO}_{2}+\mathrm{OH} \\
\mathrm{NO}_{2}+\mathrm{O} \rightarrow \mathrm{NO}+\mathrm{O}_{2}
\end{gathered}
$$

NOx compounds may form nitric acid $\left(\mathrm{HNO}_{3}\right)$ or nitrous acid $\left(\mathrm{HNO}_{2}\right)$ when dissolved in water. Both compounds are well known to influence the rate of acid rain events. The NOx compounds are known to be naturally produced in nature and are commonly found in the air. Therefore, any addition of NOx from outside sources can result in an oversaturation of these compounds in the air. However, NO is mostly produced by human activities. The natural sources are assumed to account for less than $10 \%$ of its emissions. Both $\mathrm{NO}$ and carbon dioxide $\left(\mathrm{CO}_{2}\right)$ are known to cause difficulties for the blood to absorb oxygen, which is a threat to human health. As for $\mathrm{NO}_{2}$ the main concern is its tendency to produce ozone $\left(\mathrm{O}_{3}\right)$ which in excess is the main contributor for smog [12].

NOx can also have profound impacts on aquatic life. A process called eutrophication can occur when there's an excess of nitrates present in water. Eutrophication is the process by which phytoplankton produce a surplus of nutrients which in turn cause excessive growth of certain plants in freshwater and saltwater environments that deplete the area of oxygen resulting in the death of marine life and aquatic plants [12]. This highlights the multiple factors driving regulations for a reduction of these gases.

\subsubsection{NOx Regulation}

According to the EPA, in 1997 the ozone pollution became an urgent matter regarding health hazards affecting millions of Americans. The areas designated as non-attainment were facing issues reaching the desired air quality and/or maintaining the quality. As a result, there was a need to regulate the emissions of NOx, hydrocarbons, and particulate matter for heave-duty engines. It was in 1997 that the EPA in association with the manufactures came together to create control strategies for NOx for onroad HDD vehicles [13]. This was the first attempt to reduce NOx emissions focused solely on HDD vehicles. Since 1997 multiple other regulations were passed in order to further decrease NOx emissions. As part of a study Figure 1 shows how the regulations have evolved from 1985 to the 2010 NOx regulation proposed by the CARB.

According the U.S. EPA NOx main sources are automotive, power plants, and off-road equipment. This main method that this family of compounds gets in the air is from the burn of 
fossil fuel [14]. In addition, NOx can also react with ozone and form acid rain [12]. As a result, there's a continued effort from multiple agencies to regulate and decrease the amount of NOx emitted every year. The number one NOx emitter in the United States is the agriculture sector. However, agriculture is difficult to regulate due to NOx emissions resulting mainly from fertilizers and soil treatments which are necessary to maintaining growth rate of crops. Fuel combustion only accounts for about $5 \%$ of the total NOx emission, however it has displayed a $4 \%$ increase since 1990 making it an easier target for reduction by regulation [13].

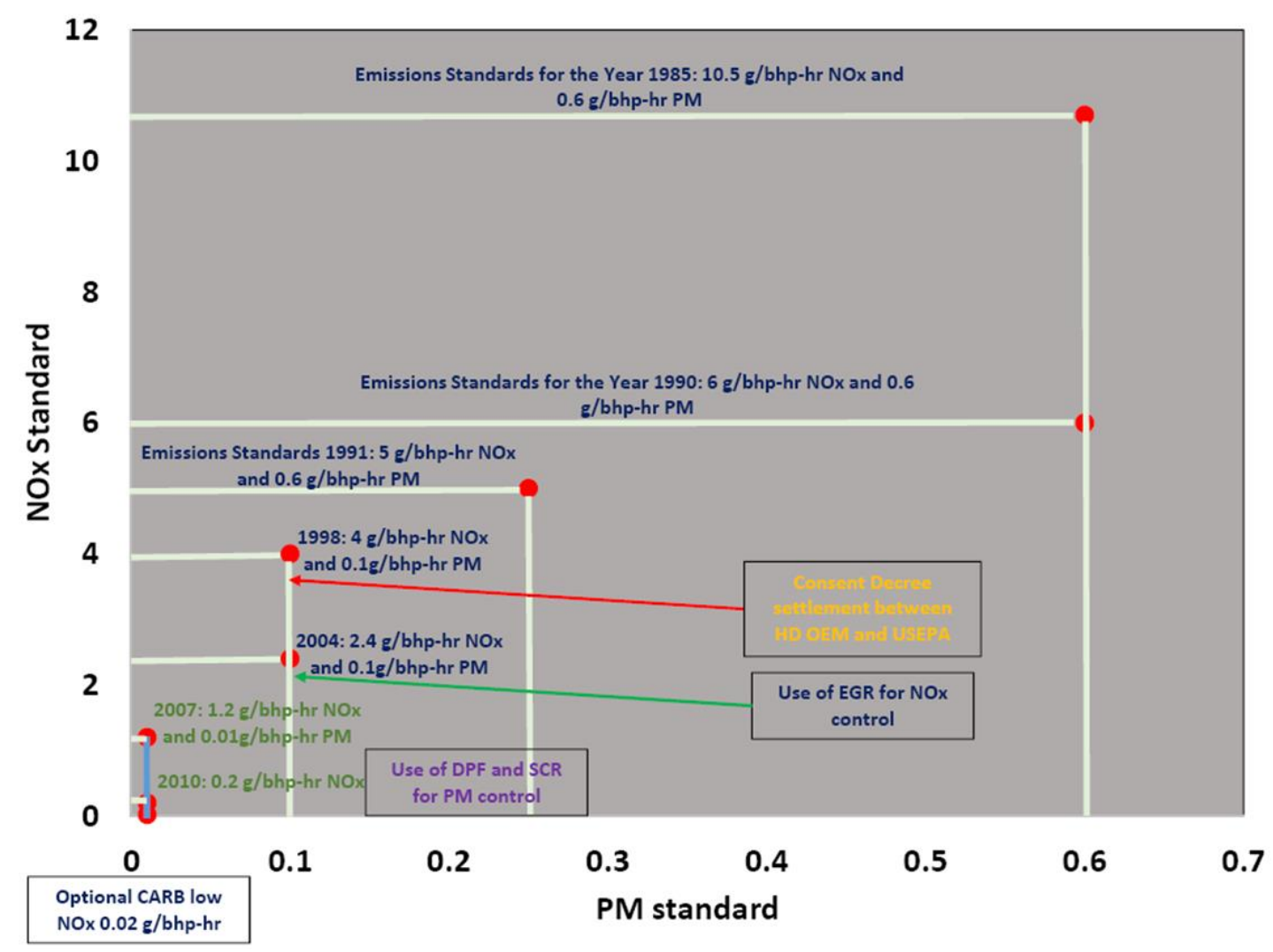

Figure 1 - NOx Emissions Standards for Heavy-Duty Diesel Vehicles Timeline [44]

Diesel engines tend to produce more NOx than gasoline engines due to the method of fuel mixture. While gas engines rely on a premixed combustion method, diesel engines have a diffusion combustion method. Due to the diffusion combustion method, the fuel and air are mixed inside of the combustion chamber turning it into a heterogeneous mixture. The resulting variables of combination of the heterogeneous mixture, ignition delay, and fuel to air ratio influence the amount of NOx generated during combustion [15]. There have been multiple studies conducted in addition 
to current studies in development to maximize the combustion efficiency of diesel engines and decrease NOx formation. However, due to the nature of combustion it's impractical to assume that NOx formation can be completely eliminated during the diffusion combustion process. To mitigate the NOx formation, aftertreatment systems have been developed to assist the reduction of the emissions.

For diesel engine emissions the main concern is NOx, therefore the vehicles are usually equipped with selective catalytic reduction (SCR) technology to reduce NOx. A SCR that is working properly can reduce NOx emissions by almost 90\% [16]. Additional aftertreatment systems common in diesel engine vehicles include diesel exhaust fluid (DEF) which is added to the exhaust before it goes through the SCR, a diesel particulate filter (DPF), and a diesel oxidation catalyst (DOC). For the SCR to function as intended, first the DEF must be injected into the exhaust flow - which is usually composed of urea - and through a reduction reaction NOx breaks down into nitrogen gas and water [17]. However, the SCR system function is dependent on temperature. The chemical reaction doesn't start until the system temperature reaches at least $200^{\circ} \mathrm{C}$. If the SCR system is operating below $200^{\circ} \mathrm{C}$ the SCR is highly inefficient. Temperature dependency causes fluctuation in diesel engine emissions due to the tendency of diesel engines operating at low speeds under low loads to not reach desired temperature resulting in higher than normal NOx emission. Therefore, even with multiple aftertreatment systems already in place, the United States EPA frequently passes regulations to incentivize the development of technologies to negate the need for a temperature dependent system. For instance, in Figure 1 the US EPA set a NOx limit of $0.2 \mathrm{~g} / \mathrm{bhp}-\mathrm{hr}$ in 2010 and as of 2013 the CARB has stablished a new optional ultralow NOx standard of $0.02 \mathrm{~g} / \mathrm{bhp}$-hr. However, there are still multiple studies being conducted in order to analyze the feasibility of this new ultra-low standard [10]. The table below summarizes the standards over the years for heavy-duty compression-ignition engines as of 2016. 
Table 2 - Heavy-Duty Highway Diesel Engines EPA Emissions Standards [47]

\begin{tabular}{|c|c|c|c|c|c|c|c|c|c|c|c|}
\hline & Year & $\begin{array}{c}\text { HC } \\
\text { (g/bhp-hr) }\end{array}$ & $\begin{array}{c}\text { NMH C } \\
\text { (g/bhp-hr) }\end{array}$ & $\begin{array}{c}\text { NMHC + } \\
\text { NOx g/bhp-hr) }\end{array}$ & $\begin{array}{c}\text { NOx } \\
\text { (g/bhp-hr) }\end{array}$ & $\begin{array}{c}\text { PM } \\
\text { (g/bhp-hr) }\end{array}$ & $\underset{\text { (gbhp-hr) }}{\text { co }}$ & $\begin{array}{l}\text { Idle CO } \\
\text { (percent } \\
\text { exhaust } \\
\text { gas flow) }\end{array}$ & $\begin{array}{c}\text { Smoke }{ }^{\mathrm{a}} \\
\text { (Percentage) }\end{array}$ & $\begin{array}{c}\text { Useful Life } \\
\text { (hours/years/miles) }\end{array}$ & $\begin{array}{c}\text { Warranty } \\
\text { Period } \\
\text { (years/miles) }\end{array}$ \\
\hline \multirow{10}{*}{ Federal ${ }^{\circ}$} & $1974-78$ & - & $=$ & 16 & - & - & 40 & - & $20 / 15 / 50$ & - & - \\
\hline & $1979-84$ & 1.5 & - & 10 & $=$ & - & 25 & $=$ & $20 / 15 / 50$ & - & $=$ \\
\hline & $1985-87$ & 1.3 & - & - & 10.7 & - & 15.5 & - & $20 / 15 / 50$ & $\begin{array}{l}\text { LHDDE: }-/ 8 / 110,000 \\
\text { MHDDE: }-/ 8 / 185,000 \\
\text { HHDDE: }-/ 8 / 290,000\end{array}$ & - \\
\hline & $1988-89$ & $1.3^{d}$ & - & - & 10.7 & 0.6 & 15.5 & $0.5^{c}$ & $20 / 15 / 50$ & \multirow{5}{*}{$\begin{array}{c}\text { 1990-97 and } 1998+\text { for } \\
\text { HC, CO, and PM: } \\
\text { LHDDE: }-/ 8 / 110,000 \\
\text { MHDDE: }-/ 8 / 185,000 \\
\text { HHDDE: - / } 8 / 290,000 \\
\text { 1994+ urban buses for } \\
\text { PM only: } \\
-/ 10 / 290,000 \\
\text { 1998+ for NOx: } \\
\text { LHDDE: - / 10 / 110,000 } \\
\text { MHDDE: }-/ 10 / 185,000 \\
\text { HHDDE: }-/ 10 / 290,000\end{array}$} & \multirow{5}{*}{$5 / 100,000^{q}$} \\
\hline & 1990 & $1.3^{d}$ & - & - & 6.0 & 0.6 & 15.5 & $0.5^{c}$ & $20 / 15 / 50$ & & \\
\hline & $1991-93$ & 1.3 & - & - & $5.0[\mathrm{ABT}]$ & \begin{tabular}{|c|}
$0.25[\mathrm{ABT}]$ \\
$0.10^{\circ}$ \\
\end{tabular} & 15.5 & $0.5^{c}$ & $20 / 15 / 50$ & & \\
\hline & $1994-97$ & 1.3 & - & - & $5.0[\mathrm{ABT}]$ & $\begin{array}{c}0.1[\mathrm{ABT}] \\
0.07^{\dagger}, 0.05^{g}\end{array}$ & 15.5 & $0.5^{c}$ & $20 / 15 / 50$ & & \\
\hline & $1998-2003$ & 1.3 & - & - & $4.0[\mathrm{ABT}]$ & $\begin{array}{c}0.1[\mathrm{ABT}] \\
0.05 \%\end{array}$ & 15.5 & $0.5^{c}$ & $20 / 15 / 50$ & & \\
\hline & $2004-2006^{h}$ & - & - & \begin{tabular}{|c|}
2.4 (or 2.5 with \\
a limit of 0.5 on \\
$\mathrm{NMHC})^{\circ}\left[\mathrm{ABT} \mathrm{A}^{\mathrm{i}, \mathrm{j}}\right]$
\end{tabular} & - & $\begin{array}{c}0.1 \\
0.05 g\end{array}$ & 15.5 & 0.5 & $20 / 15 / 50$ & \multirow{2}{*}{$\begin{array}{l}\text { For all pollutants: }{ }^{p} \\
\text { LHDDE: }-/ 10 / 110,000 \\
\text { MHDDE: }-/ 10 / 185,000 \\
\text { HHDDE: } 22,000 / 10 / \\
435,000\end{array}$} & \multirow{2}{*}{$\begin{array}{l}\text { LHDDE: } \\
5 / 50,000 \\
\text { All other HDDE: } \\
5 / 100,000^{q}\end{array}$} \\
\hline & $2007+h, k, t, m, n$ & - & $0.14^{\circ}$ & $\begin{array}{l}2.4 \text { (or } 2.5 \text { with } \\
\text { a limit of } 0.5 \text { on } \\
\text { NMHC) [ABT] }\end{array}$ & $0.2^{\circ}$ & 0.01 & 15.5 & 0.5 & $20 / 15 / 50$ & & \\
\hline
\end{tabular}

In addition to the regulations described above, the EPA has also implemented the Not-ToExceed (NTE) mission limit to analyze the HDD engine's emissions over a defined operation region under a set of rules that qualify to be an NTE operation. In theory, NTE operation method is to represent real-world long-haul truck operation [18].

\section{Not-To-Exceed (NTE):}

This approach takes in consideration that every engine has a control area, in which its emission values must be compliant. This region contains the values which represent the engine's expected engine speed and load under normal operation. In Figure 2, the blue area represents the NTE zone for the particular engine used for that map, which is bounded by the torque curve and the $30 \%$ peak torque, and the speed threshold $\left(\mathrm{n}_{15}\right)$. For the emissions to be within this category they must be quantified over a period of 30 seconds before being compared to the NTE emissions standard [4].

In addition to the boundary conditions provided in Figure 2, the NTE cycle also has a temperature conditions that must be met. For the temperature to be considered compliant ( $\left.\mathrm{T}_{\mathrm{NTE}}\right)$ it 
must lower than the ambient temperature which is also dependent on altitude [4]. The equations bellow (6-8) displays the relationship between those variables.

$$
\begin{gathered}
\text { Altitude }_{\mathrm{NTE}} \leq 5,500 \mathrm{ft} \\
\mathrm{T}_{\mathrm{NTE}}<\mathrm{T}_{\text {Ambient }} \\
\mathrm{T}_{\text {Ambient }}=-0.00254 \times \text { Altitude }(\mathrm{ft})+100
\end{gathered}
$$

For engines that are equipped with an exhaust gas recirculation (EGR) system there are two more exclusions that should be included. These conditions remove NTE points if it's under cold temperature conditions. It requires that the intake manifold temperature (IMT $\mathrm{EGR}_{\mathrm{ER}}$ ) to above or equal to the NTE reference IMT, and that the engine coolant temperature to be larger than the NTE reference value (ECT $\mathrm{EGR}_{\text {) }}$ [18].

$$
\begin{aligned}
& \operatorname{IMT}_{\mathrm{EGR}}\left({ }^{\circ} \mathrm{C}\right)=11.428 \times \mathrm{IMP}_{\mathrm{abs}}(\text { bar })+88.571 \\
& \mathrm{ECT}_{\mathrm{EGR}}\left({ }^{\circ} \mathrm{C}\right)=12.853 \times \mathrm{IMP}_{\mathrm{abs}}(\text { bar })+127.11
\end{aligned}
$$

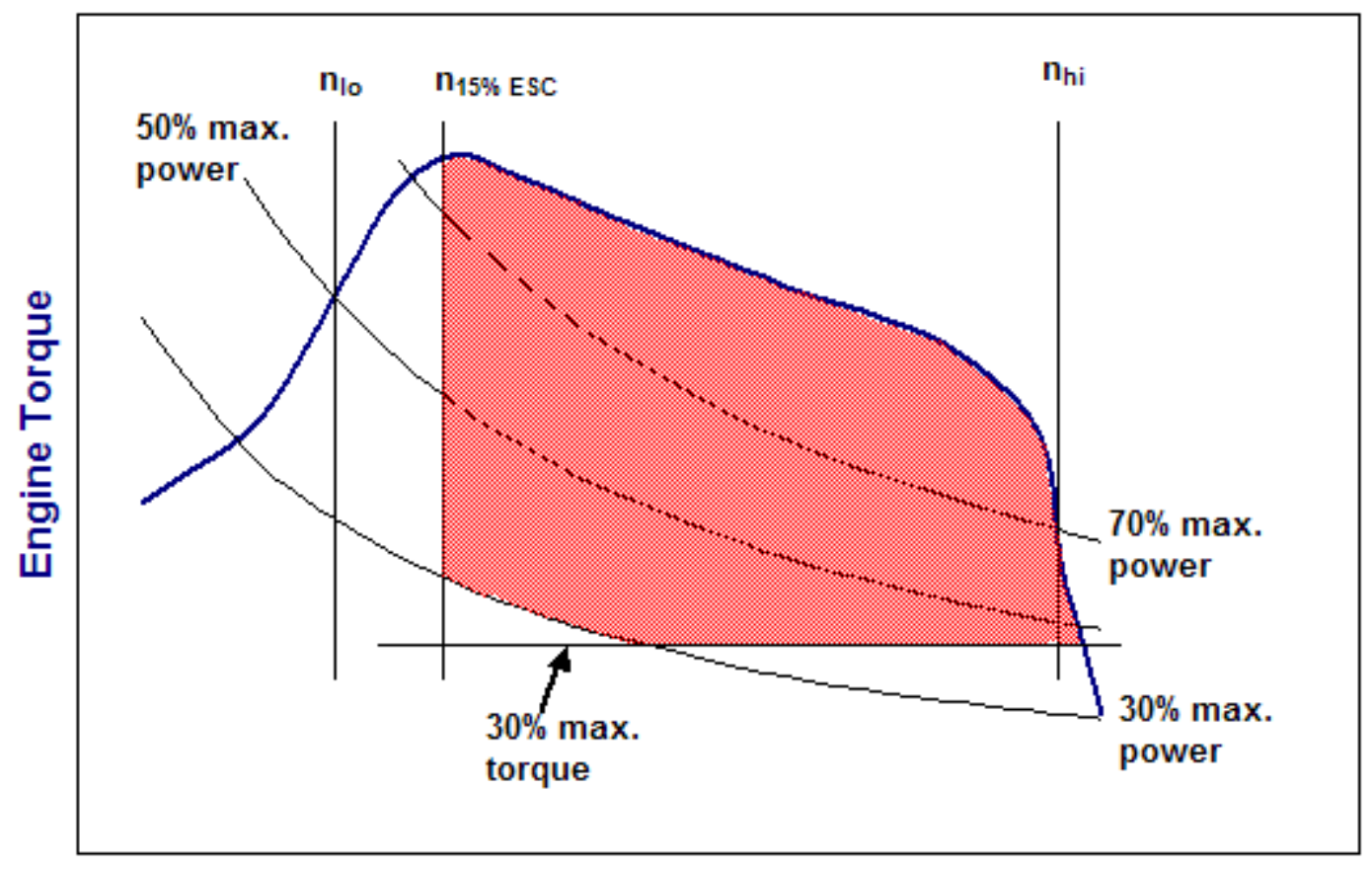

Engine Speed

Figure 2 - NTE Zone Representation for a Generic Engine Torque Curve [18]

This approach however does have several limitations. For instance, the strict boundaries of the NTE zone as well as the minimum event duration limits the amount of data inside the control zone. 
Depending of the vehicle's type of operation the driver may perform frequent gears change or have stop and go driving cycle. These driving operations may possibly exclude the data from the NTE zone. This indicates that this method may not be applicable to all vocations. In addition, the need for ambient condition and additional engine data results in a need for several more channels in the ECU which may not all be present for the required period (30 seconds) [4]. A more detailed explanation of the calculations used for this method can be found in the methodology section.

\subsubsection{Measurement Techniques}

\subsubsection{Regulatory}

Besides the commonly used zirconia sensor, there are several technologies that have been developed to detect NOx in diesel engine exhaust. Some of these technologies are more accurate than the smaller zirconia sensor, however they all have unique drawbacks. The following are some of the NOx sensor data acquisition methods and technologies acknowledged by EPA.

\section{NOx Chemiluminescent Detector (CLD):}

The NOx CLD system can only detect $\mathrm{NO}$, therefore requiring a catalyst to first convert $\mathrm{NO}_{2}$ to $\mathrm{NO}$ prior to detection. When $\mathrm{NO}$ and $\mathrm{O}_{3}$ react, they produce $\mathrm{NO}_{2}{ }^{+}$(excited state), this reaction produces photons [19]. This light (photons) can be counted with a photon counter that uses a photo multiplier tube to detect the photons. The output voltage from this process can then be linearly correlated to the NO concentration [20]. Figure 3 is a representation of the device and how it works. The NOx CLD system requires zero air supply but is quite large and expensive, making it a less than desirable candidate for onroad emissions data collection [21]. 


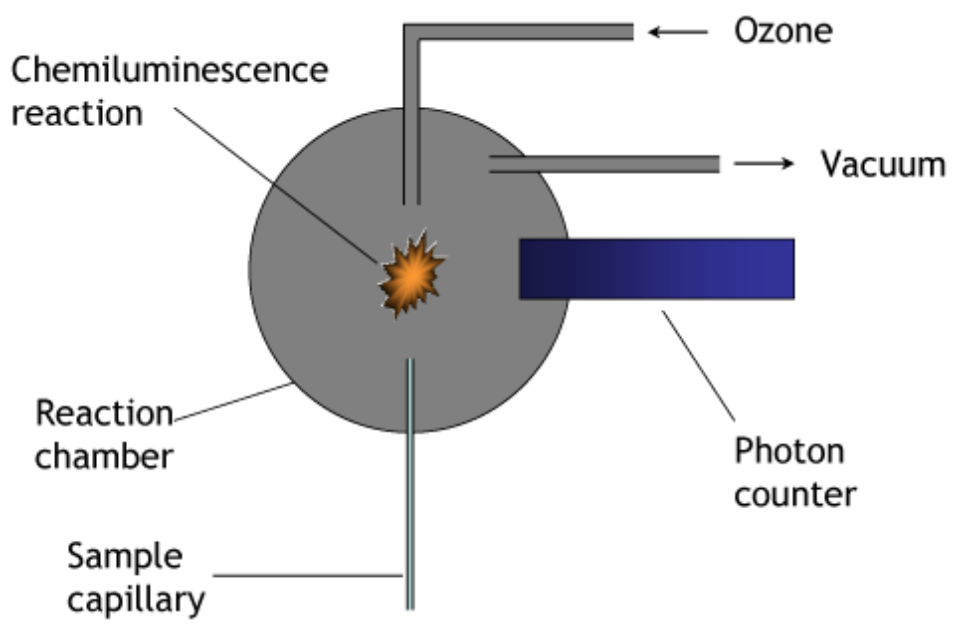

Figure 3 - Chemiluminescent Detector Working Principle [20]

\section{Electrochemical NO Sensor:}

Electrochemical NO sensors contain cells that only sense NO, which one more requires a catalyst for the conversion. This cell is known to be very small and relatively inexpensive compared to the other analyzers. However, this sensor is known to have a slower response time which impairs accuracy. Additionally, a high relative humidity can also affect the sensor's performance which requires corrections for accurate function [21].

The electrochemical NO sensor is usually amperometric and it operates by producing an electrical signal when it reacts with the analyte. The desired compound goes through either oxidation or reduction in an electrode and the concentration can be estimated from the output current [22]. Figure 4 displays a simple representation of this sensor, where the sensor in this figure is detecting carbon monoxide instead of NOx. 

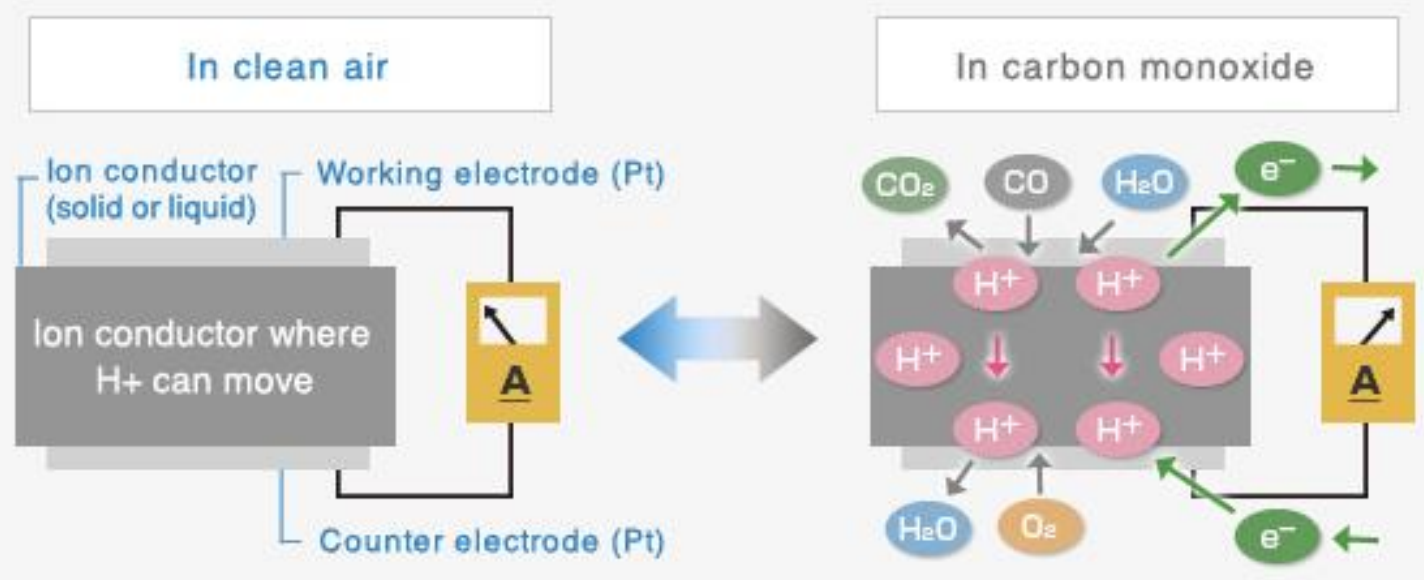

Figure 4- Electrochemical Sensor Representation [46]

\section{Nondispersive Infra-Red (NDIR) NO Analyzer with Luft Detector:}

Similarly to the other analyzers the NDIR NO analyzer with Luft Detector can only detect NO, therefore it requires a catalyst to first convert $\mathrm{NO}_{2}$ to $\mathrm{NO}$. The NDIR system is usually used for $\mathrm{CO} / \mathrm{CO}_{2}$ data collection, however with the addition of the Luft detector it can be used for NO detection. A Luft detector uses a non-dispersive optical analyzer to select the gas to analyze, which makes it more sensitive to wavelengths of the desired chemical instead of the other compounds in the exhaust gas. The system consists of a diaphragm between two sealed cells that contains the desired gas that will be analyzed. In the diaphragm a deflection occurs when there's a difference in pressure between the cells. By measuring the deflection with a capacitor, the NDIR NO analyzer can estimate the concentration of the desired gas. Because this system requires the Luft detector it is quite sensitive to vibrations which makes it unsuitable to onroad operations [21].

\section{Nondispersive Ultraviolet Detector (NDUV):}

The NDUV detector is a commonly used device to measure NOx [23]. This analyzer guides the sample gas through a chamber where it measures the wavelength of the gas when it absorbs light. These wavelengths allow the detector to return information regarding the gas composition. This system even though has good performance and accuracy, it is relatively large and complex for onroad applications [24]. 


\section{Portable Emissions Measurement System (PEMS):}

The PEMS system, which uses either a chemiluminescent or NDUV detector, has the most reliable real-time measurement when compared to all the previously described systems. It provides continuous and accurate measurement of multiple gases ( $\mathrm{NOx}, \mathrm{CO}, \mathrm{CO}_{2}$, and THC). The system is also capable of measuring accurate exhaust flow rate from the Engine Electronic Control Module (ECM) or the exhaust flow meter and GPS data [25]. The following figure represents the PEMS flow diagram according the CARB.

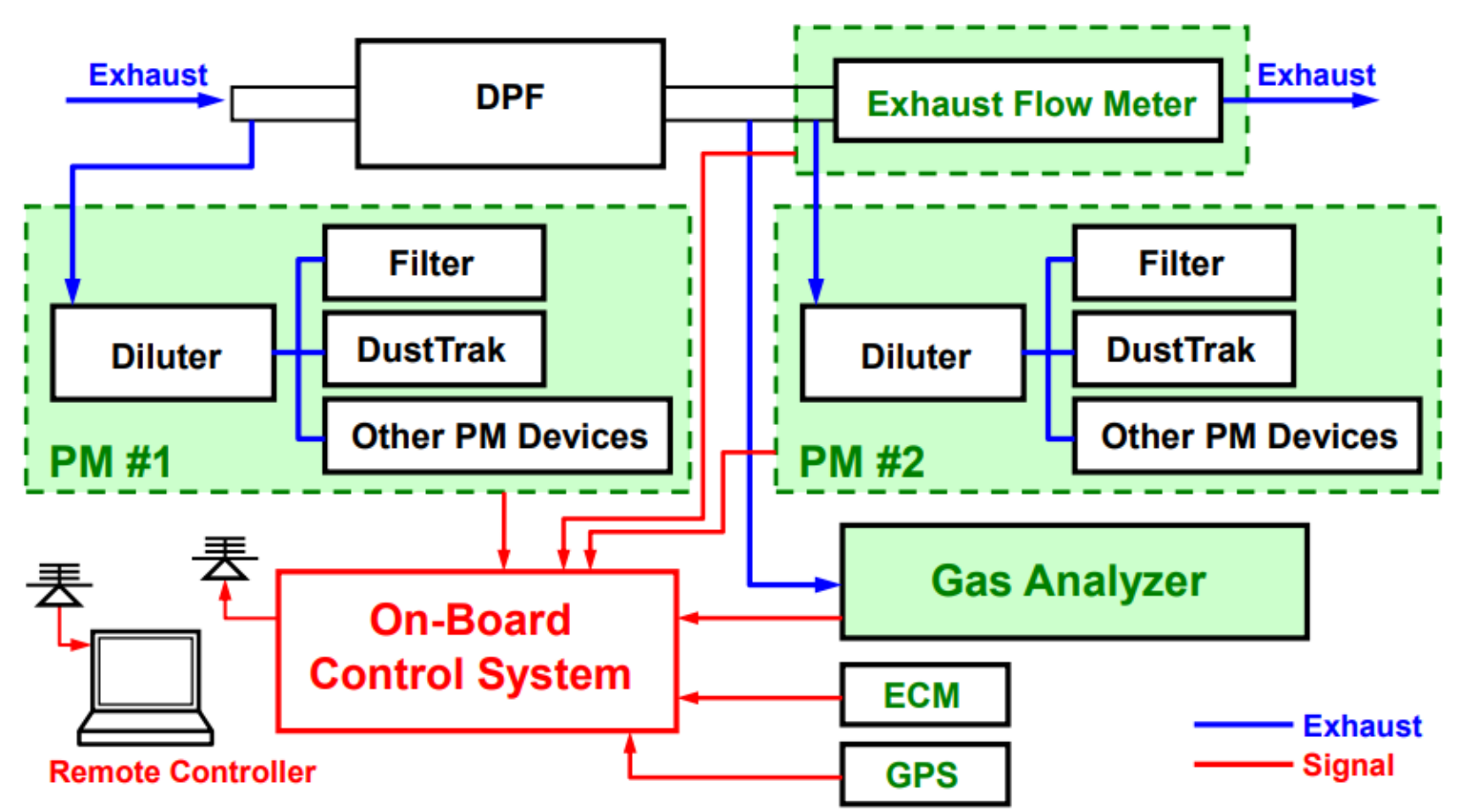

Figure 5 - PEMS Flow Diagram [25]

A PEMS can measure concentration for each gas utilizing different methods. For instance, a PEMS unit can be equipped with a chemiluminescent section so it can measure NOx while using a NDIR for the other compounds. This ability to use multiple methods in one unit to measure the exhaust flow makes the unit extremely versatile and valuable for research. However, it may be impractical for onroad applications because unit is too large and expensive to be added to every vehicle [26]. 


\subsubsection{Onboard Zirconia Sensor}

The yttrium-stabilized $\mathrm{ZrO}_{2}$ (YSZ) is most commonly used for NOx emission onroad data due to its size and cost effectiveness in comparison to the PEMS system. This type of sensor contains two chambers usually coated with platinum [3]. The first cell removes $\mathrm{O}_{2}$ so it won't interfere with the sample while the other cell dissociates $\mathrm{NO}$ into $\mathrm{N}_{2}$ and $\mathrm{O}_{2}$. The $\mathrm{O}_{2}$ removed from the second cell allows the sensor to calculate the NOx concentration by determining the voltage required to remove the $\mathrm{O}_{2}$ caused by the dissociation [21]. For optimal results, the $\mathrm{NO}_{2}$ should be first converted into NO using a catalyst, such as the SCR [27]. Figure 6 displays YSZ sensor operation. The data is then broadcasted publicly through the J1939 CAN communication protocol.

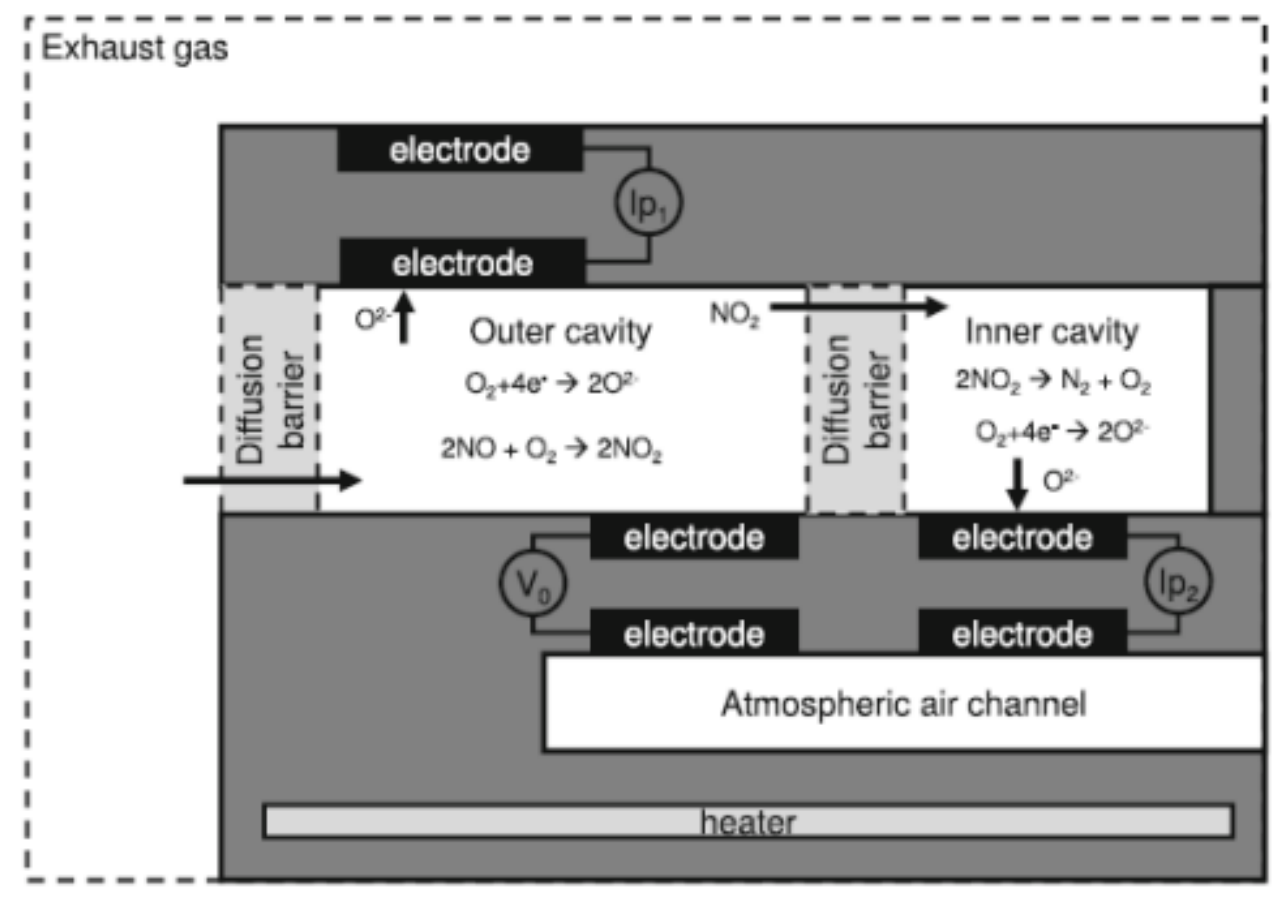

Figure 6 - Zirconia Based NOx Sensor Representation [3]

In $2002 \mathrm{WVU}$ conducted a study where it compared the $\mathrm{ZrO}_{2}$ sensor to well established analyzers, such as the NDIR. Despite indications that the zirconia sensor displays errors between 6-12\% for lower NOx concentrations in the 5-175 ppm range, the study concluded that the $\mathrm{ZrO}_{2}$ sensor was found to be the best device for onboard measurements when comparing accuracy and 
cost effectiveness [21]. Later in the study performed by Thiruvengadam et al. [28] the data from OBD-NOx was compared to the data from the control volume system (CVS) as well as PEMS in order to analyze the limitations of these sensors. At high concentrations the OBD sensor displayed readings within $10 \%$ of the PEMS and CVS, while at lower concentrations were the SCR functioned properly the values between the OBD sensor and the other two systems had a much larger difference. Overall, the sensor displayed acceptable results when compared to PEMS and FTIR measurements. However, the authors suggest that for a more accurate dataset a predictive algorithm or filtering algorithm could be used in the sensor data. The authors note that the large errors could be attributed to the original equipment manufacturers' (OEM) method to correct/predict the data. Figure 7 displays the results from the study.

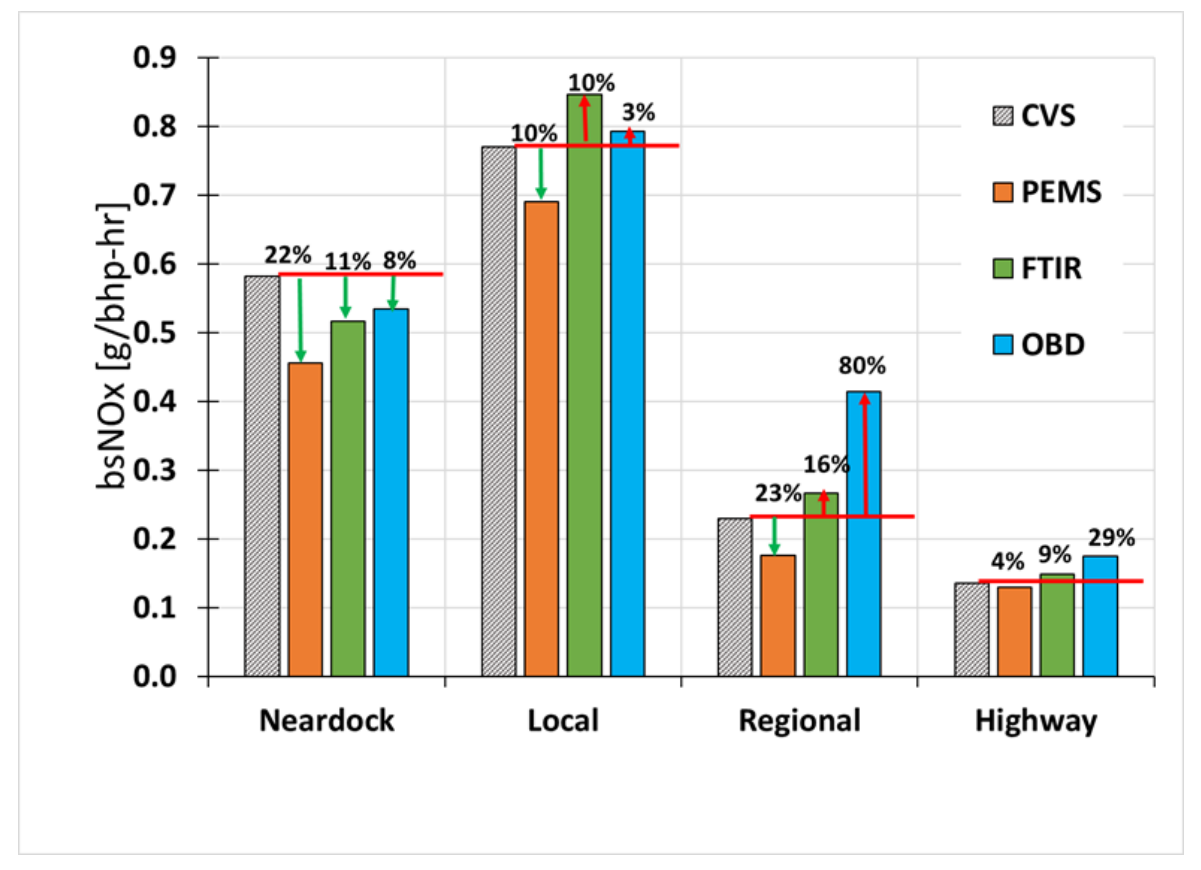

Figure 7 - FTIR vs PEMS vs NOx Sensor [28]

Some of the limitations of this sensor includes being affected by multiple engine subsystems such as the SCR catalyst deterioration, urea dosing control and EGR control. In addition, the sensor may be turned off during the vehicle operation for the safety of the device [29]. Also, the sensor can't differentiate the components of the exhaust gas. Therefore, it has a high cross-sensitivity with certain compounds such as ammonia, isocyanic acid (HNCO), and hydrogen cyanide (HCN). $\mathrm{HCN}$ is usually found in ethanol systems. Most of these compounds are a result from the urea dosing control system defects [30]. Note that this sensor required a temperature of $700{ }^{\circ} \mathrm{C}$ to work 
properly, therefore during cold start operation the sensor doesn't record reliable data [3]. Because of the high temperature water droplets may affect the sensor by causing rapid cooling [21].

\subsubsection{Onboard Diagnostic (OBD) System}

Over the years CARB and the EPA have implemented several regulations for the types of technologies and systems used in the acquisition and monitoring of data, and emissions standards for the vehicles, some of the regulations cover onboard diagnostic (OBD) systems. The system can be referred as either OBD or OBD II, where the later describes the last generation of the technology [31]. These regulations can be found in the California Code of Regulations (CCR) or in the Code of Federal Regulations (CFR). While most states only must comply with the CFR the vehicles used in California must be in compliance with both regulations. The OBD has the purpose of monitoring the engine's emissions and detecting any possible malfunction in the emissions system based on the current emissions standards. While the Clean Air Act Amendments (CAAA) only required the monitoring of the catalyst and oxygen sensor, the OBD regulation now requires the monitoring of several system for emission control such as the EGR, misfire, oxygen sensor heater, and others [32]. These malfunctions should be displayed to the vehicle operator and also recorded in the onboard computer system [31].

According to the CFR, all vehicles MY 2017 or later must be equipped with an OBD system and the system must comply with CCR's OBD II requirements. Note that all light-duty trucks and complete heavy-duty vehicles weighing 14,000 pounds of gross vehicle weight rating (GVWR) or less must have OBD system [33]. The system must be able to monitor the engine system and emissions throughout the useful life [32]. The regulation is reviewed and regulated every year. According to title 13 section 1971 of the CCR [32], the OBD system should be able to operate without any type of maintenance. The system is also not allowed to be programed.

\subsubsection{Moving-Average Windows (MAW)}

There are multiple studies that have aimed to understand and better analyze the emission data recorded by the onboard sensors. For instance, in 2008 WVU Center of Alternative Fuels Engines and Emissions (CAFEE) proposed the use of WBW method to calculate break-specific NOx (bsNOx) for HDD engine. Shade et al. [34] describes that as long as the Engine Control Unit 
(ECU) broadcasts all channels that are needed to calculate NOx and work - which are later described in detail - this method can be easily used. In order to perform this method, first the instantaneous work (bhp-hr) and NOx rate (g/s) must be calculated using the ECU channels. The following equations describes how the bsNOx can be calculated, where $\mathrm{N}$ is the engine speed, $\mathrm{T}$ is engine Torque, and $\mathrm{t}$ is time, and $\Delta \mathrm{t}$ is the window duration in seconds.

$$
\begin{gathered}
\text { WorkWindow (bhp-hr })=\sum_{\mathrm{i}=0}^{\mathrm{i}^{*}}\left(\frac{\mathrm{N}_{\mathrm{i}}\left(\frac{\text { rev }}{\mathrm{min}}\right) \times \mathrm{T}_{\mathrm{i}}(\mathrm{ft}-\mathrm{lb})}{\left(\frac{1 \mathrm{rev}}{2 \pi \mathrm{rad}}\right)\left(\frac{60 \mathrm{sec}}{1 \mathrm{~min}}\right)\left(\frac{550 \mathrm{ft}-1 \mathrm{~b}_{\mathrm{f}}}{1 \text { sec-bhp }}\right)} \times \Delta \mathrm{t}_{\mathrm{i}}(\mathrm{sec}) \times\left(\frac{1 \mathrm{hr}}{3600 \mathrm{sec}}\right)\right) \\
\text { bsNOx }\left(\frac{\mathrm{g}}{\text { bhp-hr }}\right)=\frac{\sum_{\mathrm{i}=0}^{\mathrm{i}^{*}} \operatorname{NOx}_{\mathrm{i}}\left(\frac{\mathrm{g}}{\mathrm{sec}}\right) * \Delta \mathrm{t}_{\mathrm{i}}(\mathrm{sec})}{\text { WorkWindow }(\text { bhp-hr })}
\end{gathered}
$$

The WBW method has some limitations, such as the data becomes invalid if the pressure is less than $82.5 \mathrm{kPa}$, the ambient temperature is less than $-7^{\circ} \mathrm{C}$, engine coolant temperature is less than $70^{\circ} \mathrm{C}$, and altitudes above $1600 \mathrm{~m} \mathrm{[3].} \mathrm{This} \mathrm{method} \mathrm{follows} \mathrm{a} \mathrm{similar} \mathrm{approach} \mathrm{to} \mathrm{the} \mathrm{MAW.}$

In order to bin the data, first it must go through MAW. This method is acknowledged by the Euro VI Regulation [35]. The moving average can function as a way to smooth the data by replacing a segment of data points with their average. These averages are stored into windows which are later compiled into one vector [36]. Like the WBW, this method could be used to analyze the exhaust temperature, distance, and power. Where for each of these parameters the dataset is compiled in segments (windows) for a specific amount of time, also known as the data sampling period $(\Delta t)$. According to CARB the sampling period should be set for 15 seconds [37]. The following equations were used to generate the window for the other parameters. Similar to equation (13, where ' $i$ ' indicates the window number (individual variables, e.g. Window1, Window2, etc.). The final continuous vector can be created by concatenating the windows as shown in equation $\left(14, \mathrm{~W}_{\text {parameter }}\right.$ is the new vector for a specific parameter after it goes through the averaging window method and count is just a variable used to keep track of the windows created by the this procedure (e.g. $\mathrm{W}_{\text {parameter }}(1,1), \mathrm{W}_{\text {parameter }}(2,1), \mathrm{W}_{\text {parameter }}(3,1)$, etc.).

$$
\begin{gathered}
\text { Window }(\mathrm{i}, 1)=\operatorname{mean}(\operatorname{Parameter}(\mathrm{t}: \mathrm{t}+\Delta \mathrm{t}-1)) \\
\mathrm{W}_{\text {Parameter }}(\operatorname{count}, 1)=\text { Window }(\text { 'count') }
\end{gathered}
$$




\section{Methodology}

\subsection{Vehicle Selection}

In order to properly analyze the data, first the manufacturers must provide enough parameters that are streamed by the ECU. The availability of the channels dictates which vehicles are suitable to be used for the analysis and which ones aren't. Certain channels can't be easily estimated, such as the exhaust mass flow which requires refined algorithms to be estimated. This parameter could alone remove a vehicle from the list of suitable vehicles. Alongside the exhaust mass flow channel, the raw NOx channel must be present as well. The data from this channel should come from a sensor located downstream the aftertreatment section of the exhaust pipe. There are several other channels that are desired for this type of study; however, they are more commonly found than the previous ones stated.

Based on the needs described above a simple program can be generated to analyze each individual vehicle available and generate a spreadsheet for each one of them describing the quality of each file and availability of each channel. By using MATLAB, a code was generated to analyze each trip of each vehicle and return an excel spreadsheet with the channels' availability and quality to ensure that the channels weren't filled with Not-a-Numbers (NaNs) or zeros. The program returned either a 1 if the channel was available or a 0 if it wasn't. Then it investigates the data to see if it was composed of NaNs or zero. For this project the following channels were to be analyzed: exhaust flow temperature, exhaust flow mass, engine speed, vehicle speed, NOx downstream from SCR, NOx stable, and torque (nominal, actual, and reference). Certain vehicles can display entire trips filled with NaNs, making them not suitable options. Finally, once the spreadsheet is done a vehicle can be selected.

\subsection{Data Setup}

\subsubsection{Filtering Raw NOx Data}

In order to implement the tracking concept first one needs to analyze the quality of the NOx data. That can be done by using the NOx stable channel or if it's not present an exponentially weighted moving average (EWMA). 


\subsubsection{NOx Stable}

As part of the vehicle's ECU channels list is the NOx stable channel. This parameter works as a control channel to the NOx raw channel. This channel indicates the stability of the NOx sensor throughout the vehicle's activity. For the vehicle chosen, the sections in which the value of the NOx Stable channel was wither 1 or 3 the NOx raw channel displayed instability. Therefore, the values in those parts were replaced with NaNs.

When calculating the bsNOx bin for this method, the position in which the NOx values were replaced with NaNs were also applied to the work vector. Therefore, when the total NOx (g) for a bin were divided by the total work (bhp-hr) in that same bin the amount of NaNs in each vector were at the same position. This ensures that the total emission in the bin are not underestimating the value in the bsNOx bin.

\subsubsection{Exponentially Weighted Moving Average (EWMA)}

Before one can explain what EWMA is, one needs to understand what a moving average is and how it works. A simple moving average (SMA) calculates the average of $n$ values where $n$ represents the number of values of which the average is taken [38]. Equation (15 below demonstrates how it functions.

$$
\text { Simple Moving Average }(\mathrm{SMA})=\frac{\mathrm{x}_{1}+\mathrm{x}_{2}+\mathrm{x}_{3}+\ldots+\mathrm{x}_{\mathrm{n}}}{\mathrm{n}}
$$

As for the EWMA it has the same roots as the SMA method, however there's a weigh assigned to each point. Meaning, the early data points will have a smaller impact on the later data points [39]. The equations below represent this method. The coefficient alpha, which is the exponential weighting factor (EWF) is calculated based on the amount of points back in the data (n) that it should influence the current point being calculated. This method allows the current data point being analyzed to have more weight than the previous one when it goes through a moving average [40]. This indicates that the method takes into consideration the vehicle's operation history when smoothing the set. The equation bellow represents the method. Where $\mathrm{P}_{\mathrm{t}}$ is the original data value at point $\mathrm{t}$.

$$
\begin{gathered}
\mathrm{EWMA}_{\mathrm{t}}=\mathrm{EWMA}_{\mathrm{t}-1}+\alpha\left(\mathrm{P}_{\mathrm{t}}-\mathrm{EWMA}_{\mathrm{t}-1}\right)[40] \\
\alpha=\frac{2}{\mathrm{n}+1}[40]
\end{gathered}
$$


There is a function already built in MATLAB that performs the EWMA. In order to use it, first one must select which kind of moving average it wants to perform. For this project the method selected was the "exponential weighting". This method requires the user to input a value for the exponential weighting factor (EWF) which can range from 0 to 1 , where 0 would have no filtering done and 1 has the most. Because this method can cause over smoothing of the data several coefficients were tested. A more precise coefficient could be selected if data from PEMS was available, but because this project did not have such data the filtered data was compared to the original [29]. According to the 2017 HD OBD program update, CARB suggests using 0.1 for the exponential weight coefficient value [37].

\subsubsection{NOx Conversion}

Next one must estimate the NOx mass per second using the tailpipe NOx sensor output and the exhaust flow mass. The NOx channel output provides the concentration in parts-per-million (ppm) while the exhaust follow channel is in kilogram-per-hour $(\mathrm{kg} / \mathrm{hr})$. Those two channels should be available throughout the whole dataset in order to avoid time alignment issues. By using the ideal gas law equation, and assuming the density of the fuel to be $1.2 \mathrm{~kg} / \mathrm{L}$, and standard temperature $\left(25^{\circ} \mathrm{C}\right)$ and pressure $(1 \mathrm{~atm})$, the NOx rate $(\mathrm{g} / \mathrm{sec})$ can be calculated. The equations $18-21$ bellow were used to perform such calculation [41]. Note that this method does not take into account humidity corrections, and it does use the molar mass of air for the exhaust gas.

$$
\text { Ideal Gas Law: Pن் } \dot{\mathrm{n} R T}
$$

Volumetric Flow Rate: $\dot{V}\left(\frac{\mathrm{L}}{\mathrm{s}}\right)=$ Exhaust Flow $\left(\frac{\mathrm{kg}}{\mathrm{hr}}\right) \times \frac{1 \mathrm{hr}}{3600 \mathrm{~s}} \times \frac{1}{\rho}\left(\frac{\mathrm{L}}{\mathrm{kg}}\right)$

$$
\text { Molar Rate: } \dot{\mathrm{n}}\left(\frac{\mathrm{mol}}{\mathrm{s}}\right)=\frac{\operatorname{Pressure}(\mathrm{Pa}) \times \dot{\mathrm{V}}\left(\frac{\mathrm{L}}{\mathrm{s}}\right)}{\mathrm{R}\left(\frac{\mathrm{J}}{\mathrm{mol}^{*} \mathrm{~K}}\right) \times \mathrm{T}(\mathrm{K})}
$$

NOx Mass Rate: $\mathrm{NO}_{\mathrm{x}}\left(\frac{\mathrm{g}}{\mathrm{s}}\right)=\left(\mathrm{NO}_{\mathrm{x}}\right)_{\mathrm{ppm}} \times 10^{-6} \times\left(\frac{\mathrm{mol}}{\mathrm{mol}}\right) \times \dot{\mathrm{n}}\left(\frac{\mathrm{mol}}{\mathrm{s}}\right) \times \mathrm{MW}\left(\frac{\mathrm{g}}{\mathrm{mol}}\right)$ 


\subsubsection{Torque, Work, and Power}

To properly segregate the data according to the CARB regulations, work and power fraction must be present before the window averaging can take place. Both work and power are a function of torque, therefore if one can calculate the engine torque from the channels provided then the other parameters can be easily calculated. From the actual percent torque, nominal frictional torque, and reference torque, the engine break torque can be calculated using equation (22.

$$
\text { Torque }(\mathrm{lb}-\mathrm{ft})=\frac{\left(\text { Torque }_{\text {Actual }}-\text { Torque }_{\text {Frictional }}\right) \times \text { Torque }_{\text {Reference }}}{100} \times 0.73756
$$

From the value calculated above one can now calculate the power, power fraction, as well as work for the engine [1]. Note that the max power varies by engine and can be acquired from the manufacturer.

$$
\begin{gathered}
\text { Power(bhp) }=\frac{\text { Engine Speed }(\mathrm{rpm}) \times \operatorname{Torque}(\mathrm{lb}-\mathrm{ft})}{5252} \\
\text { Power Fraction }=\frac{\text { Power }(\mathrm{bhp})}{\text { Max Power (bhp) }} \\
\text { Work (bhp-hr) }=\frac{\text { Power(bhp) }}{3600}
\end{gathered}
$$

\subsection{NTE Method}

In order to analyze onroad data, the NTE method can be used to evaluate emission for in-use compliance based on the engine operation along specific bounds in the control area. Points which fall in the control area are considered to be part of the engine's normal operation. According to 40 CFR Part 86.1370, subpart C - Not-to-Exceed Test Procedures, the control area must be bounded by the lug curve, the $30 \%$ max power, and engine speed limits ( $n_{\text {high }}$ and $n_{\text {low }}$ ). One of the criteria requires the engine speed ( $n_{\mathrm{NTE}}$ ) to be higher than the variable $\mathrm{n}_{15}$ which can be calculated using equation (27. Where $\mathrm{n}_{\text {high }}$ represents the highest engine speed at $70 \%$ maximum power and $\mathrm{n}_{\text {low }}$ represents the lowest engine speed at 50\% maximum power [4].

$$
\begin{gathered}
\mathrm{n}_{\mathrm{NTE}}>\mathrm{n}_{15} \\
\mathrm{n}_{15}=0.15\left(\mathrm{n}_{\text {high }}-\mathrm{n}_{\text {low }}\right)+\mathrm{n}_{\text {low }}
\end{gathered}
$$

If the engine speed is compliant with the specification above then the brake torque must be equal or greater than $30 \%$ of the maximum engine torque. Finally, the instantaneous power must 
also be greater or above $30 \%$ of the engine's maximum power. The torque curve, also known as the lug curve, can be generated using the values recorded by the ECU for each of the positions of the curve. The peak torque corresponds to the highest torque value in the lug curve. The rated power at a specific engine speed is provided, therefore the torque corresponding to $30 \%$ of peak power for a particular engine speed can be calculated using the equations bellow [4].

$$
\begin{gathered}
\text { Torque }_{\mathrm{NTE}}=5252 \times \frac{\text { Power }_{\max }(\mathrm{bhp}) \times 0.3}{\text { Engine Speed }_{\mathrm{NTE}}(\mathrm{rpm})} \\
\text { Torque }_{\mathrm{NTE}} \geq 0.3 \times \text { Torque }_{\text {max }} \\
\text { Power }_{\mathrm{NTE}} \geq 0.3 \times \text { Power }_{\text {max }}
\end{gathered}
$$

\subsection{Binning}

In addition to the MAW method, one must implement binning to perform the NOx tracking approach by collecting data from a vehicle over time - after the data has gone through MAW - and segregating each parameter in an array and finally binning each one of those parameters according to specific boundaries.

In the 2017 CARB workshop [37] a proposal was made for a method to analyze real-world NOx data. The workshop proposed to use 68 trucks with at least one-month worth of data with the MY's between 2010 and 2018. The trucks were from several different manufactures and vocations. On all the data was collected for the trucks the NOx emission in $\mathrm{g} / \mathrm{bhp}$-hr was measured for each vehicle. Only a few of the trucks were compliant with the current NOx regulation $(0.2 \mathrm{~g} / \mathrm{bhp}-\mathrm{hr})$. The workshop then used the data accumulated from the trucks to analyze the SCR efficiency using SCR inlet temperature. Finally, the proposal moves towards a comparison between the OBD data and PEMS data. In order to have a better understanding of the different between the OBD and PEMS data the workshop proposes the use of bins [41]. During the OBD program update they proposed the schematics in Figure 8 for the procedure for the NOx tracking approach. While the

proposal only asked for 100 hours of operation, this project used the data of approximately three months-worth of operation. 


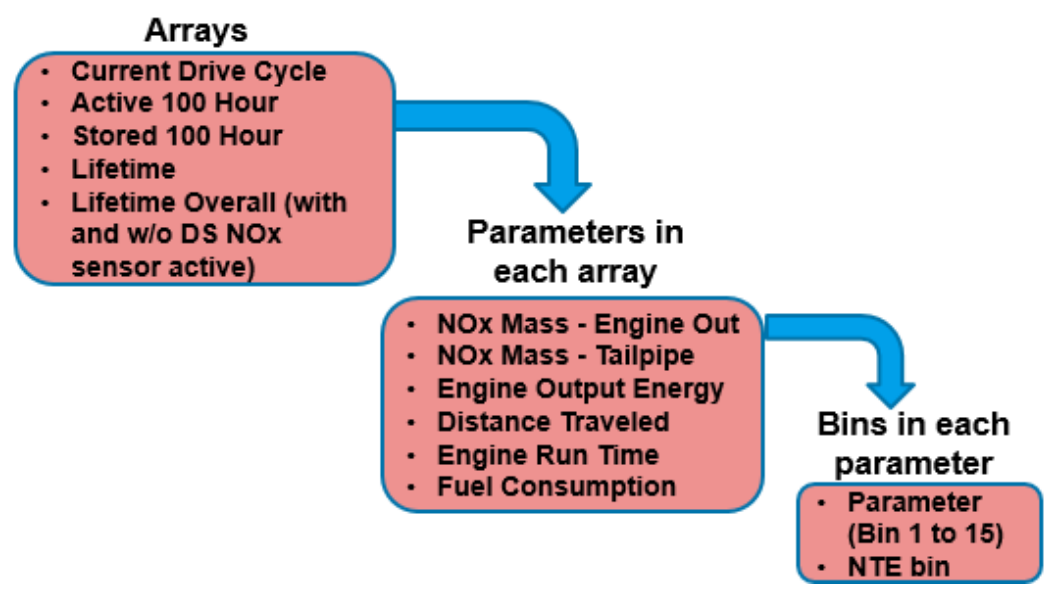

Figure 8 - NOx Tracking Binning Proposal [45]

The method of binning has been used in data analysis for many years. Before the data can be fragmented into sections for binning, first something similar to MAW must be done. For the purpose of this thesis the sampling period used is the same suggested by CARB of 15 seconds, depending on the time of data the set in the window is either summed or averaged. After all the data is properly segregated into windows containing a single value, it can be reestablished into a single vector representing the continuous data. This process must be done for all the parameters that one wishes to analyze [29].

These parameters that were binned can then be broken down into sections [42]. For OBD data, the workshop proposed the data to be segregated based on vehicle speed and power fraction. For vehicle speed, this project segregated the data into idle, 1-10, 10-25, 25-40, and $+40 \mathrm{mph}$. Meanwhile for power fraction this project broke it into 0-25\%, 25-50\%, and 50\%+ segments. Like stated previously one could pick theoretically any set of parameters that they may need, the set used in this project follows the proposal by CARB. Once the data has gone through the MAW and the segregation based on the parameters chosen each parameter that has been binned can be analyzed. By analyzing the binning dataset one can see trends fort different type of vehicle speed operations. By using this method one can better associate parameters that otherwise would be hard to compare. Table 3 represents the schematics of the bin structure as determined by CARB. 
Table 3 - Proposed Bin Structure According to CARB as of 2018

\begin{tabular}{|c|c|c|c|c|c|}
\hline $\begin{array}{c}\text { \% } \\
\text { Power } \\
\text { Fraction }\end{array}$ & \multicolumn{5}{|c|}{ Vehicle Speed (mph) } \\
\cline { 2 - 6 } & Idle & $0-10$ & $10-25$ & $25-40$ & $>40$ \\
\hline$<25$ & Bin 1 & Bin 2 & Bin 3 & Bin 4 & Bin 5 \\
\hline $25-50$ & Bin 6 & Bin 7 & Bin 8 & Bin 9 & Bin 10 \\
\hline$>50$ & Bin 11 & Bin 12 & Bin 13 & Bin 14 & Bin 15 \\
\hline
\end{tabular}

In addition to binning NOx, this project also investigated several other parameters. Table 4 summarizes how the data of each one of the parameters analyzed was segregated using the window method and binned. For instance, for the engine work the windows that fell inside a specific bin were summed and returned a single value for that particular bin. As for the bsNOx bin, the value was calculated by dividing the result in the NOx bin by their respective bin values in the engine work bin. This procedure follows the equations (11 and (12 described in the Background section. As for the count and NTE bins, they show how the data set is distributed over the two desired specifications: vehicle speed and power fraction. In addition, the count bin can be used to calculate the time that each bin contains, since each count point represents a 15 seconds segment of the original data.

Table 4 - WBW and Binning Analysis Method

\begin{tabular}{|c|c|}
\hline Parameter & Analysis Method \\
\hline Engine Work & Summation \\
\hline Exhaust Temperature & Average \\
\hline NOx & Summation \\
\hline Distance & Summation \\
\hline Count & Summation \\
\hline NTE & Summation \\
\hline
\end{tabular}




\section{Results and Discussion}

From the method described in the Vehicle Selection Section of the Methodology, the data set selected for this project came from a goods movement truck (GMT) 2013 Freightliner M2. This vehicle contained all the channels required for the month analyzed.

\subsection{Lug Curve and NTE Zone}

With the ECU providing the torque and engine speed channels for each of the points for the lug curve, and using the equations (26)-(30 in Section 3.3 the following graph was generated. Where each point that's binned must fall in the shaded area to be considered part of the NTE control zone.

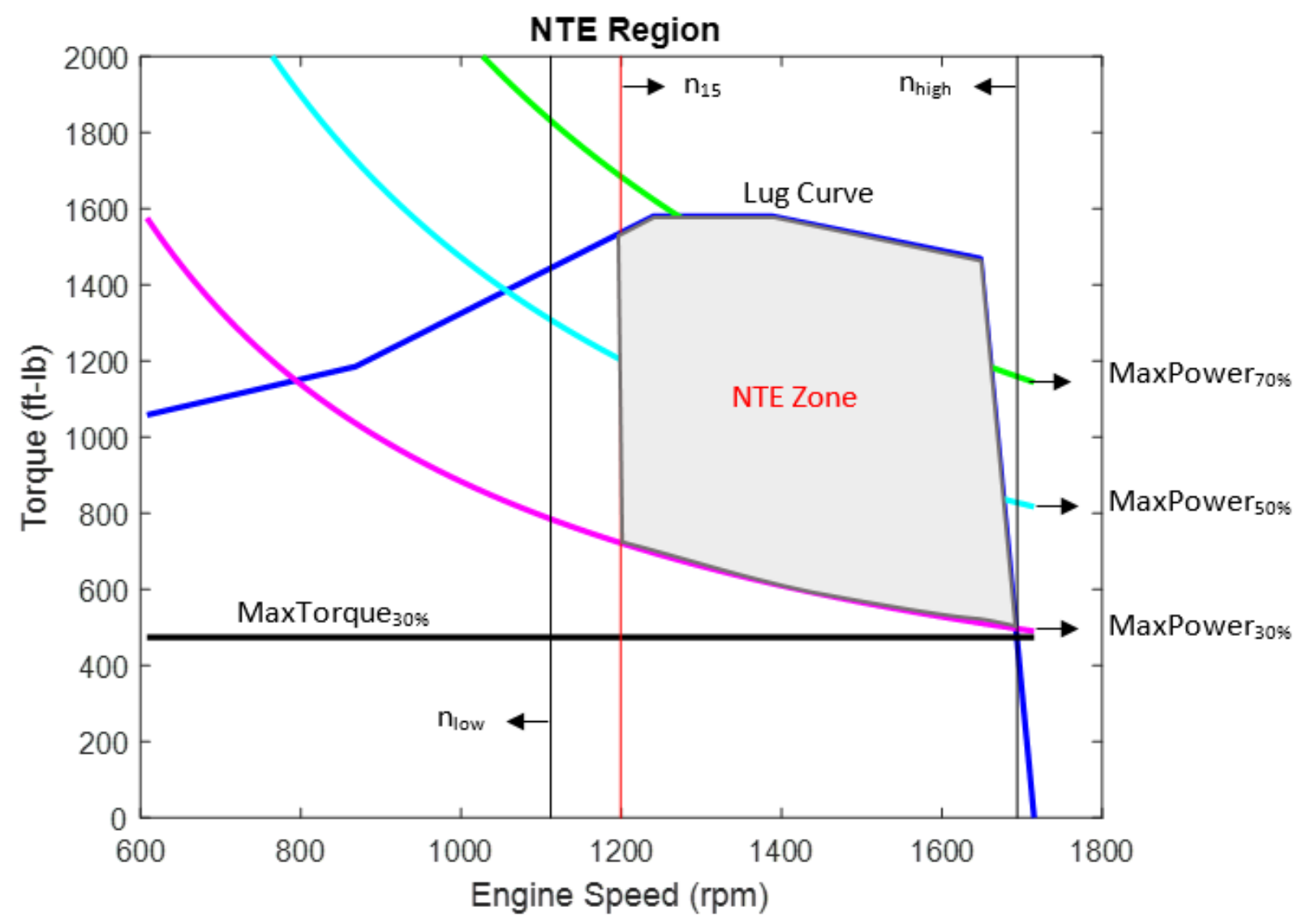

Figure 9 - Lug Curve and NTE Zone for the Desired Vehicle 
The table below summarizes the boundary conditions of the NTE zone which was used to calculate the NTE points of the dataset. For the purposes of this thesis, only the load conditions were used for the NTE zone.

Table 5 - Boundary Conditions for NTE Zone

\begin{tabular}{|c|c|}
\hline Boundary Parameter & Value \\
\hline Max Toque & $1580 \mathrm{ft}-\mathrm{lb}$ \\
\hline $30 \%$ Max Torque & $474 \mathrm{ft}-\mathrm{lb}$ \\
\hline Max Power & $500 \mathrm{hp}$ \\
\hline $\mathrm{n}_{\text {high }}$ & $1199.2 \mathrm{rpm}$ \\
\hline $\mathrm{n}_{\text {low }}$ & $1111.9 \mathrm{rpm}$ \\
\hline $\mathrm{n}_{15}$ & $1199.2 \mathrm{rpm}$ \\
\hline
\end{tabular}

\subsection{NOx Data Reduction}

A section of the data was selected so a comparison between the reduction methods could be analyzed. The data displayed next is the data collected from one working day, April $10^{\text {th }}, 2018$, which went through both data reduction methods described in the methodology section.

\subsubsection{NOx Stable Method}

As described in the methodology section the NOx stable channel can be used to filter the data and remove the points in which the deviates from the pattern. Figure 10 and Figure 11 show the overall results from this data segment. As one can see the peaks in the original dataset were removed and replaced with NaNs. The rest of the data that did not display noise remained intact. This method could potentially cause the data to deviate when it goes through the binning stage since it assumes that all these peaks were caused by errors in the sensor. In order to confirm if this method is an acceptable representation or not one would need to compare the new data set to a more accurate set, this could only be done with more robust analyzers instead of just the zirconia sensor. 


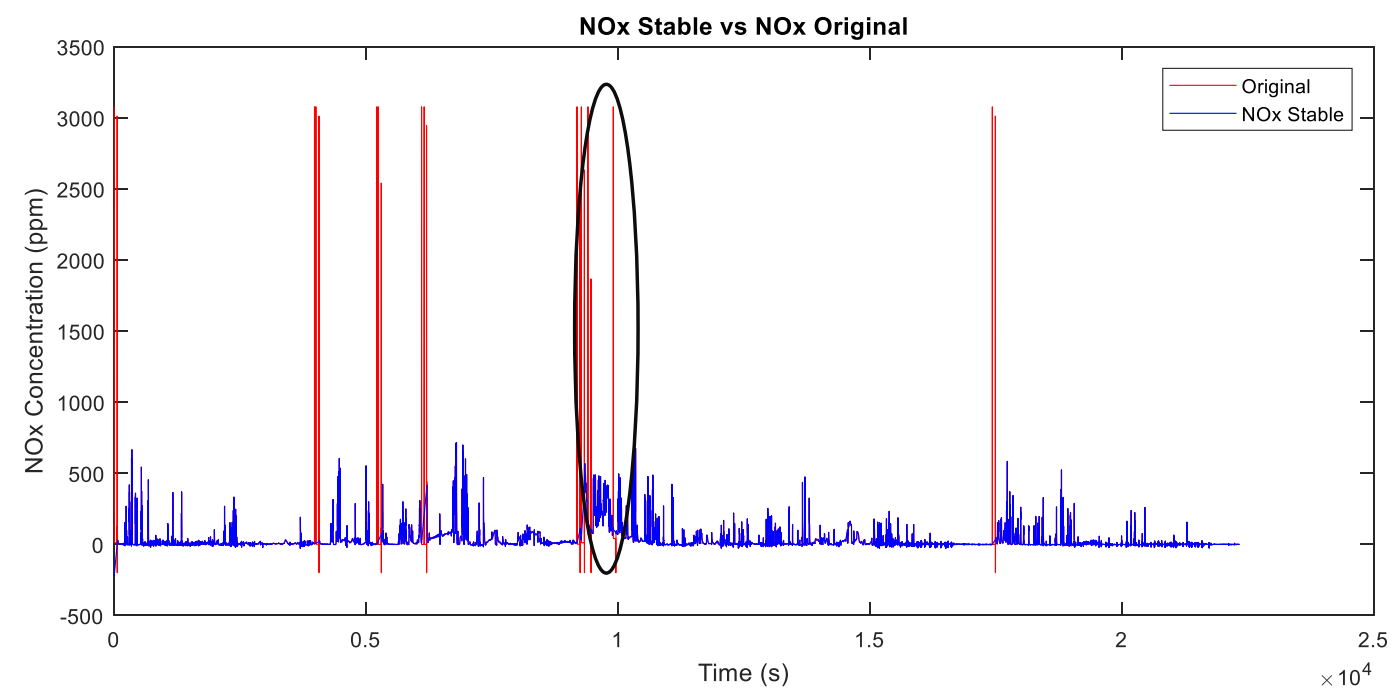

Figure 11 - NOx data filtered with NOx Stable vs Original Data

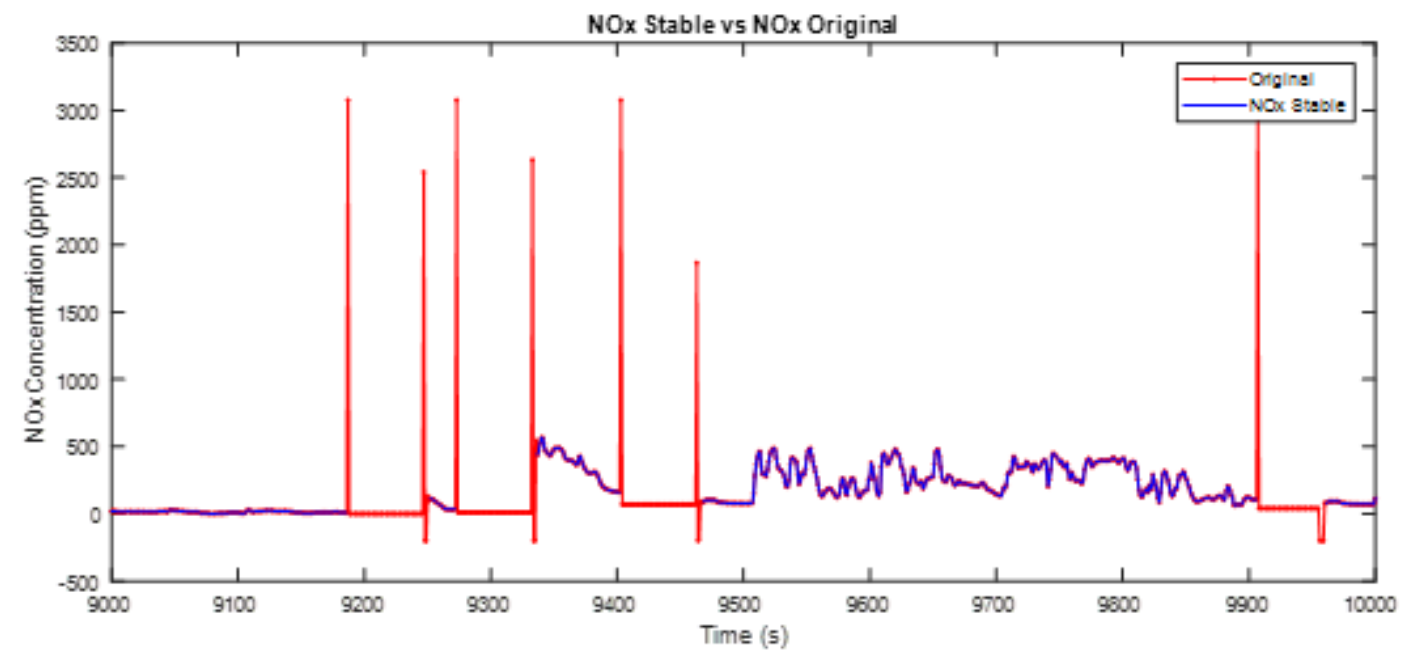

Figure 10 - Amplified NOx data filtered with NOx Stable vs Original Data

\subsubsection{EWMA Method}

The other possible filtering method is the EWMA. Although CARB suggests an EWF of 0.1, this project analyzes different EWFs in order to analyze the effect of these factors. These different values could also potentially suit the data set better than what was suggested. The data that went through the 0.1 filtering process was plotted versus the original data as shown in Figure 12. As one can see the data only display a slight difference from the original in the points in which the sensor 
has extremely high NOx concentration. While in the lower NOx concentration areas, as shown in Figure 13, the filtered data has values much closer to the original NOx data set.

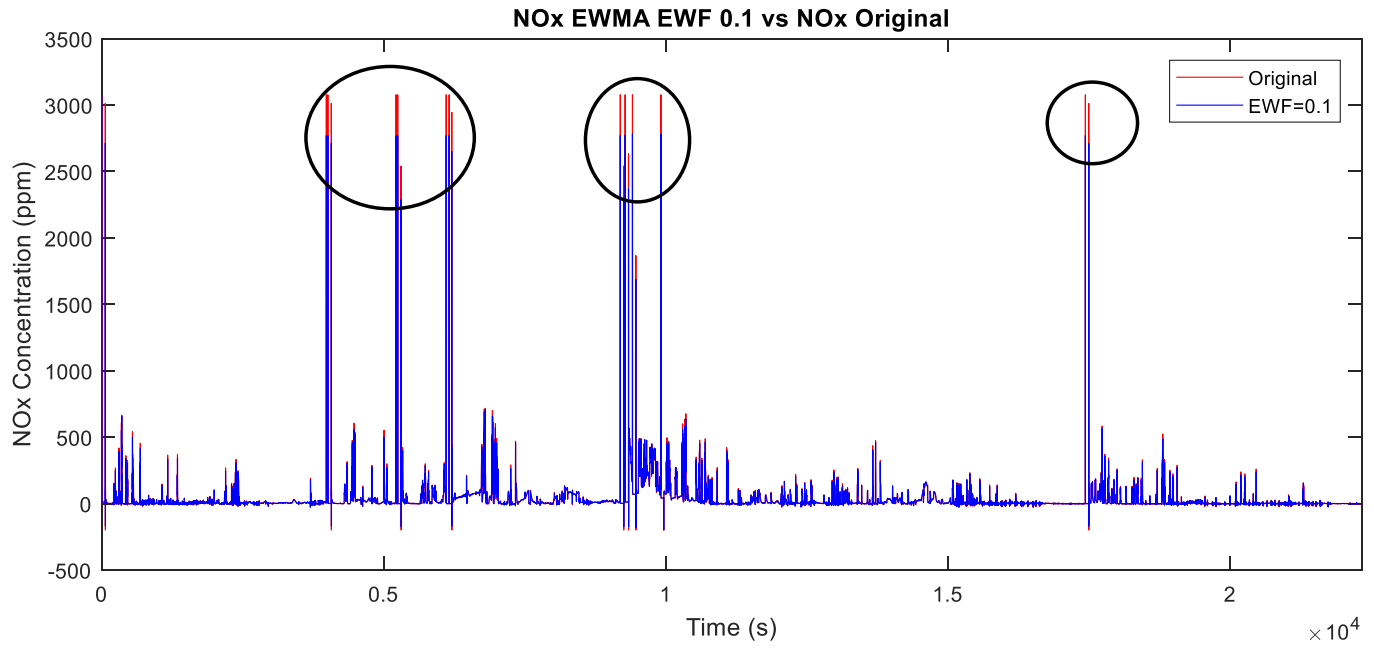

Figure 12 - Filtered NOx EWF=0.1 vs Original data

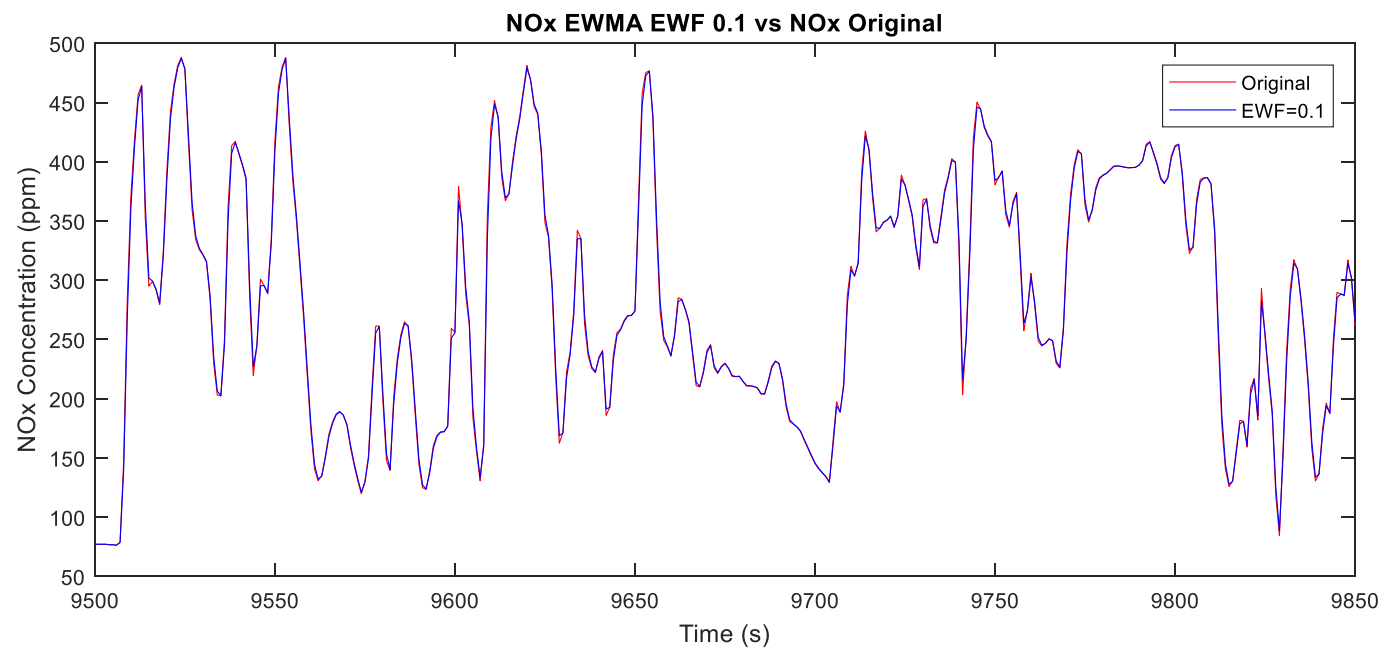

Figure 13 - Amplified Filtered NOx EWF=0.1 vs Original data

After comparing several options for EWF the original data was compared to the filtered data using a EWF of 0.25 and 0.35 . In Figure 14 a large segment of the dataset is displayed, and as one can see the values between the raw data and the filtered data are quite similar. Upon closer inspection in Figure 15, the filtered data seems to start ever so slightly sifting the data to the right as well as lessening the peaks. However, the data reduction method did reduce the main relevant 
peaks where the sensor didn't work properly. The higher the EWF selected was, the more the peak points were reduced. As for possible time alignment issues, these EWFs didn't seem to affect the data enough to actually shift the data enough. In fact, looking at Figure 16 one can see that the main noise peaks happen at the same position in time as the original data.

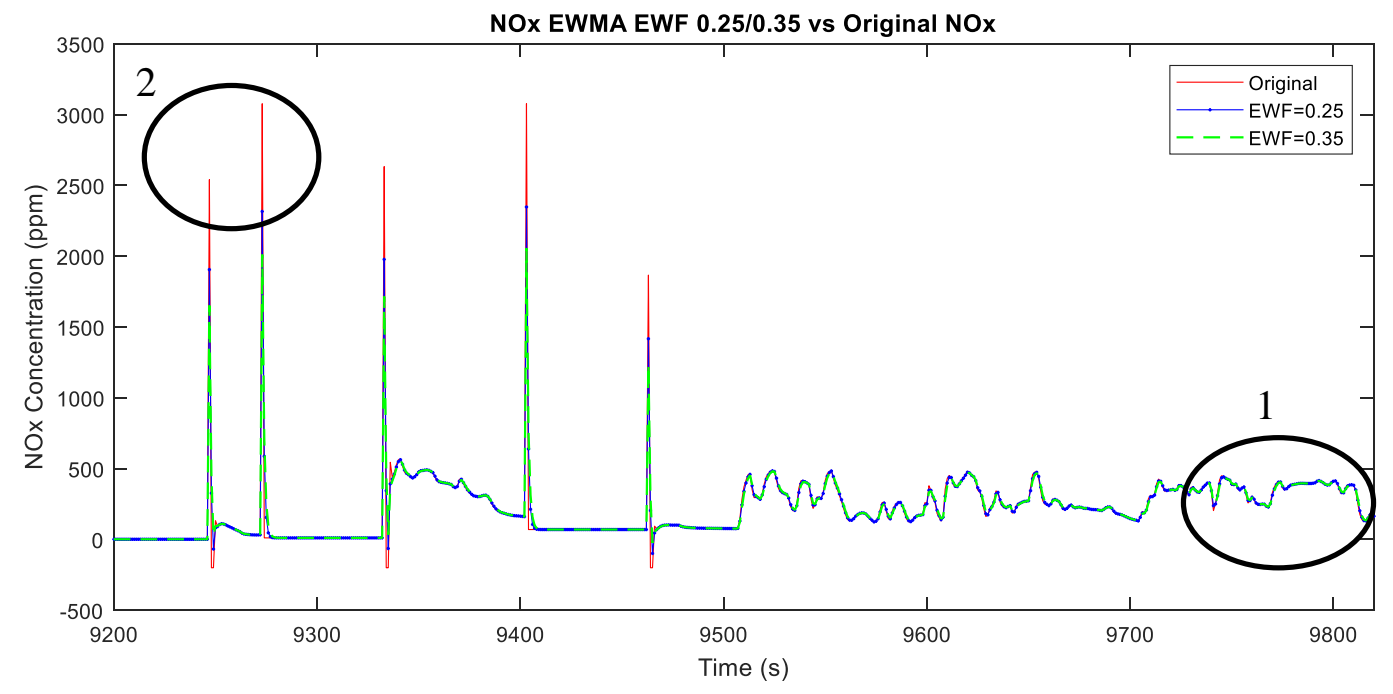

Figure 14 - Filtered NOx Data vs Original

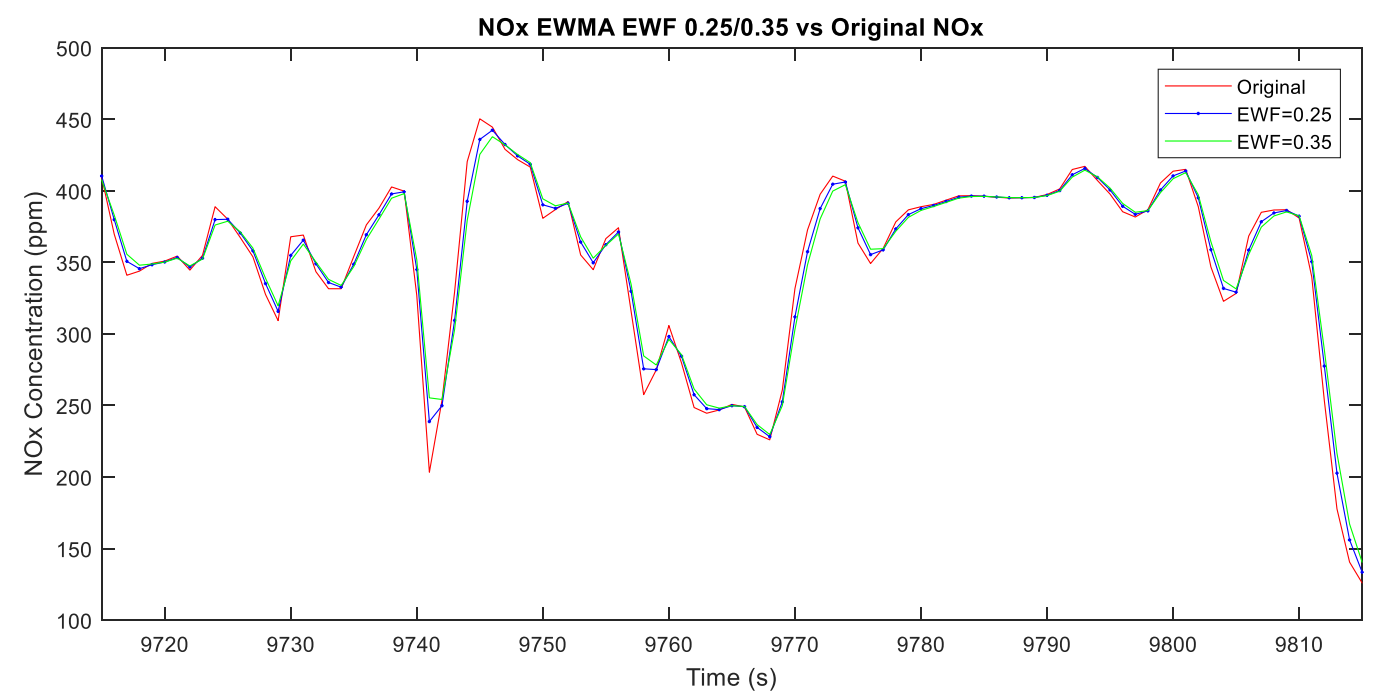

Figure 15 - Amplified Point 1: Filtered NOx Data vs Original 


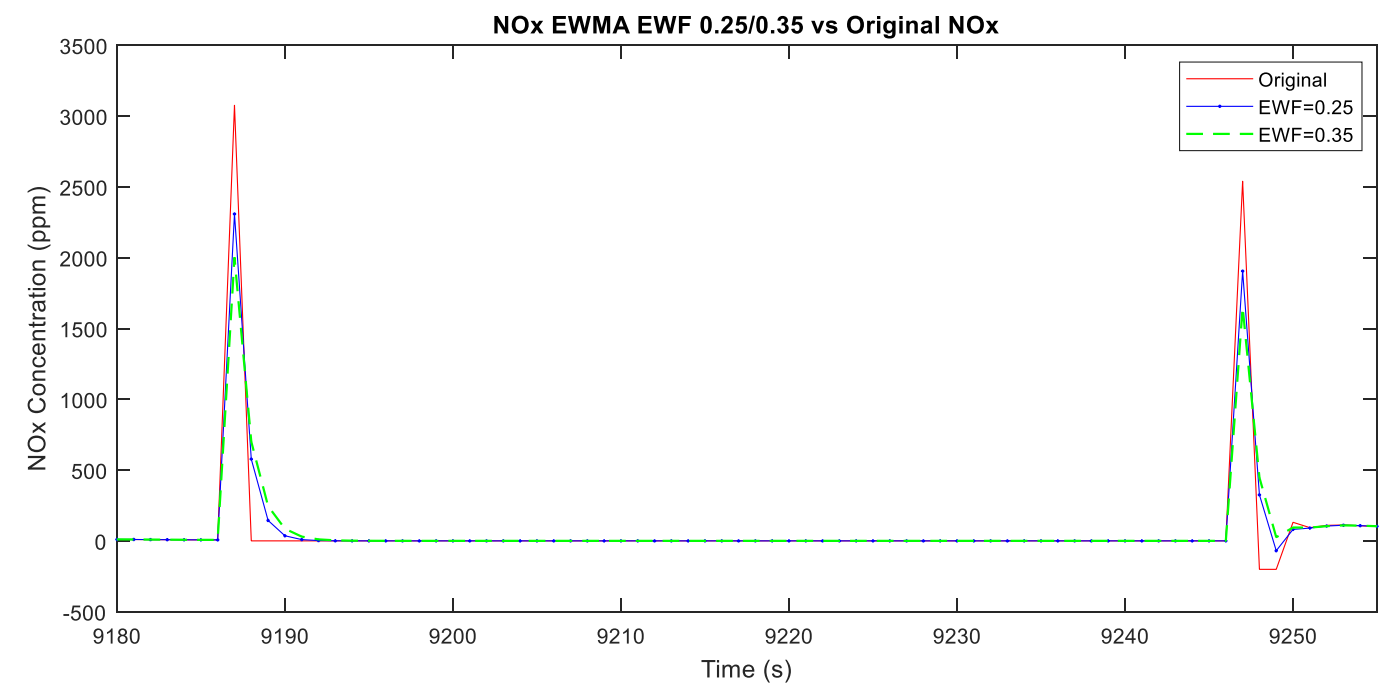

Figure 16 - Amplified Point 2: Filtered NOx Data Peaks vs Original Data

\subsection{Binned Data}

In this section the data for each time frame was binned based on the methods described in the methodology section. Since the only parameter that had to be smoothed was the NOx dataset, the exhaust temperature, engine work, distance, NTE, and count bins remained the same for all the methods applied. These bins can be used to analyze the results in the NOx bins and further describe the engine operation. Considering the speed ranges selected for the bin's schematics, one could infer what kind of activity falls inside each range. For bins 2, 7, 8, 12, and 13 one can expect urban activity. Bins 4, 9, and 14 should represent regional activity. Bins 5, 10, and 15 should represent highway activity. In addition. Most the vehicle's activity should be expected to be populated in bins 1 to 5 , where the power fraction is $25 \%$ or less. In addition, the NOx raw data displayed no $\mathrm{NaN}$ values prior to any filtering approach was used.

\subsubsection{Monthly}

For the monthly binning set, the data shown next is the data collected in the month of April, 2018. The following results are from the original raw dataset, before any filtering method was applied. 


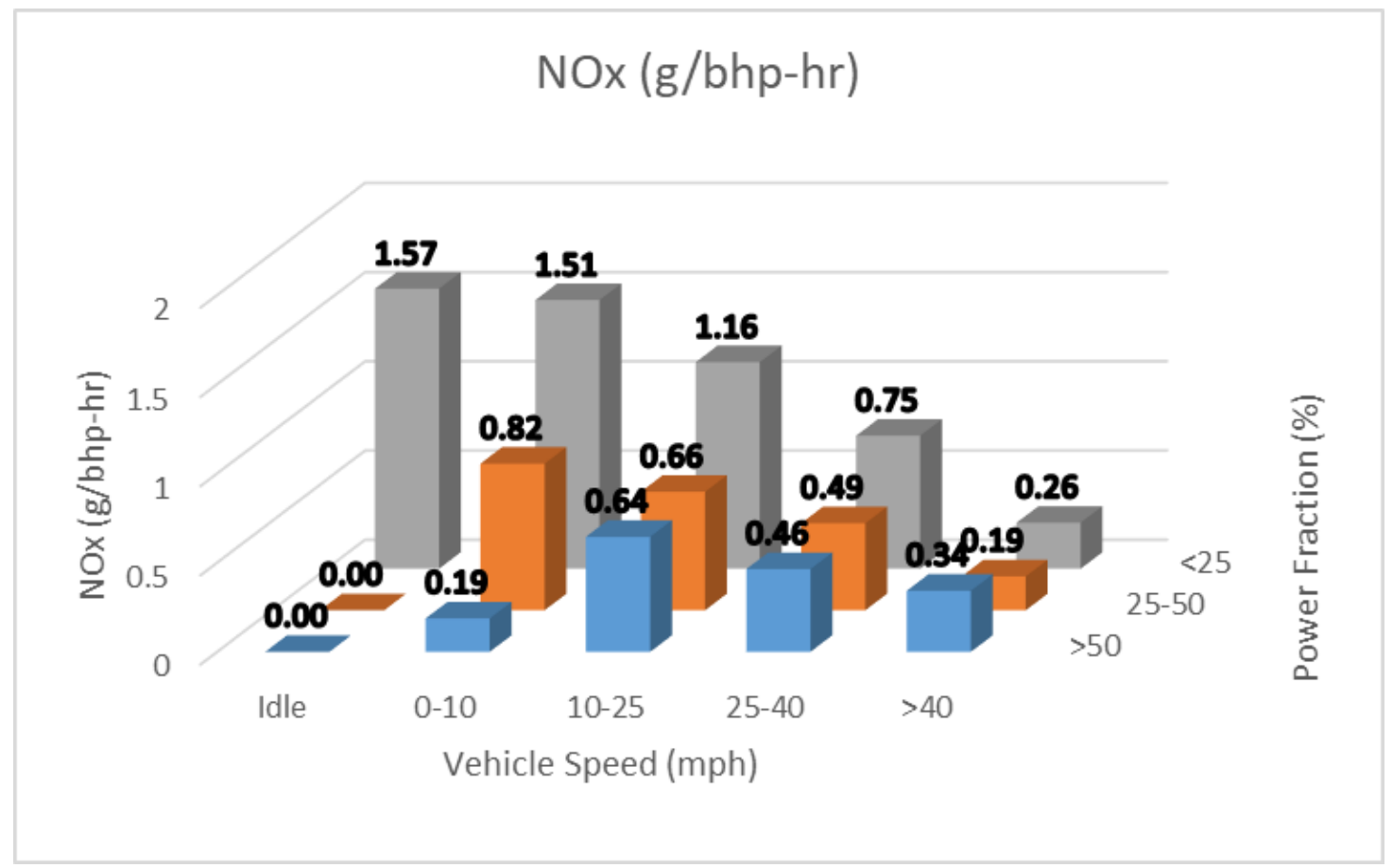

Figure 17 - Original Data NOx (g/bhp-hr) Bin - Monthly

The bsNOx bin follows the pattern that one would expect for a dataset such as the one used in this project. Under normal operation the higher emissions are expected to be in the earlier bins (14) while the lower emissions should be at higher speed and power fraction. Figure 18 and Table 6 summarize how the overall data was distributed over the NTE zone and its total duration.

Table 6 - Total Duration Summary - Monthly

\begin{tabular}{|l|r|}
\hline \multicolumn{2}{|c|}{ Monthly Data } \\
\hline Total Duration (sec) & 554655 \\
\hline Total NTE Duration (sec) & 95505 \\
\hline NTE Time \% & 17.22 \\
\hline Total NOx (g) & 306.27 \\
\hline Total Distance (miles) & 4830.21 \\
\hline
\end{tabular}




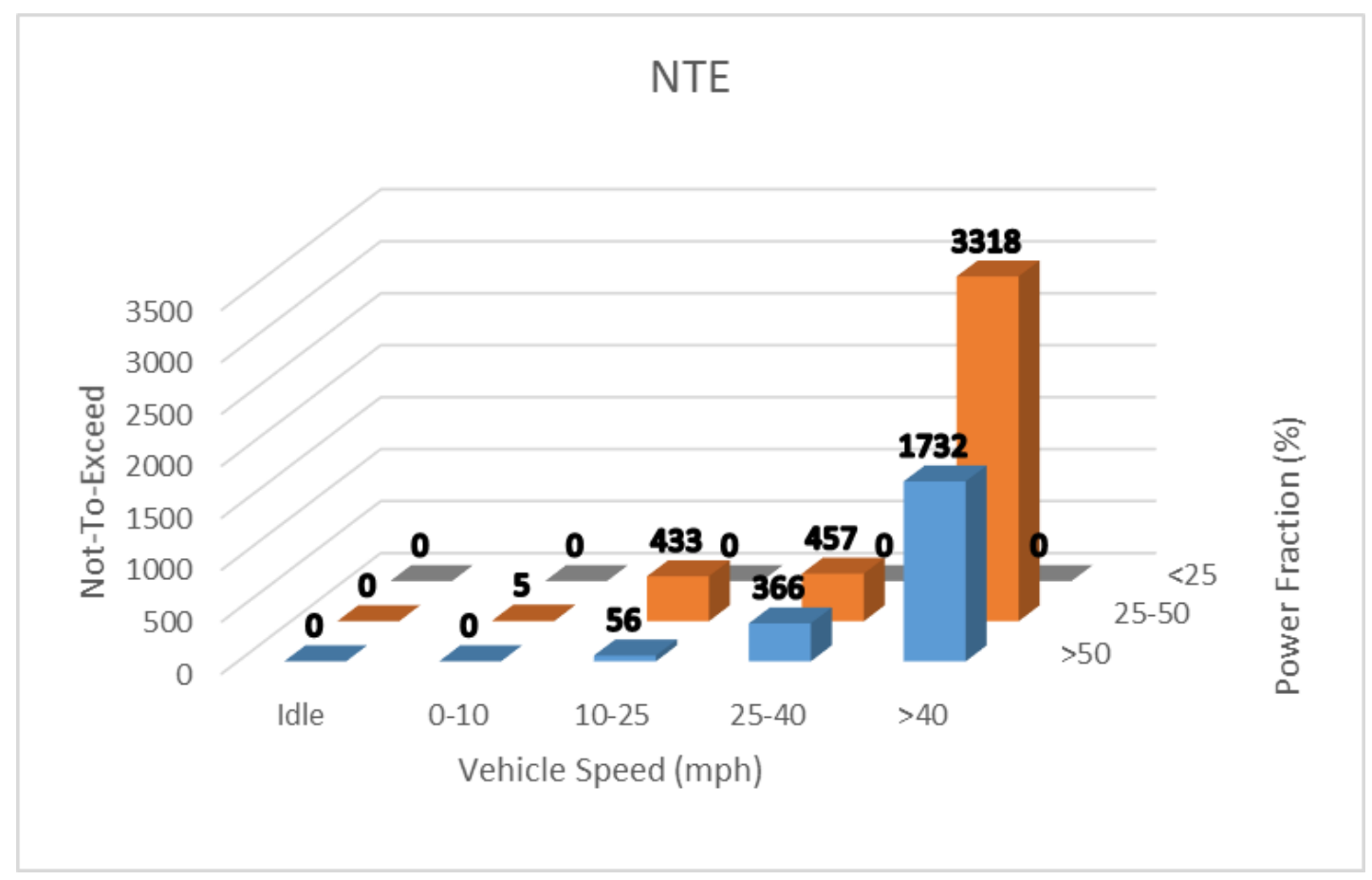

Figure 18 - Original Data NTE Bin - Monthly

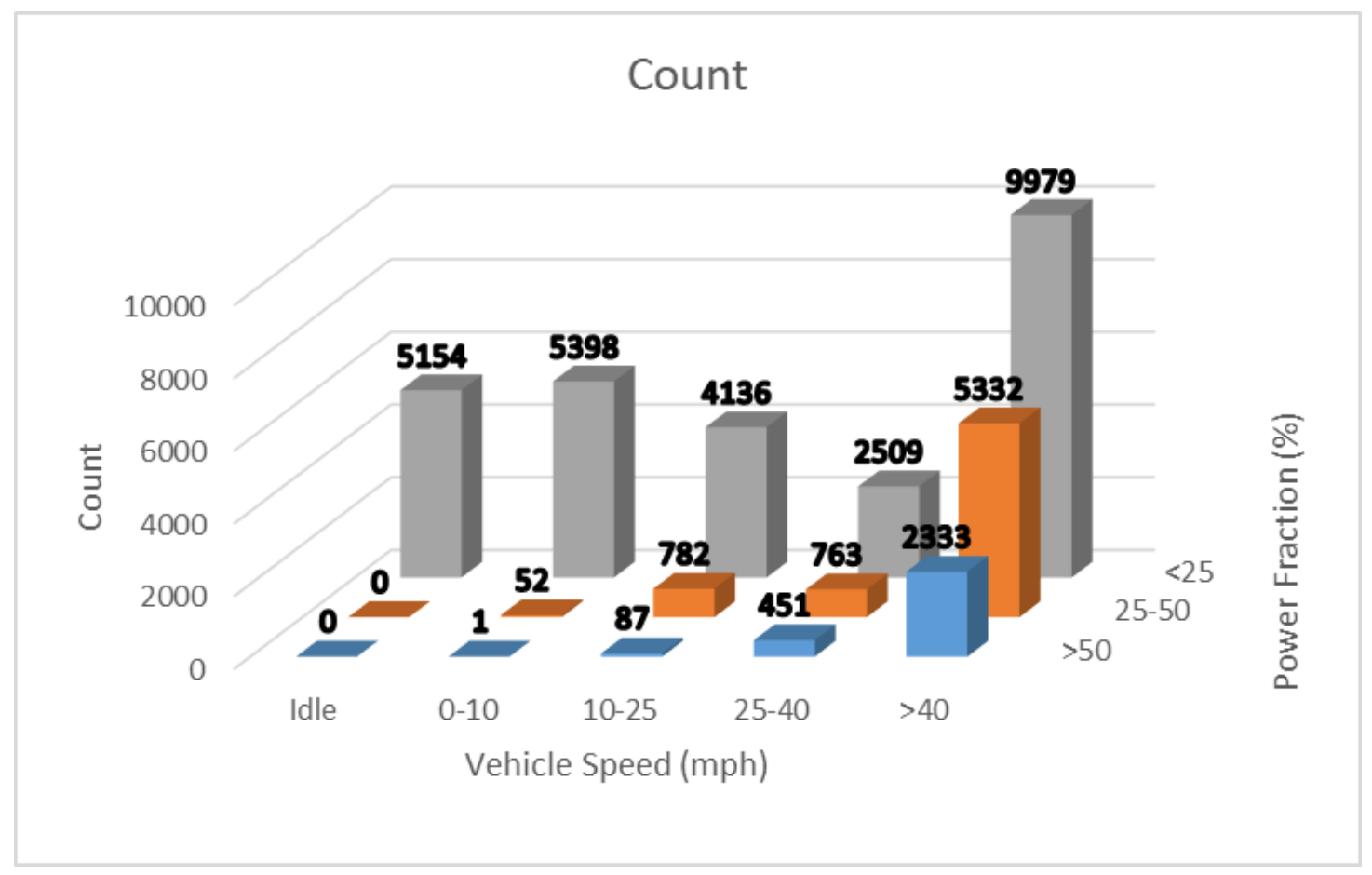

Figure 19 - Original Data Bin Count - Monthly 
By comparing Figure 18 to Figure 19 it's possible to infer that the majority of the dataset wasn't inside the NTE zone ( $<25 \%$ power fraction). In fact, according to Table 6 only $17.22 \%$ of its monthly operation was inside the control zone. Even though the majority of the data didn't fall inside of the NTE zone, there were still a noticeable amount of the points that did. Bin 10 contained the largest amount of NTE points ( $\sim 62 \%$ of the points inside this bin) as well as the lowest bsNOx emission compared to the other bins that were inside the NTE zone.

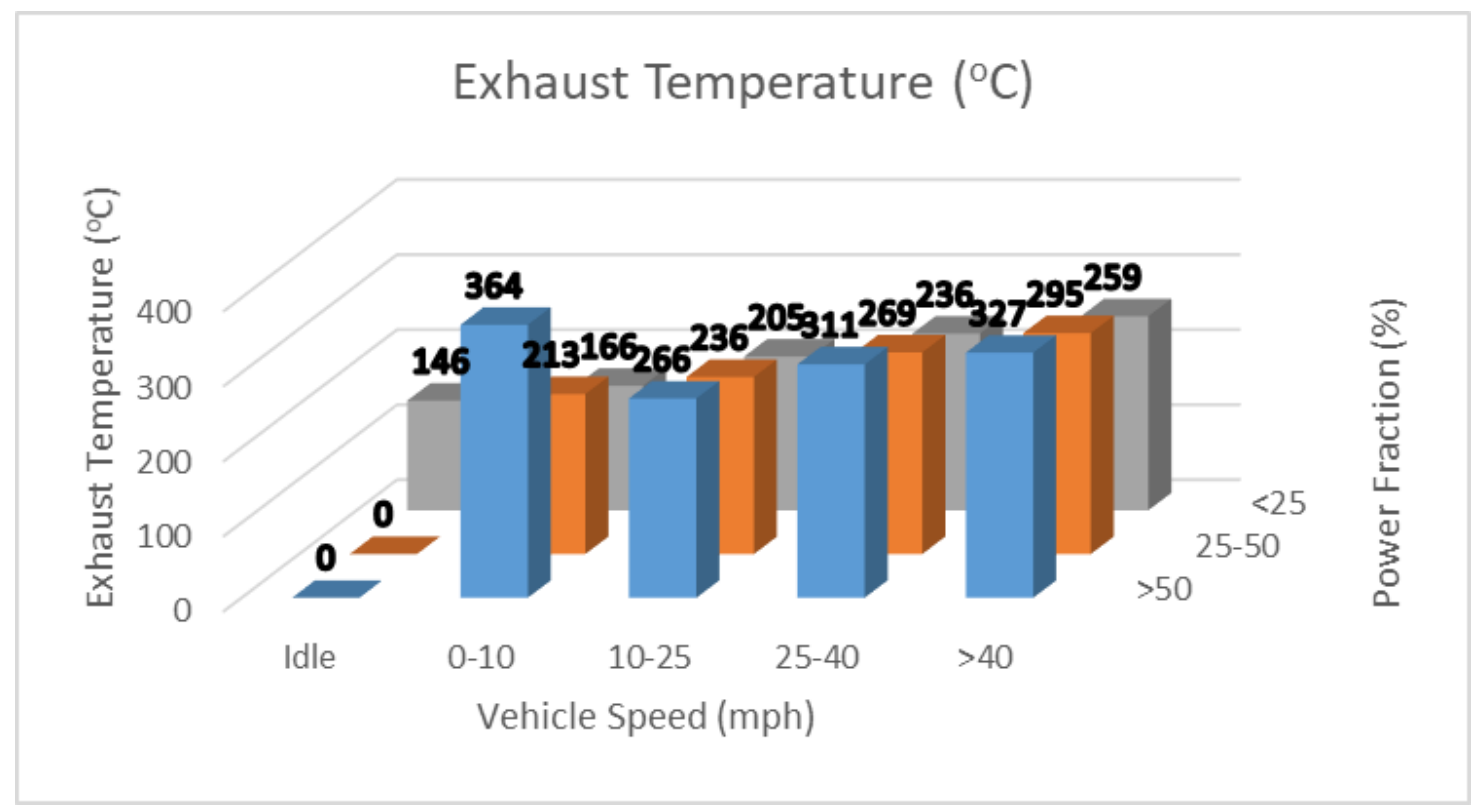

Figure 20 - Original Data Post-SCR Exhaust Temperature $\left({ }^{\circ} \mathrm{C}\right)$ Bin - Monthly

If one looks at Figure 20 the temperature follows the expected trend - higher temperatures at higher vehicle speeds and power fraction. However, the dataset does have its highest value located at bin $12(0-10 \mathrm{mph}$ and power fraction $>50 \%)$ which also represents the lowest value for NOx rate (g/bhp-hr). According to Figure 19, this is the same bin that only contains one window. This indicates that the lack of data in that bin category may not be representative of the actual operation condition. This point even though it's supposedly compliant to the regulation didn't even fall inside of the NTE zone. 


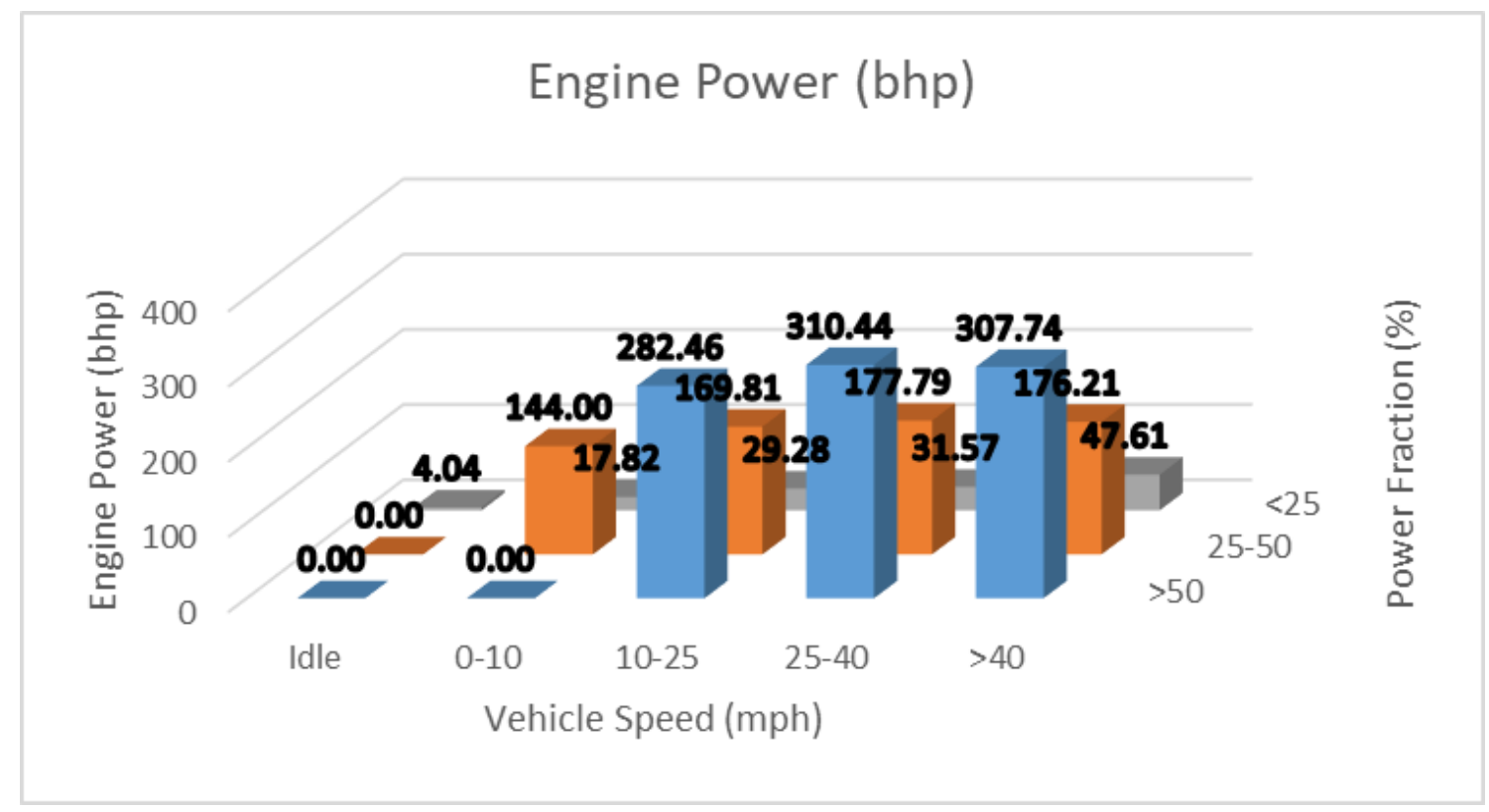

Figure 21 - Original Data Power (bhp) Bin - Monthly

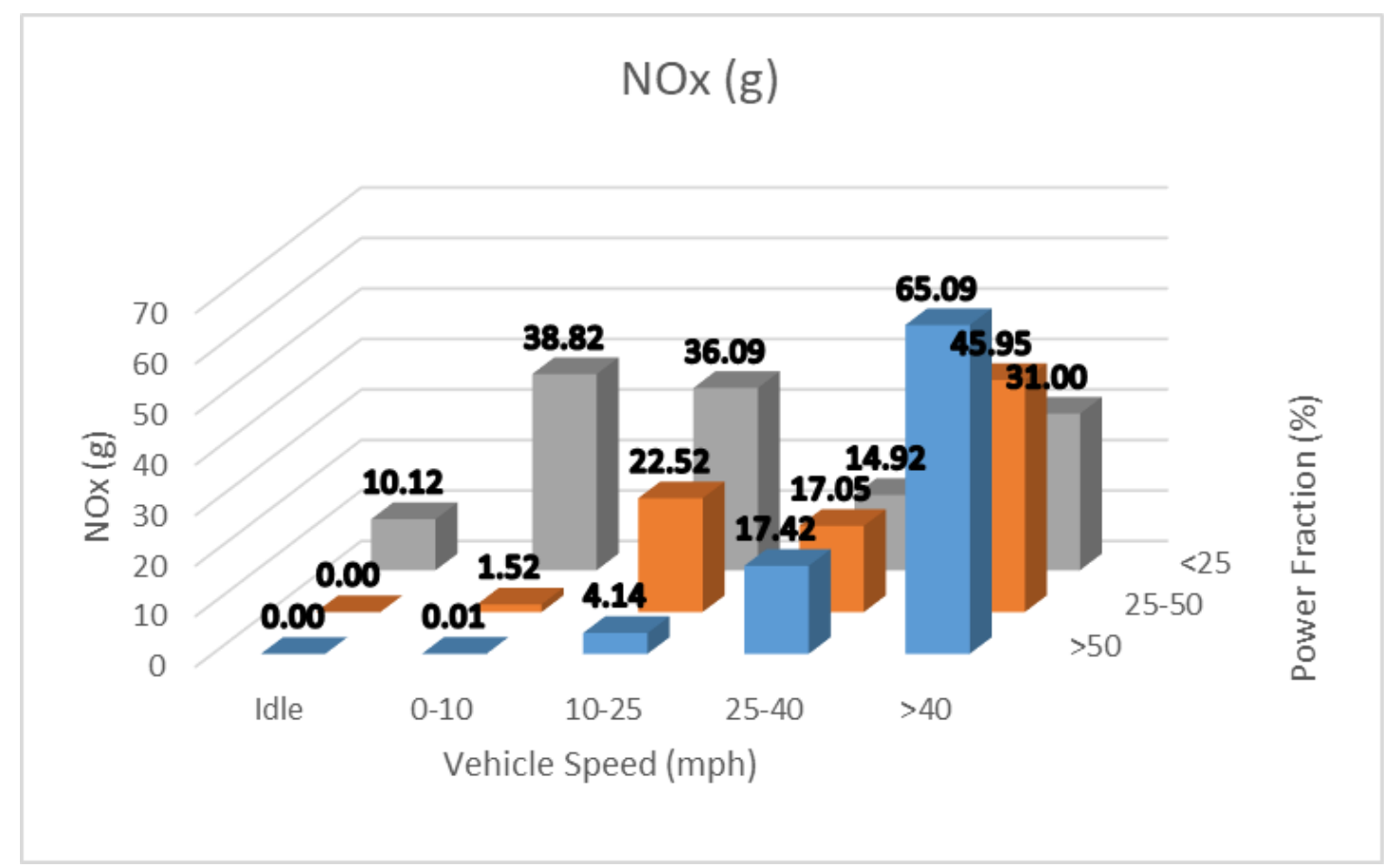

Figure 22 - Original Data NOx (g) Bin - Monthly 


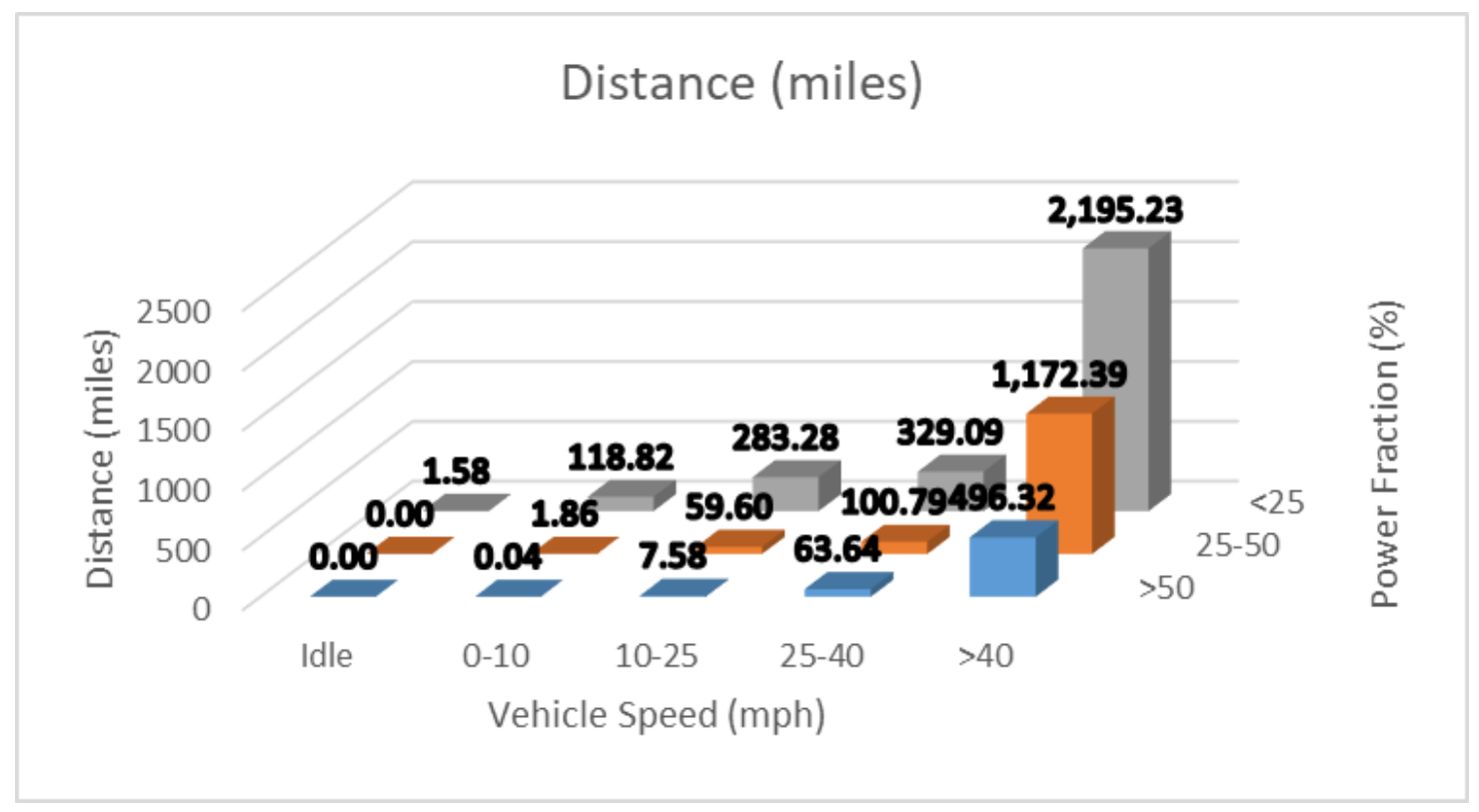

Figure 23 - Original Data Distance (miles) Bin - Monthly

Figures 22 to 24 display the other binned parameters. These bins help solidify and confirm what the previous bins stated. These bins provide a further insight on the engine operation. Figure 23 shows that not only most of the windows fall into bin 1 to 5 but also that it covered the most distance in these bins. This solidifies that the majority of this engine's operation falls outside of the NTE control zone. 


\subsubsection{NOx Stable}

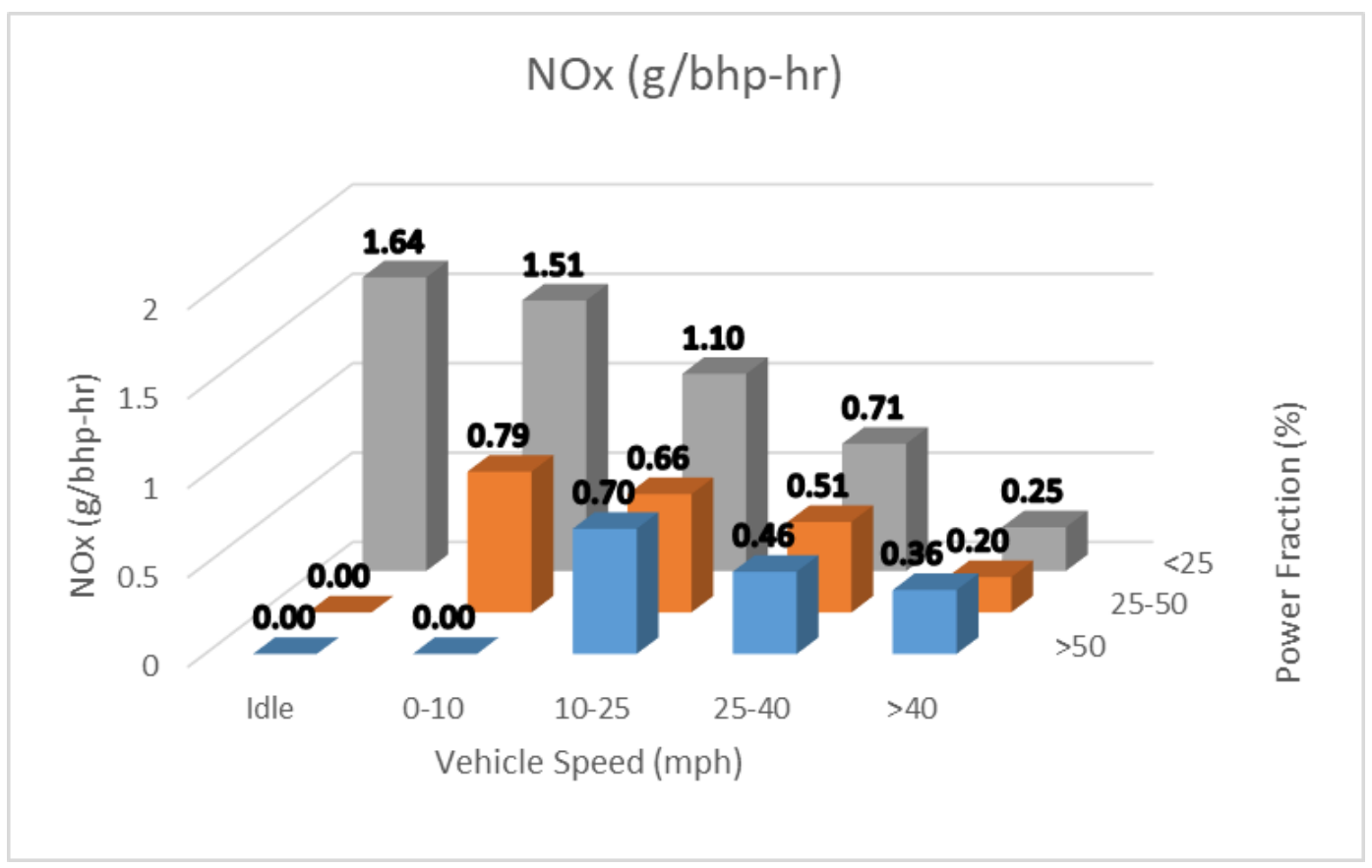

Figure 24 - Stable Reduction Method NOx Data (g/bhp-hr) Bin - Monthly

The data replaced with NaNs account for $3.48 \%$ of the sensor's operation. The NOx stable data display similar results to the original dataset. Its values are almost the same values as the original at bins at medium to high speed (>25mph). Due to the reduction, the values where the vehicle speed is less than $25 \mathrm{mph}$ the bins start diverting from the original dataset. Those bins probably contained the majority of the noise that was removed and replaced with NaNs. However, according to Figure 18 the majority of these bins that display a difference are not in NTE region. In addition, the low NOx value found in bin 12 was removed thus it can be attributed to the issues described in the original data section. 


\subsubsection{EWMA}

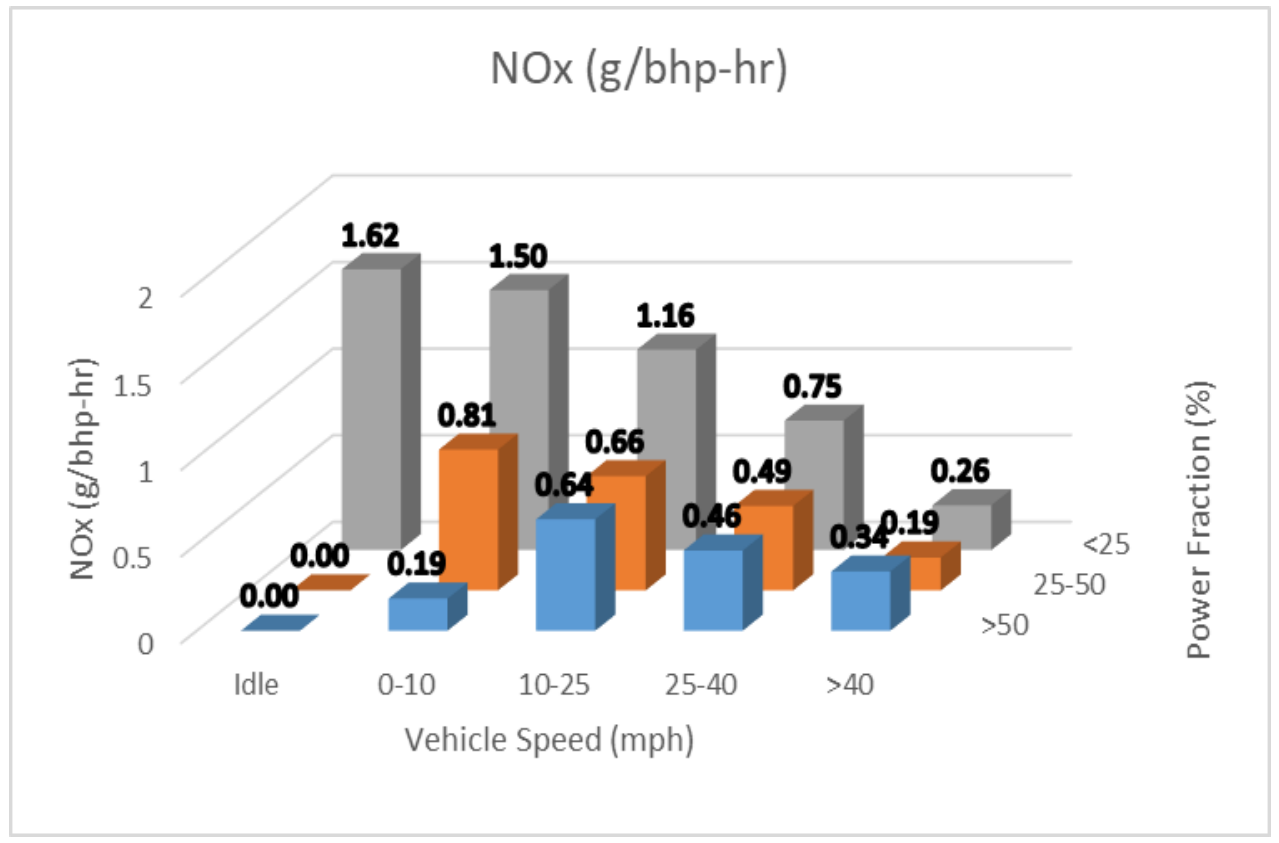

Figure 25 - EWMA Method (EWF=0.1) NOx Data (g/bhp-hr) Bin - Monthly

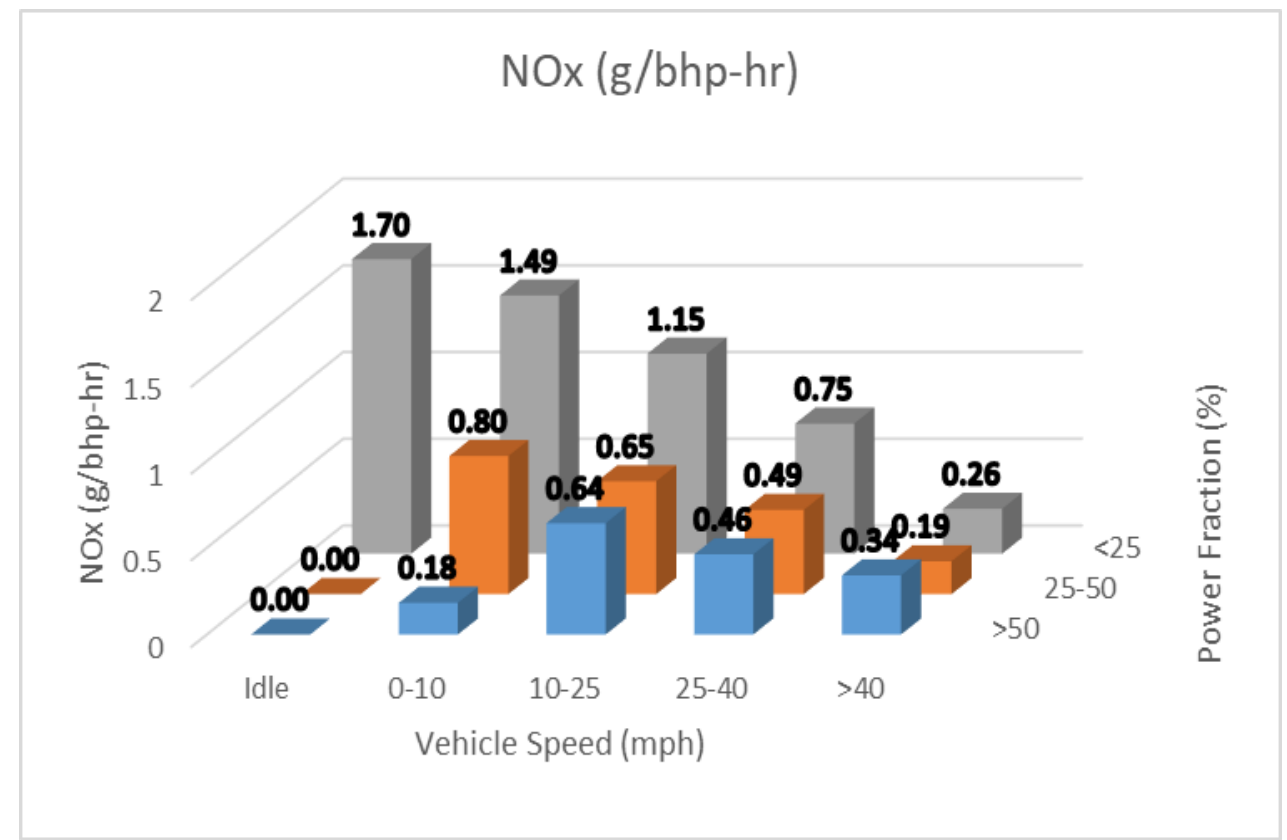

Figure 26 - EWMA Method (EWF=0.25) NOx Data (g/bhp-hr) Bin - Monthly 


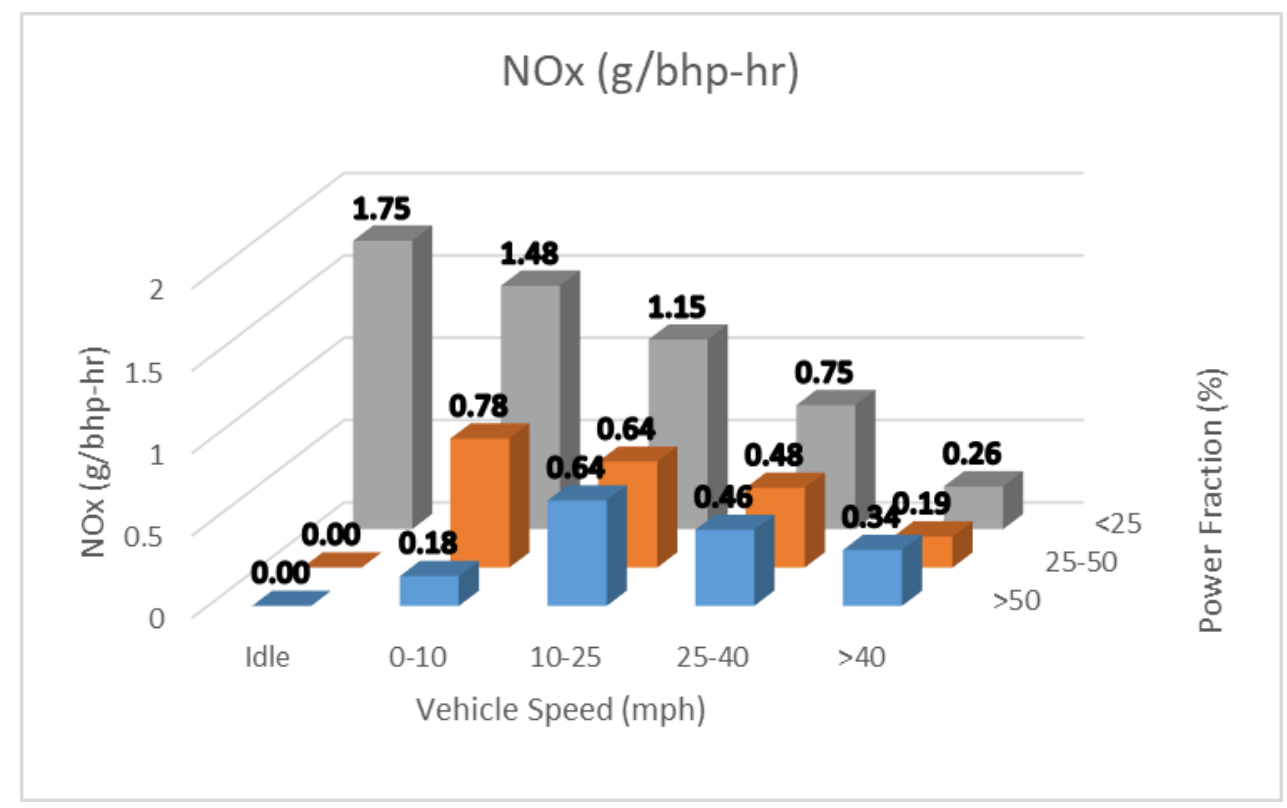

Figure 27 - EWMA Method (EWF=0.35) NOx Data (g/bhp-hr) Bin - Monthly

When applying the EWMA method three different EWF values were used to see how it affects the overall dataset. These binning only displays a noticeable difference between each other at the lower power fraction and lower vehicle speeds. It is to be expected that at the lower bins $(<25 \%$ and $<25 \mathrm{mph}$ ) the NOx rate to be higher, since it the aftertreatment system at those bins usually haven't met the desired temperature yet. In Figure 19 it shows that bin 12 only had one value in it, and this value for NOx mass, as shown in Figure 22, is the lowest non-zero value in the bin set. Therefore the lack of data in that bin and the very low value in the only data in that set is probably the reason why the data in that bin doesn't follow the trend of the rest of the data. In fact, this point could be the result from errors in the system making that point not relevant to the overall engine's operation. Overall, all the bsNOx bins that went through reduction displayed higher values at the lower speed/lower power fraction and lower values at higher speed/higher power fraction.

\subsubsection{Weekly}

For the weekly binning set, the data shown next is the data collected between April $8^{\text {th }}$ and April $14^{\text {th }}$ of 2018 . The data for the week timeframe displayed similar results to the data from the month analysis. Therefore, most of the bin graphs for this section can be found in Appendix A. 


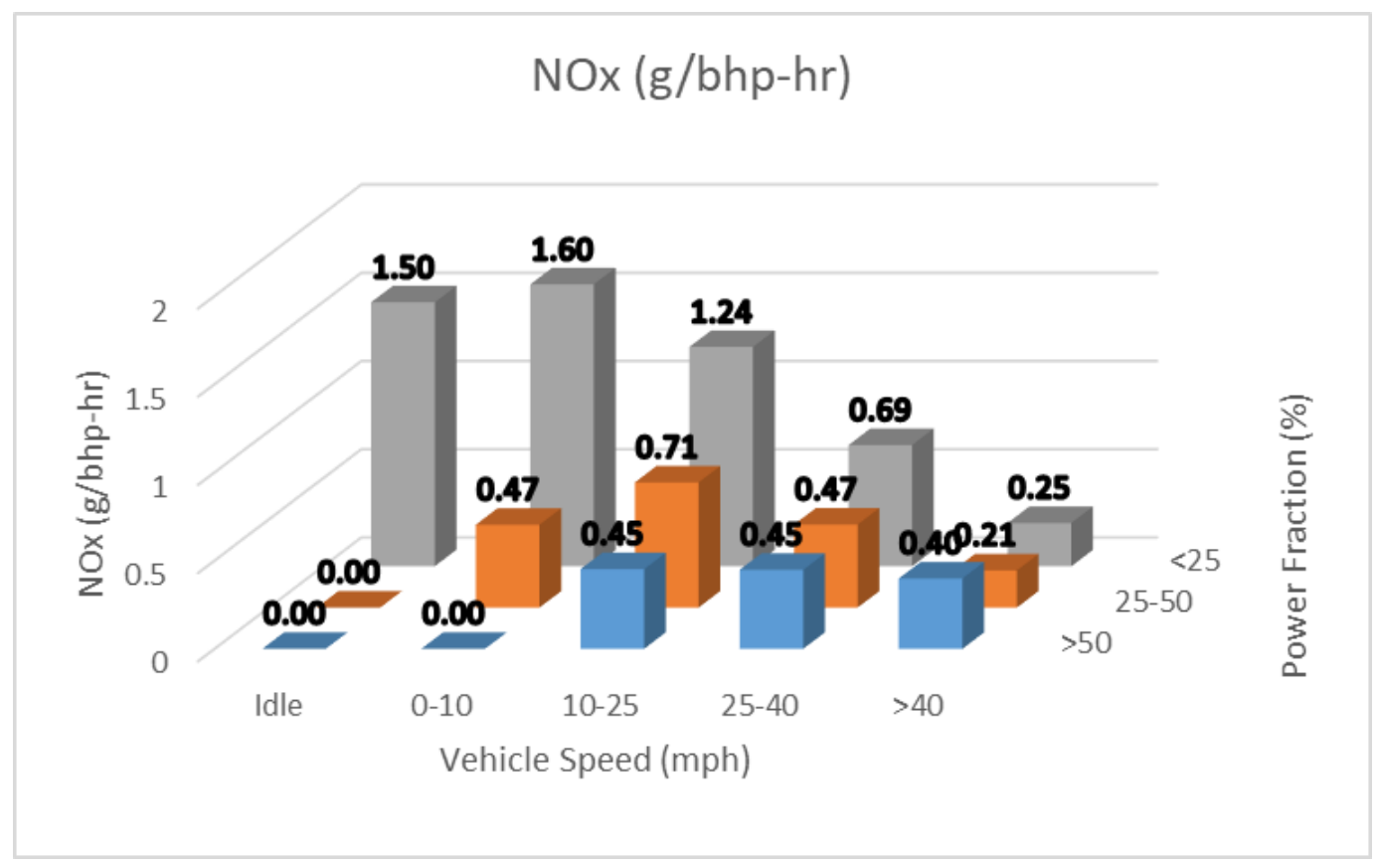

Figure 28 - Original Data NOx (g/bhp-hr) Bin - Weekly

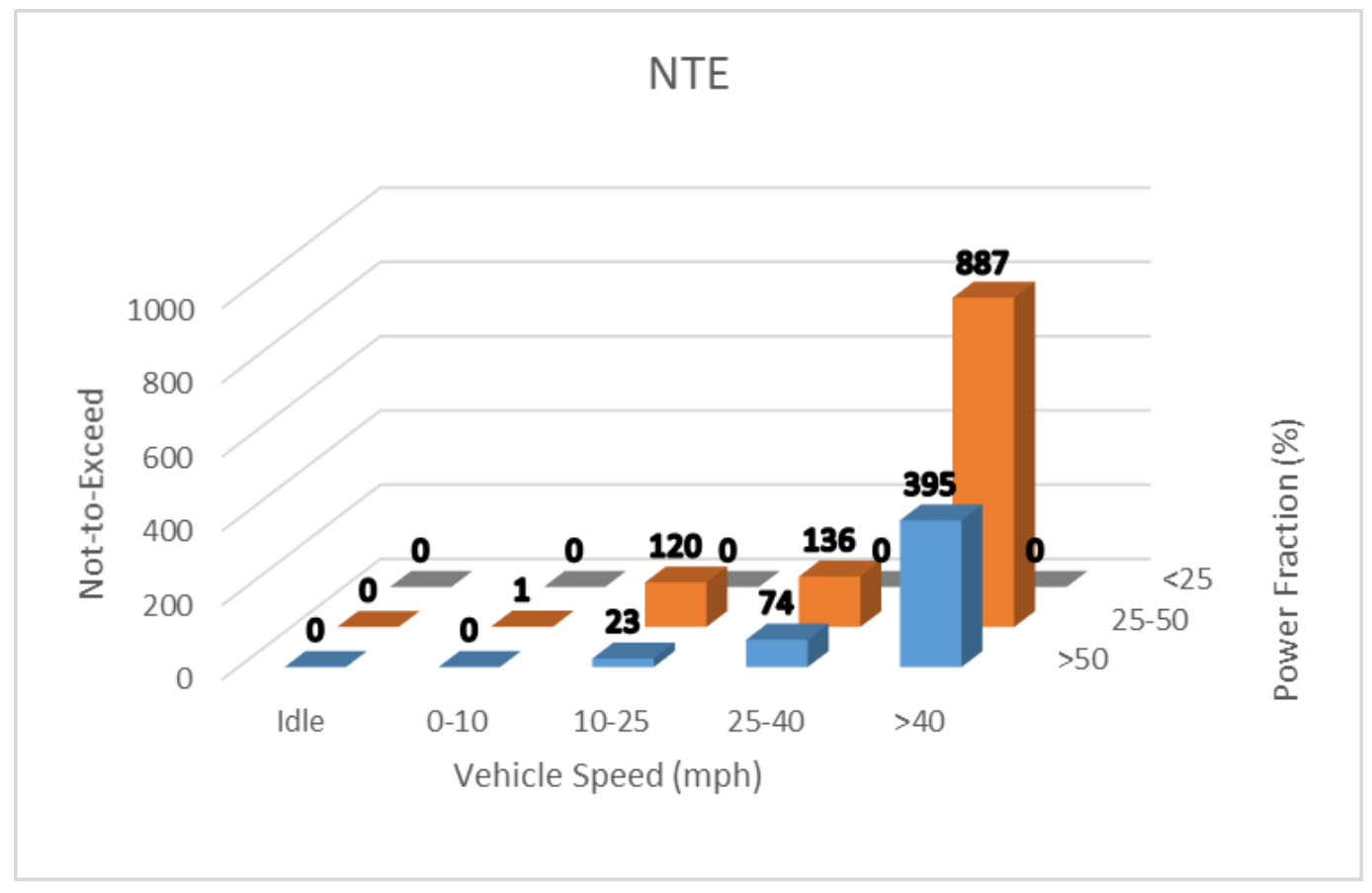

Figure 29 - Original Data NTE Bin - Weekly 
Table 7 - Total Duration Summary - Weekly

\begin{tabular}{|l|r|}
\hline \multicolumn{2}{|c|}{ Weekly Data } \\
\hline Total Duration (sec) & 160455 \\
\hline Total NTE Duration (sec) & 24540 \\
\hline NTE Time \% & 15.29 \\
\hline Total NOx (g) & 87.31 \\
\hline Total Distance (miles) & 1332.68 \\
\hline
\end{tabular}

By reducing the time frame the bin that displayed issues in the monthly dataset (bin 12) was removed. The bsNOx bin follows a similar trend to the monthly dataset, however the weekly set displayed less values in the NTE zone (less than $16 \%$ of its weekly operation has fallen in the NTE zone). The highest NTE count, similarly to the monthly dataset, is located on bin 10, which in this dataset also displays the lowest bsNOx value. The value in this bin is very close to the regulation which could indicate compliance, considering that only $31 \%$ of the values in that bin fell inside the NTE zone. In addition, the higher bsNOx value in bin 2 could be attributed to the larger amount of windows in that category when compared to the other adjacent bins. This dataset shows that by reducing the dataset to almost a quarter of the original set the bins still display reasonable patterns. However, the overall bsNOx values are higher than the monthly dataset. This could be attributed to this particular week that was selected, meaning that in different weeks the vehicle could have higher operation weeks than others. 


\subsubsection{NOx Stable}

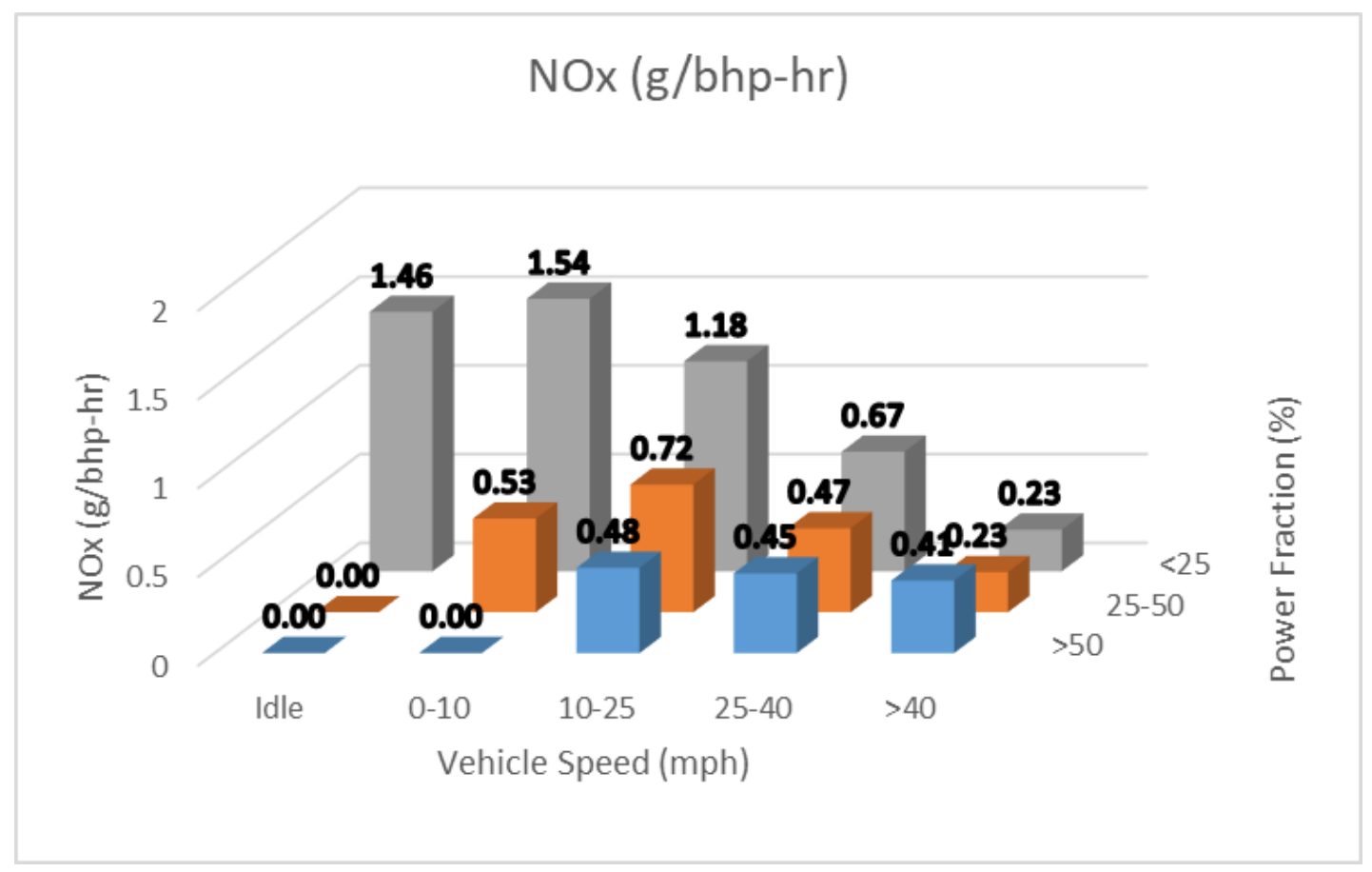

Figure 30 - Stable Reduction Method NOx Data (g/bhp-hr) Bin - Weekly

The data replaced with NaNs accounts for 3.00\% of the sensor's operation, almost the same amount as the monthly result. Similar to the previous results, the bsNOx data diverted from the original the most at lower speed/power bins. This indicates that the data that was removed has definitely affected the overall results. Considering that the original dataset contained several spots in which the NOx (ppm) values were negative by removing them a difference in the data should be expected, just as Figure 30 shows. This set actually displayed less of a shift than the monthly dataset. 


\subsubsection{EWMA}

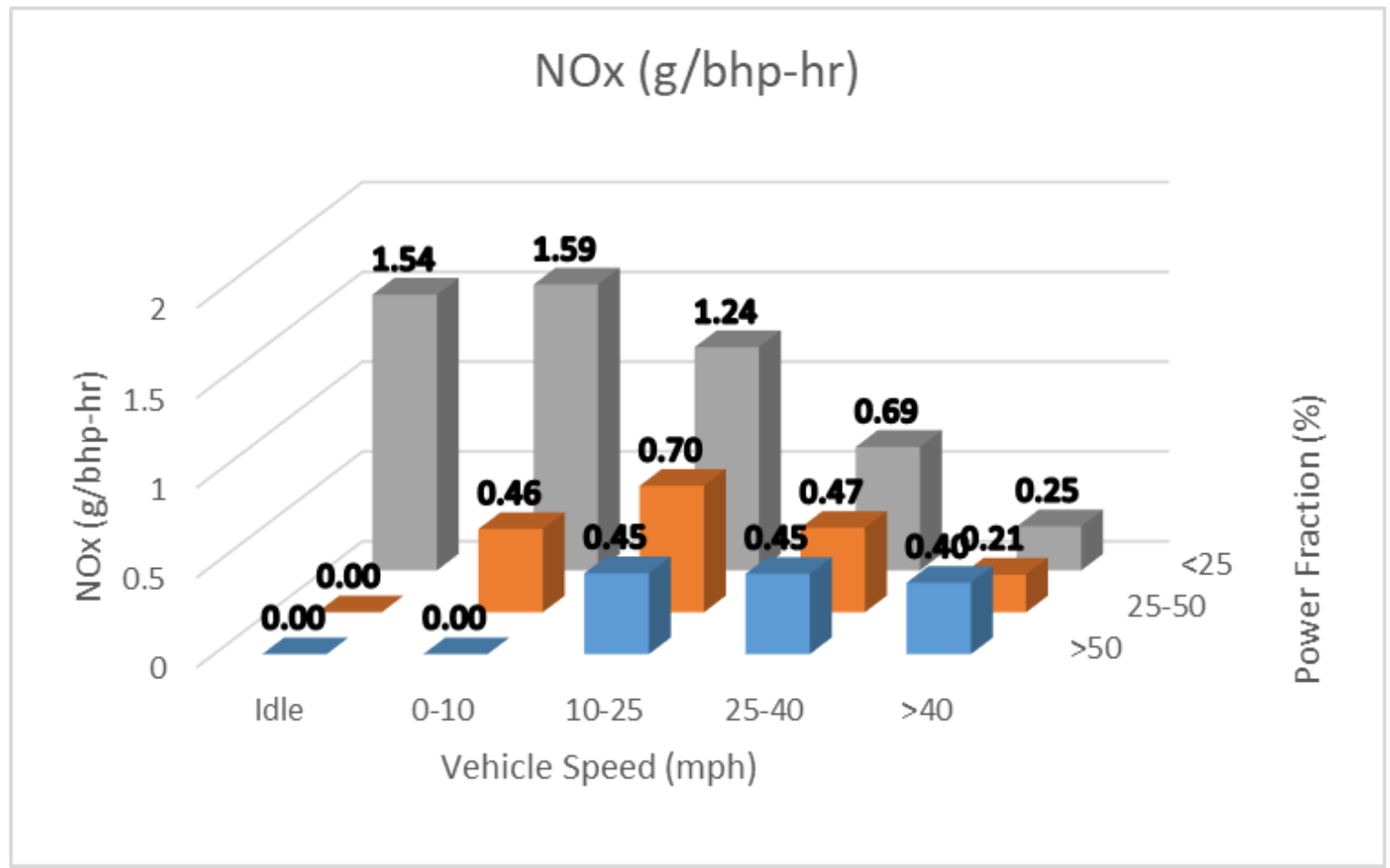

Figure 31 - EWMA Method (EWF=0.1) NOx Data (g/bhp-hr) Bin - Weekly

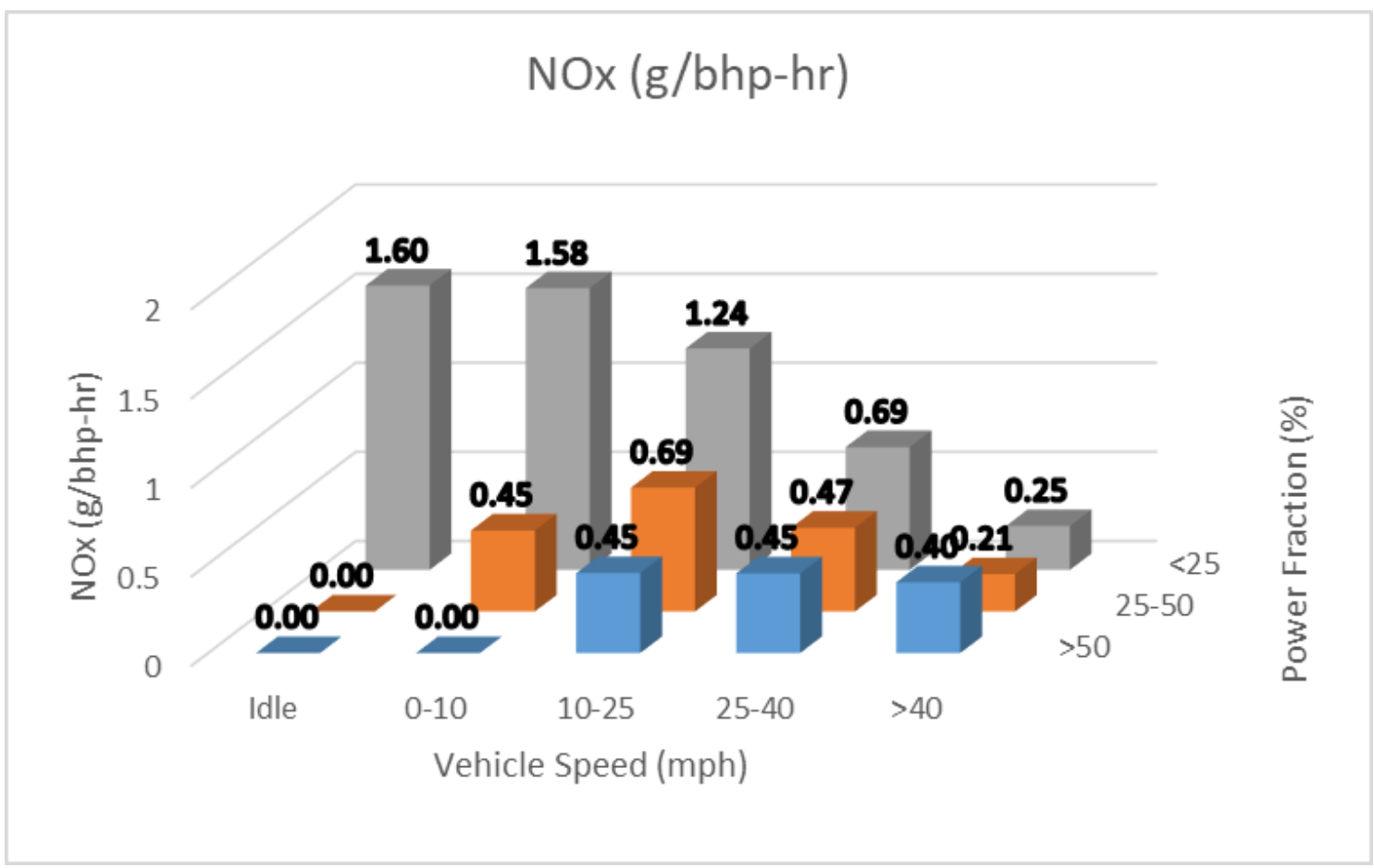

Figure 32 - EWMA Method (EWF=0.25) NOx Data (g/bhp-hr) Bin - Weekly 


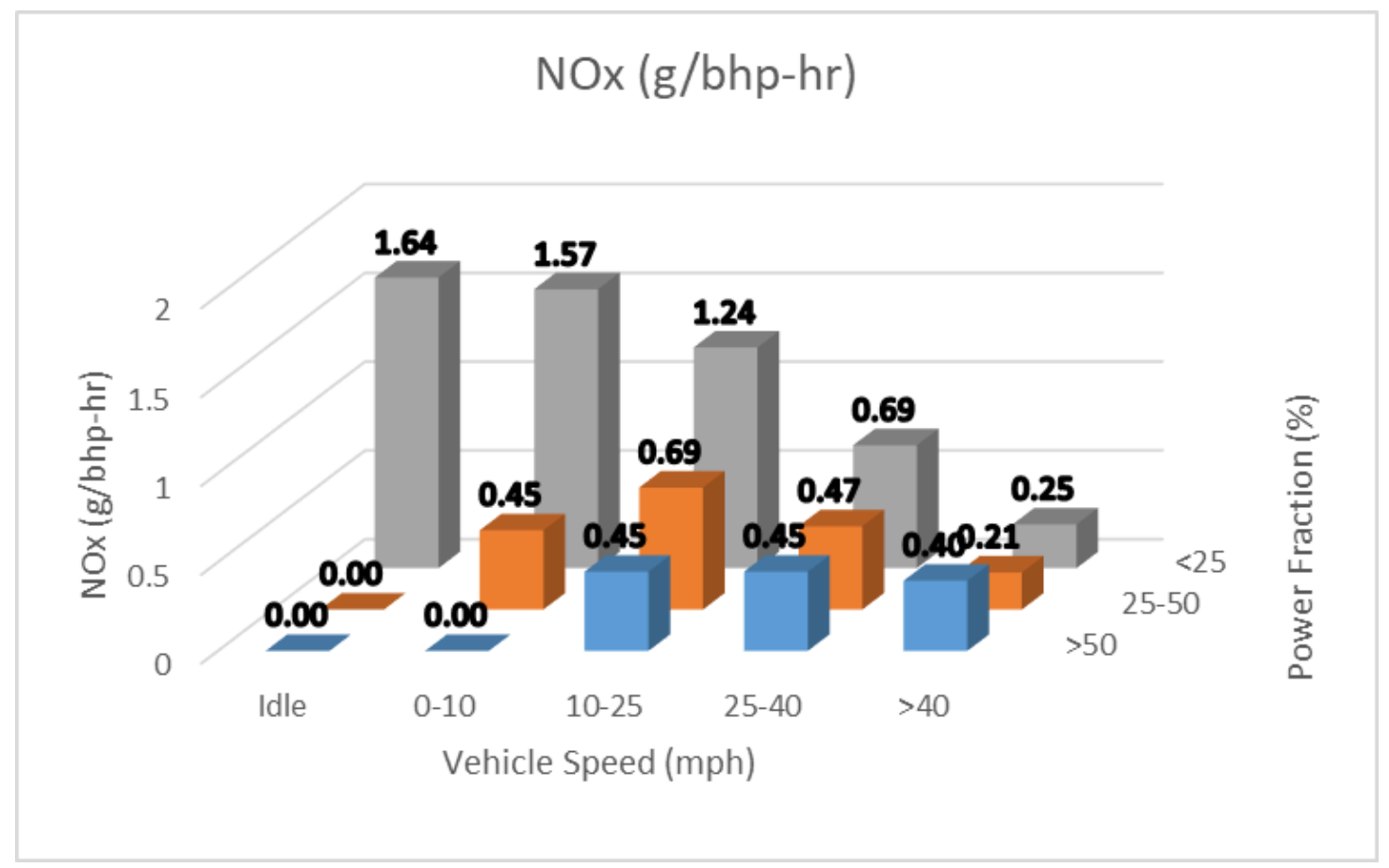

Figure 33 - EWMA Method (EWF=0.35) NOx Data (g/bhp-hr) Bin - Weekly

For the weekly dataset, once more the increase in EWF caused an increase of bsNOx in the overall dataset which is concentrated on the lower power fraction $(<25 \%)$. When comparing this method to the NOx stable method, all the EWFs displayed lower values in the bsNOx bin than the other method. In fact, the EWF of 0.1 showed the closest values to the original dataset.

\subsubsection{Daily}

For the daily binning set, the data shown next is the data collected on April $10^{\text {th }} 2018$. The following results are from the original raw dataset, before any data reduction was applied. Similarly to the weekly data the daily data displayed similar results to the data from the monthly analysis. Therefore, most of the bin graphs for this section can be found in Appendix B.

Table 8 - Total Duration Summary - Daily

\begin{tabular}{|l|r|}
\hline \multicolumn{2}{|c|}{ Daily Data } \\
\hline Total Duration (sec) & 22320 \\
\hline Total NTE Duration (sec) & 3120 \\
\hline NTE Time \% & 13.98 \\
\hline Total NOx (g) & 9.83 \\
\hline Total Distance (miles) & 153.60 \\
\hline
\end{tabular}




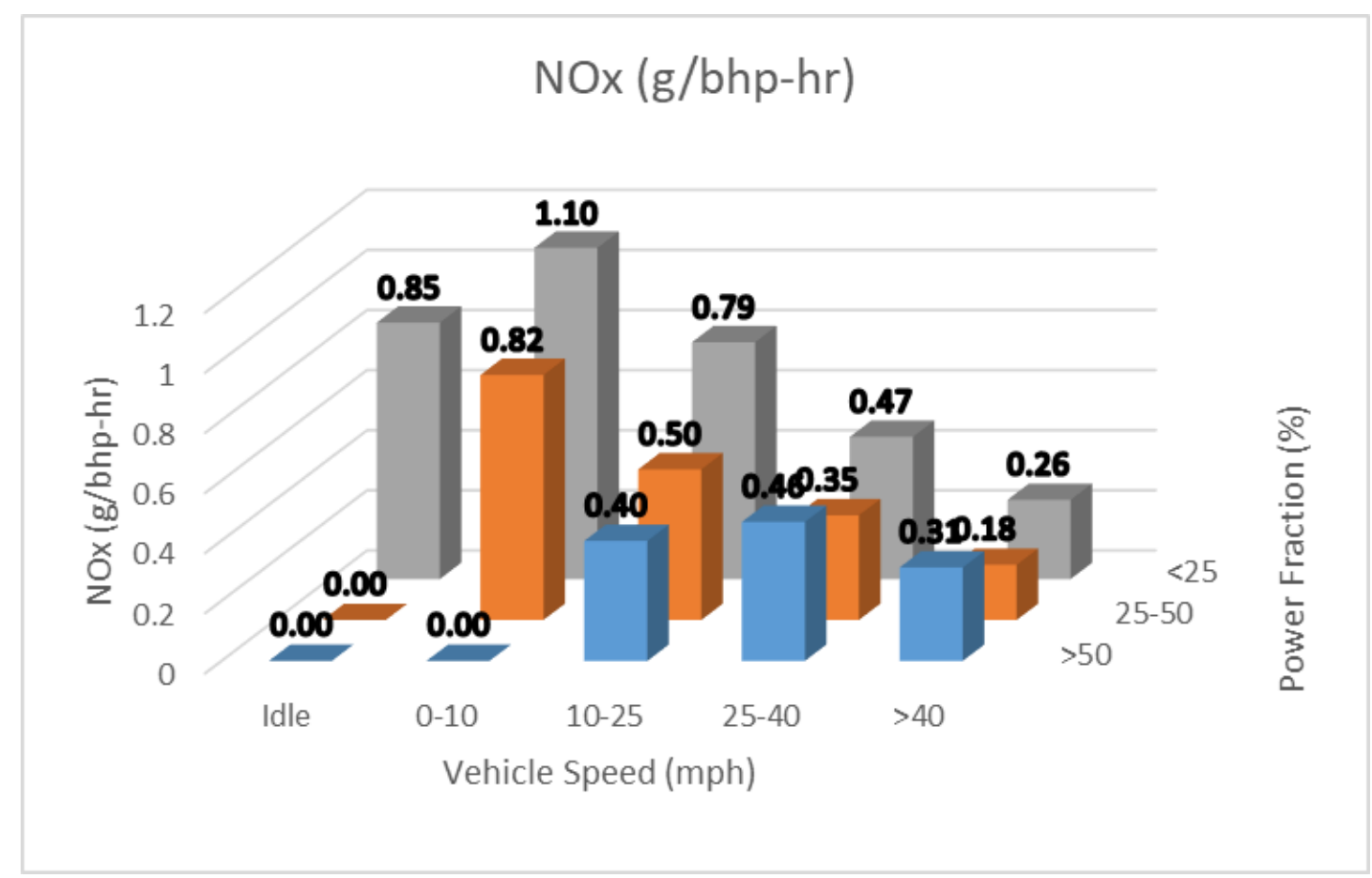

Figure 34 - Original Data NOx (g/bhp-hr) Bin - Daily

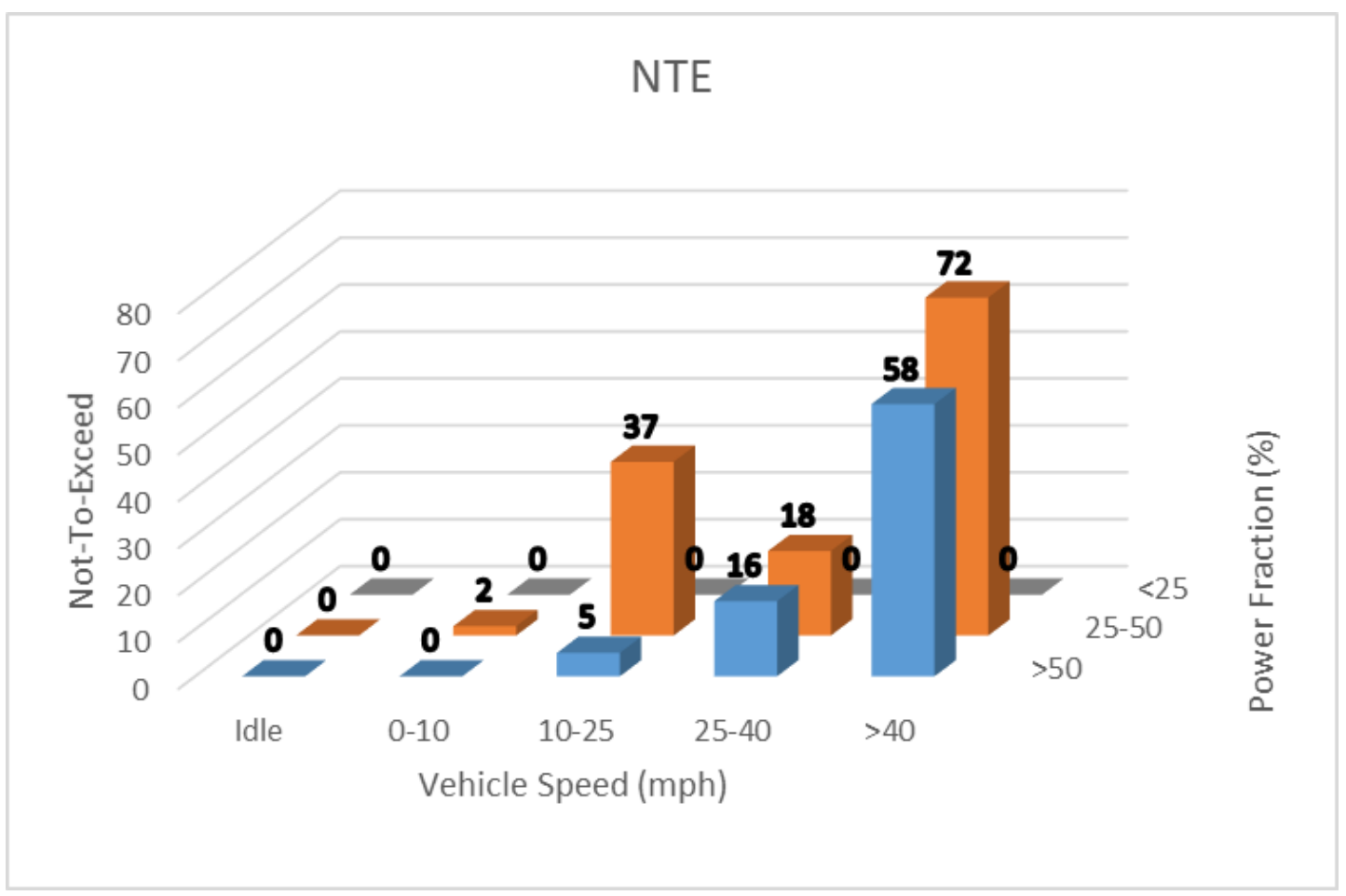

Figure 35 - Original Data NTE Bin - Daily 
Once more the daily dataset displayed a similar distribution to the previous time frames. This indicates that this method could be used to analyze an engine's operation. The main difference in this dataset relies on the fact that the majority of its operation happened at idle. The bins that fall into this category are outside the NTE control zone. In addition, the NTE zone has even less points than the previous methods ( $14 \%$ of the total operation) which is a result of the majority of its operation happening outside the NTE boundary and this being the shortest dataset among all sets analyzed.

\subsubsection{NOx Stable}

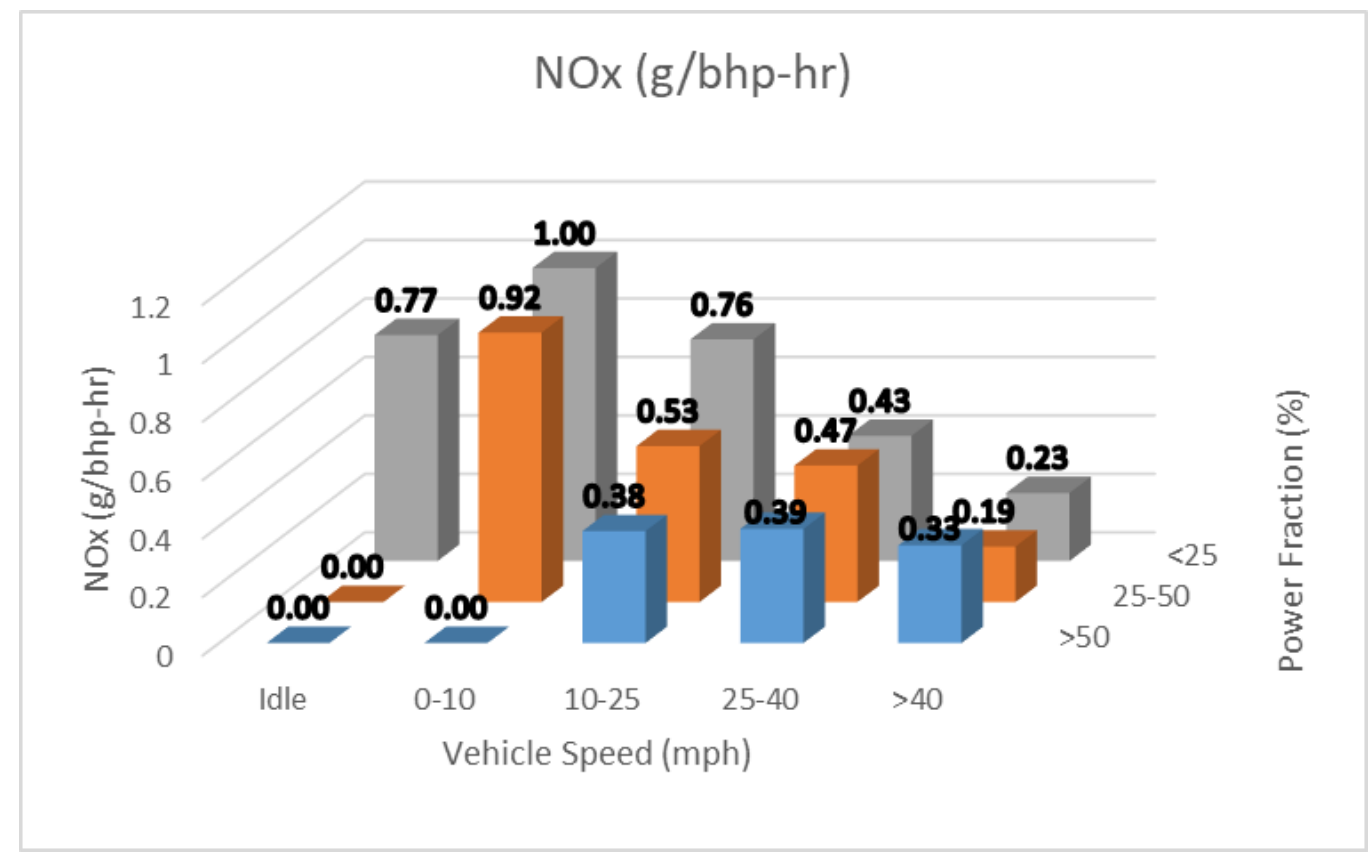

Figure 36 - Stable Reduction Method NOx Data (g/bhp-hr) Bin - Daily

The data replaced with NaNs account for $3.11 \%$ of the sensor's operation, only slightly less than the monthly operation. Compared to the previous sets, in this one the bsNOx had the largest difference between the original values and reduced values that went through the Stable NOx method. Several of the bins were greatly reduced, but none of the bins reached NOx regulation value. This is most likely due to the amount of data available for this time segment, making it more susceptible to cold start effects. The dataset probably had more transient values than the previous datasets analyzed. 


\subsubsection{EWMA}

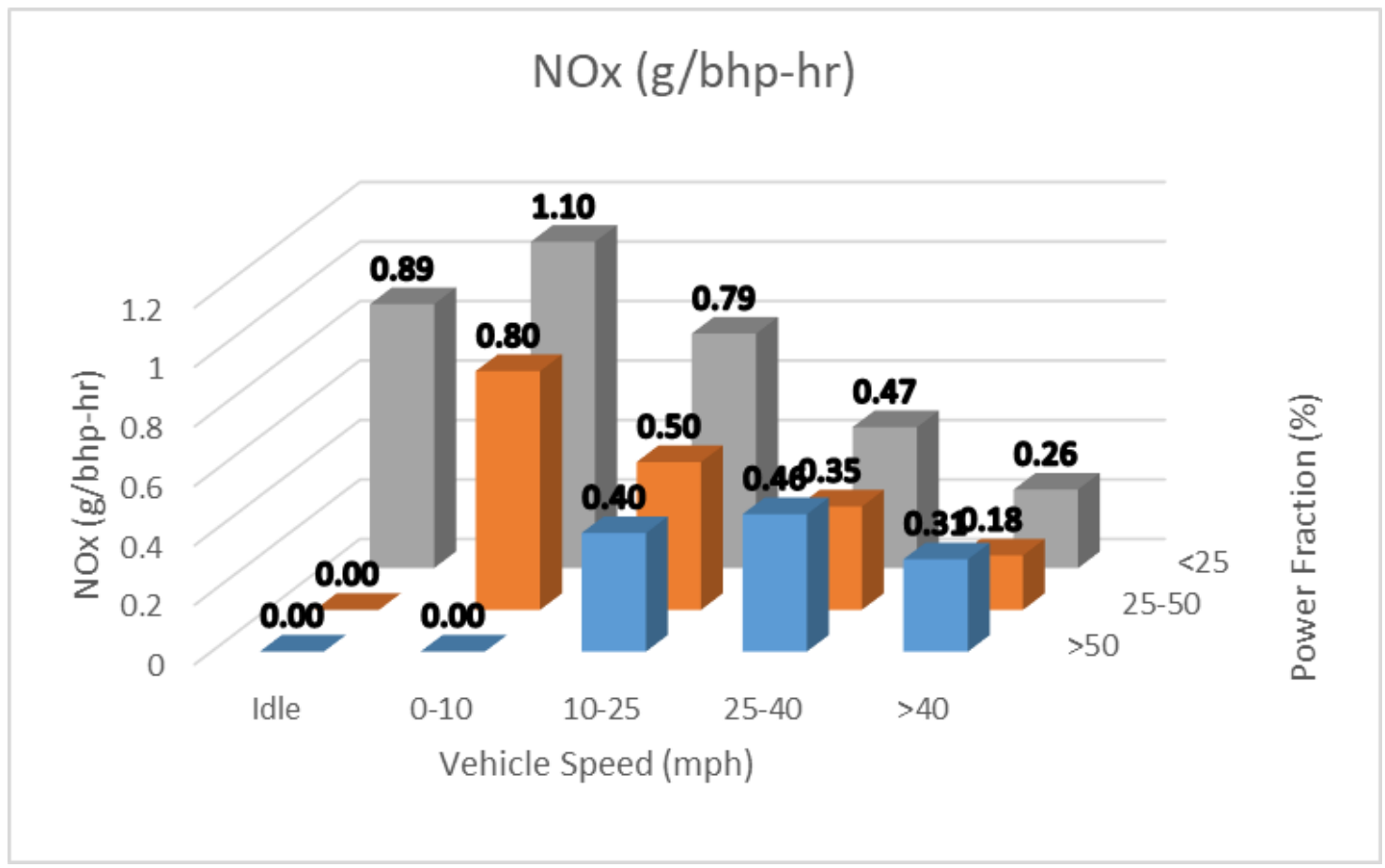

Figure 37 - EWMA Method (EWF=0.1) NOx Data (g/bhp-hr) Bin - Daily

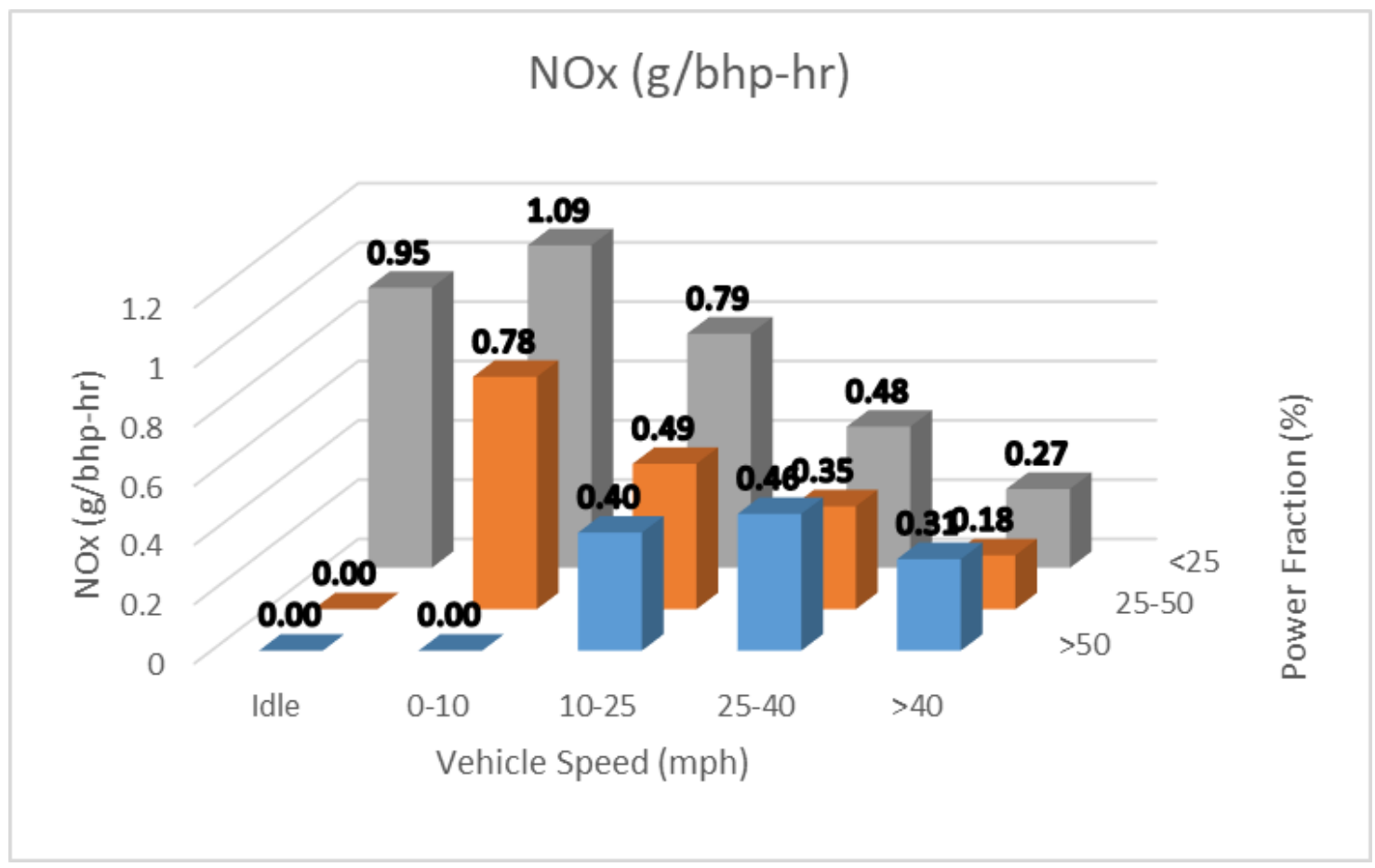

Figure 38 - EWMA Method (EWF=0.25) NOx Data (g/bhp-hr) Bin - Daily 


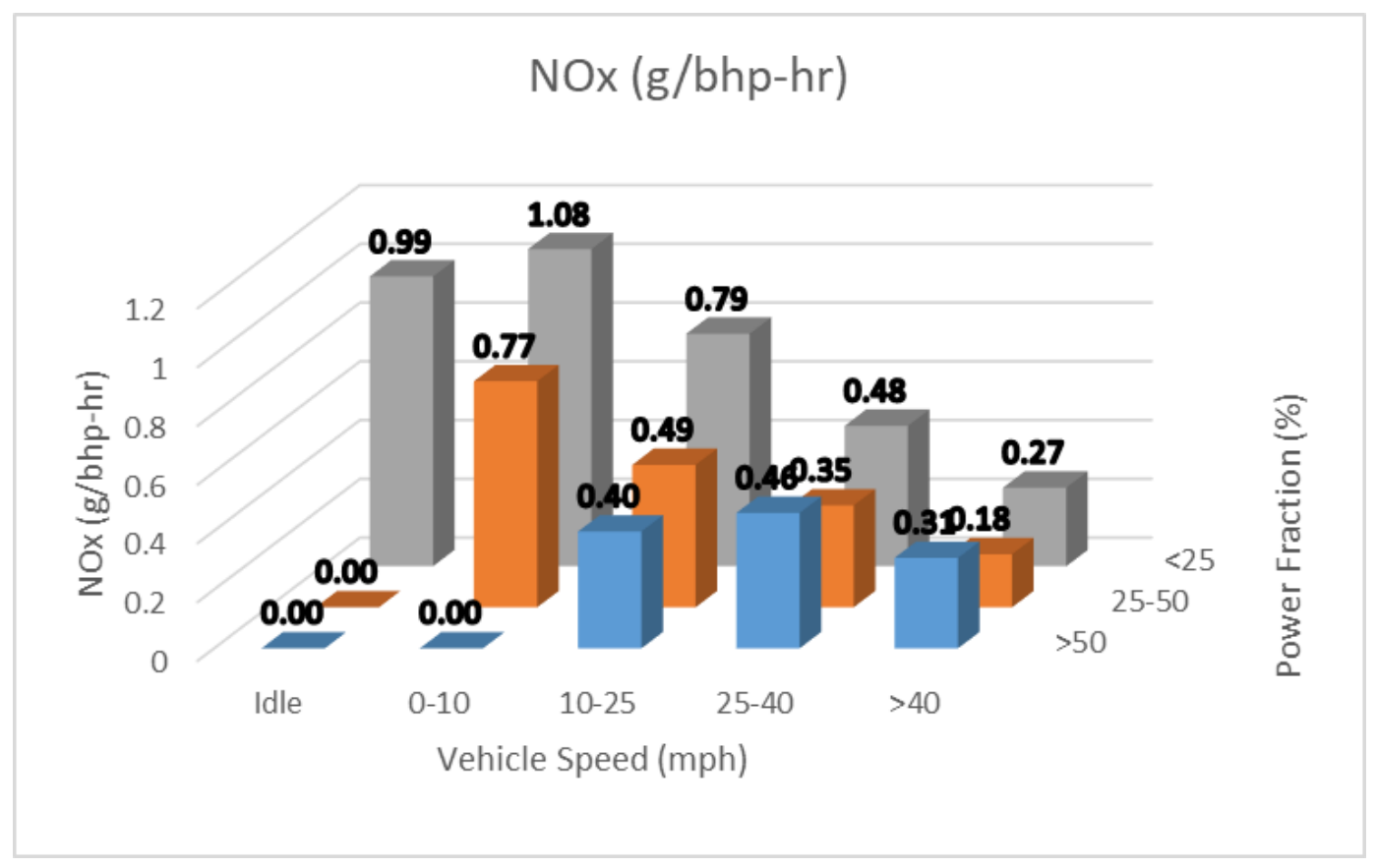

Figure 39 - EWMA Method (EWF=0.35) NOx Data (g/bhp-hr) Bin - Daily

The daily dataset follows the same trend for the EWF as the previous timeframes. The reduction didn't affect the data enough to cause the points to become compliant or to increase enough to the point in which it exceeds regulation.

\subsection{Limitations}

From the results described above, the binning method displays certain limitations. For instance, regardless of the time frame selected for analysis the method does indicate a certain type of vehicle vocation. From the binned set one could say that this vehicle does mostly long transit operation. This indicates that this is most likely not a stop and go driving cycle vehicle. However, the data doesn't indicate anything more specific about its vocation. Only that the majority of its operation happen at $>25 \mathrm{mph}$ bins. In addition, during cold start periods the sensor doesn't record data. This indicates that the NCPT method may not be the most representative method for vehicles that have mostly stop and go driving operation. 


\section{Conclusions and Recommendations}

\subsection{Conclusion}

When implementing the NTE in this project not all the boundary conditions for the control zone were included. This means that several of the points that did fall inside of the zone may be removed once all the restrictions are applied. In addition, the protocol for NTE control zone requires the points to be continuously compliant with the boundary conditions for a period of 30 seconds. Both of these considerations most likely will reduce the number of points in the NTE zone, which more than likely will affect the emission in those bins. In addition, by only using the load parameters in the NTE zone the majority of the data was already excluded from the zone. This is due to the $30 \%$ peak torque and rated power restriction. Most of this engine's operation fell inside the $<25 \%$ power fraction bins. Therefore, the binning method without the NTE zone restrictions provide a much better insight of the engine's operation.

Another option would be to reduce the number of bins by removing the power fraction parameter and only use vehicle speed activity for binning - broken into urban, regional, and highway. However, this could cause an unbalanced shift in the emission's profile. For urban activity the high emission in the lower power fraction bins would be distributed across the bins where it displays much lower emissions. In the other hand, for the highway bins the data wouldn't have such an impactful outcome compared to keeping it into separate bins. This is because the values in those bins are much closer than the bins in the urban activity. As for the idle bins, the only bin that is populated is the $<25 \%$ rated power bin. These bins' differences become more apparent when the data is reduced to a shorter time period, such as the daily data analysis. In those cases the data in the bins differ from each other to their respective vehicle activity range. This indicates that if all bins in the idle section were combined the value would be representative of the idle operation emissions where not the same can be said for the urban operation. The bins schematics could be potentially reduced in certain sections but not all without changing the data distribution. In addition, the NCPT binning method shows the most suitable representation for all vehicle's vocation. In cases in which a vehicle displays stop and go operation, the NOx data would become more transient and therefore more unstable. Due to cold start sensor limitation, in these cases the binning wouldn't best represent the vehicles emission profile. 
Regarding the data reduction method, the results show that by modifying the raw dataset the bsNOx bins do display changes. This indicates a need to properly reduce the data in order to remove the points in which there's noise. When studying emissions one should expect positive values under 1000 ppm [43] and low non-negative concentration values. This is because when the true concentration is near zero the sensor may display negative values. However, the results in this study display several values above $1000 \mathrm{ppm}$ as well as several values in the negative zone $(<-$ $100 \mathrm{ppm})$. These values if not addressed can affect the emission results and considering how low the regulation is for bsNOx $(0.2 \mathrm{~g} / \mathrm{bhp}-\mathrm{hr})$ the difference in the values could be extremely impactful. The NOx stable reduction did method removed all the points that exceeded reasonable expectation. However, replacing them with interpolated value may not be the most representative option. Meanwhile, the EWMA method provides the option to smooth the original data without the removal of any data points. The key issue with this method is selecting the best EWF. All the reducing methods analyzed only affected the data significantly at locations were the emissions exceed the regulation by more than double. Therefore, when binning the data, even for a short duration, the reduction method does not impact the overall engine's emission significantly if it's to be compared to the emissions regulations.

\subsection{Recommendations}

With the development of better EATS technology and more strict regulations there's a need to find a way to ensure that these engines are following regulations. In addition, the current methods to analyze the engine operation are outdated and are not representative of the current vehicles' driving cycles. Therefore, a further analysis of this method should be performed. Some of the recommendations for the future projects related to this topic include:

1. Perform NTE calculations including all the boundary parameters as well as increase the time averaging to 30 seconds increment.

2. Perform the NTE NOx emissions calculations for the points that do fall inside the control zone.

3. Investigate the possibility of changing the NTE boundaries, such as reducing minimum torque/power or minimum NTE event duration, in order to decrease the amount of excluded data. 
4. Study how the noise and error from other parameters, such as the exhaust flow, affect the bsNOx emission.

5. Investigate the impact of the duration of the windows $(\Delta t)$ on the emission's profile and NTE.

6. Investigate data by comparing the onboard sensors to PEMS when applying the NOx control approach.

7. Further analyze more possibilities of combing certain bin categories.

8. Study other possible parameters that could assist the analysis of the engine's operation, such as fuel consumption. 


\section{References}

[1] J. B. Heywood, Internal Combustion Engine Fundamentals, New York: McGrawHill, 1988.

[2] U.S. Department of Tranportation, "2017 Pocket Guide to Large Truck and Bus Statistics," $\quad$ June $2017 . \quad$ Anline]. Available: https://www.fmcsa.dot.gov/sites/fmcsa.dot.gov/files/docs/safety/data-andstatistics/81121/2017-pocket-guide-large-truck-and-bus-statistics-final-508c-0001.pdf. [Accessed 21 January 2019].

[3] B. Demirgok, Development of an Emissions Monitoring Methodology Using OnBoard NOx Sensors and Revision to Current In-Use Emissions Regulatory Protocols, Morgantown: WVU, 2018.

[4] R. P. Pondicherry, Effects of boundary parameters on the Work-Based Window $(W B W)$ and Not-to-Exceed (NTE) in-use emissions quantification methods, Morgantown: West Virginia, 2017.

[5] CARB, "CARB gets "REAL" to further cut pollution from diesel and gas vehicles," CARB, 15 November 2018. [Online]. Available: https://ww2.arb.ca.gov/news/carb-getsreal-further-cut-pollution-diesel-and-gas-vehicles. [Accessed 22 April 2019].

[6] History.com, "Automobile History," A\&E Televiosion Networks, 21 August 2018. [Online]. Available: https://www.history.com/topics/inventions/automobiles. [Accessed 28 January 2019].

[7] R. Dundon, "Photos: L.A.'s mid-century smog was so bad, people thought it was a gas attack," TIMELINE, 23 May 2018. [Online]. Available: https://timeline.com/lasmog-pollution-4ca4bc0cc95d. [Accessed 29 January 2019].

[8] EPA, "Evolution of the Clean Air Act," United States Environmental Protection Agency, [Online]. Available: https://www.epa.gov/clean-air-act-overview/evolutionclean-air-act. [Accessed 29 January 2019].

[9] "The Air Quality Act of 1967," Journal of the Air Pollution Control, vol. 18, no. 2, pp. 62-71, 1968.

[10] California Air Resources Board, "California Air Resources Board," California Air Resources Board, 11 May 2018. [Online]. Available: https://www.arb.ca.gov/msprog/hdlownox/hdlownox.htm. [Accessed 12 December 2018].

[11] V. Akkerman, Fundamentals of Combustion, Morgantown: West Virginia University, 2018.

[12] EPA, "Technical Bulletin: Nitrogen Oxides (NOx), Why and How They are Controlled," November 1999. [Online]. Available: Technical Bulletin: Nitrogen Oxides (NOx), Why and How They are Controlled. [Accessed 22 January 2019].

[13] EPA, "Control of Air Pollution From Heavy-Duty Engines," Code of Federal Regulations, vol. 60, no. 169, pp. 45580-45604, 1995. 
[14] U.S EPA, "Nitrogen Dioxide (NO2) Pollution," U.S EPA, 13 October 2017. [Online]. Available: https://www.epa.gov/no2-pollution/basic-information-aboutno2\#What\%20is\%20NO2. [Accessed 18 April 2019].

[15] M. K. Khair and H. Jääskeläinen, "Emission Formation in Diesel Engines," 2015.

[16] Diesel Technology Forum, "Diesel Technology Forum," [Online]. Available: https://www.dieselforum.org/about-clean-diesel/what-is-scr\#. [Accessed 12 December $2018]$.

[17] H. Kannisto, "Volvo Penta," Volvo, November 2017. [Online]. Available: http://nordicblog.volvopenta.com/exhaust-aftertreatment-system-cleaning-processexhausts/. [Accessed 12 December 2018].

[18] DieselNet, "NTE (Not-To-Exceed) Testing," DieselNet, October 2016. [Online]. Available: https://www.dieselnet.com/standards/cycles/nte.php. [Accessed 1 April 2019].

[19] A. Thiruvengadam, Heavy-Duty Vehicle Emissions Exhaust Aftertreatment System and Emissions, Morgantown: West Virginia University, 2018.

[20] CAMBUSTION, "CLD Principles," CAMBUSTION, [Online]. Available: https://www.cambustion.com/products/cld500/cld-principles. [Accessed 22 March 2019].

[21] M. Gautam, W. C. Riddle, G. J. Thompson, D. K. Carder, N. N. Clark, D. W. Lyons and C. Lyond, Measurement of Brake-Specific NOx Emissions using Zirconia Sensors for In-Use, On-Board Heavy-Duty Vehicle Applications, Nevada: SAE International, 2002.

[22] MEMBRAPOR, "Electrochemical Gas Sensors," MEMBRAPOR, 2019. [Online]. Available: http://www.membrapor.ch/electrochemical-gas-sensors/. [Accessed 25 March 2019].

[23] P. J. Popp, G. A. Bishop and D. H. Stedman, "Development of a High-Speed Ultraviolet Spectrometer for Remote Sensing of Mobile Source Notric Oxide Emissions," Journal of the Air \& Waste Management Association, vol. 49, no. 12, pp. 1463-1468, 2011.

[24] J.-L. Tirpitz, D. Pöhler, N. Bobrowski, B. Christenson, J. Rüdiger, S. Schmitt and U. Platt, "Non-dispersive UV Absorption Spectroscopy: A Promising New Approach for insitu Detection of Sulfur Dioxide," Frontiers in Earth Science, 13 March 2019. [Online]. Available: $\quad$ https://www.frontiersin.org/articles/10.3389/feart.2019.00026/full. [Accessed 20 April 2019].

[25] J. Tu, "Portable Emission Measurement System (PEMS)," [Online]. Available: https://www.cert.ucr.edu/events/pems2011/13_Jesse\%20Tu.pdf. [Accessed 13 March 2019].

[26] W. J. Miller, T. Durbin, K. Johnson and D. Cocker, "Evaluation of Portable Emissions Measurement Sustems (PEMS) for Inventory Purposes and the Not-ToExceed Heavy-Duty Diesel Engine Regulation," University of California, Sacramento, 2006. 
[27] S. Carstens and W. A. Majewski, "NOx Sensors," DieselNet, October 2018. [Online]. Available: https://www.dieselnet.com/tech/sensors_nox.php. [Accessed 31 January 2019].

[28] A. Thiruvengadam, S. Pradhan, B. Demirgok, M. Besch, P. Thiruvengadam and D. Carder, Evaluation of In-Use Emissions Using On-Board NOx Sensors on Heavy-Duty Diesel Trucks, Long Beach: WVU, 2017.

[29] A. Thiruvengadam, M. Besch, B. Demirgok and D. Carder, Heavy-Duty OBD: Evaluation of NOx Control Performance Tracking Parameter, Garden Grove: West Virginia University, 2018.

[30] A. Frobert, S. Raux, C. Yann and E. Jeudy, About Cross-Sensitivities of NOx Sensors in SCR Operation, SAE International, 2013.

[31] EPA, On-Board Diagnostic (OBD) Regulations and Requirements: Questions and Answers, U.S. Environmental Protection Agency, 2003.

[32] CARB, California Code of Regulations Title 13 Section 1971.1, Sacramento: CARB, 2016.

[33] Code of Federal Regulations, "40 CFR 86.1806-17," 28 April 2014. [Online]. Available: https://www.law.cornell.edu/cfr/text/40/86.1806-17. [Accessed 12 March 2019].

[34] B. Shade, D. Carder, G. Thompson and M. Gautam, A Work-Based Window Method for Calculating In-Use Brake-Specific NOx Emissions of Heavy-Duty Diesel Engines, Morgantown: SAE International, 2008.

[35] California Air Resources Board, "Heavy-Duty Low NOx Program Workshop," 23 January 2019. [Online]. Available: file:///C:/Users/recastiglionialveste/Desktop/03HDIUT_WS01232019.pdf. [Accessed 15 April 2019].

[36] H. Lohninger, "Fundamentals of Statistics," Epina, 0810 2012. [Online]. Available: http://www.statistics4u.com/fundstat_eng/cc_moving_average.html. [Accessed 10 April 2019].

[37] J. Ellis, Heavy Duty OBD Program Update, SAE International, 2017.

[38] A. Milton, "Simple, Exponential, and Weighted Moving Averages," the balance, 31 December 2018. [Online]. Available: https://www.thebalance.com/simple-exponentialand-weighted-moving-averages-1031196. [Accessed 5 February 2019].

[39] L. Smith, "Exponentially Weighted Moving Average," COMPOSE, 8 March 2017. [Online]. Available: https://www.compose.com/articles/metrics-maven-calculating-anexponentially-weighted-moving-average-in-postgresql/. [Accessed 2019 February 2019].

[40] Breaking Down Finance, "Exponentially Wrighted Moving Average," Breaking Down Finance, [Online]. Available: https://breakingdownfinance.com/tradingstrategies/technical-analysis/exponentially-weighted-moving-average/. [Accessed 21 March 2019].

[41] Emission Compliance, Automotive Regulations, "Workshop for 2018 HD OBD Regulations Update," California Air Resources Board, El Monte, 2017. 
[42] AnswerMiner, "Histogram - The Ultimate Guide of Binning," AnswerMiner, 1 August 2017. [Online]. Available: https://www.answerminer.com/blog/binning-guideideal-histogram. [Accessed 12 December 2018].

[43] DieselNet, "Gaseous Emissions," Ecopoint Inc., January 2018. [Online]. Available: https://www.dieselnet.com/tech/emi_gas.php. [Accessed 2 February 2019].

[44] A. Thiruvengadam, Heavy-Duty Vehicle Emissions Engine Technology and Emissions, Morgantown: West Virginia University, 2018.

[45] T. Montes, Heavy Duty OBD Program Update, Barcelona: SAE International, 2018.

[46] Figaro, "Electrochemical-type Operating System," Figaro USA Inc., 2018. [Online]. Available: https://www.figaro.co.jp/en/technicalinfo/principle/electrochemicaltype.html. [Accessed 11 March 2019].

[47] EPA, "Heavy-Duty Highway Compression-Ignition Engines and Urban Buses: Exhaust Emissions Standards," EPA, March 2016. [Online]. Available: https://nepis.epa.gov/Exe/ZyPDF.cgi?Dockey=P100O9ZZ.pdf. [Accessed 10 February 2019]. 


\section{Appendix A: Bin Plots for Week Dataset}

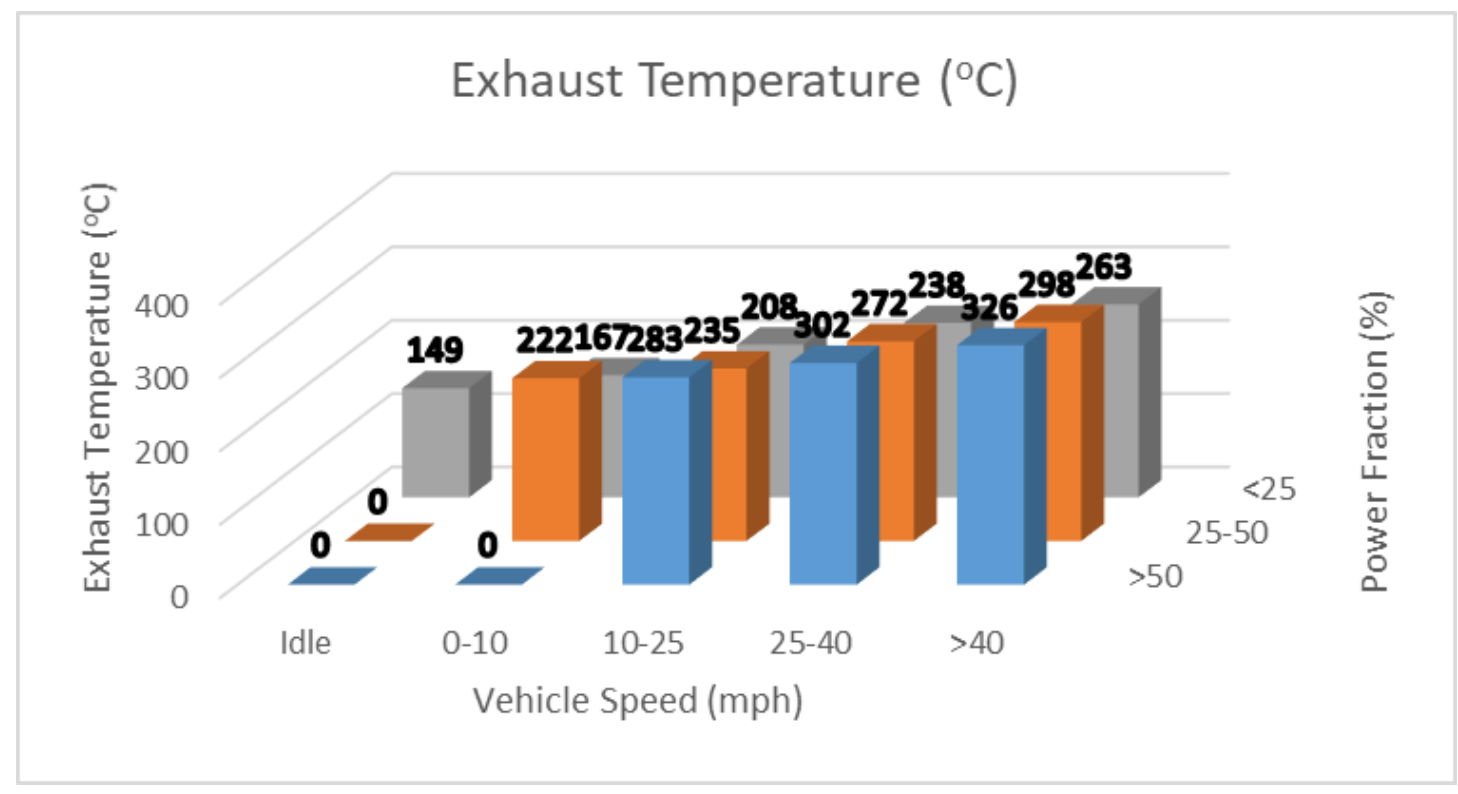

Figure 40 - Original Data Post-SCR Exhaust Temperature $\left({ }^{\circ} \mathrm{C}\right)$ Bin - Weekly

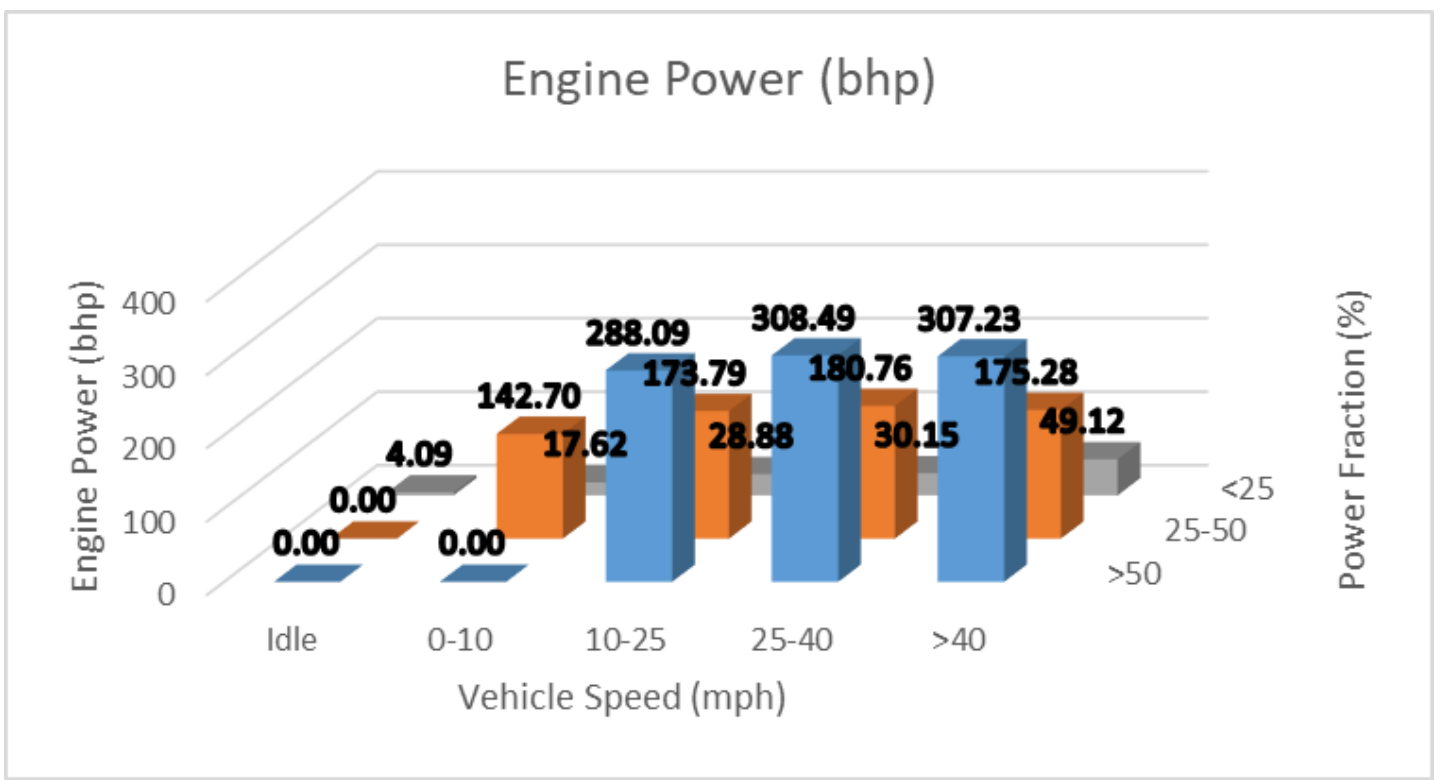

Figure 41 - Original Data Power (bhp) Bin - Weekly 


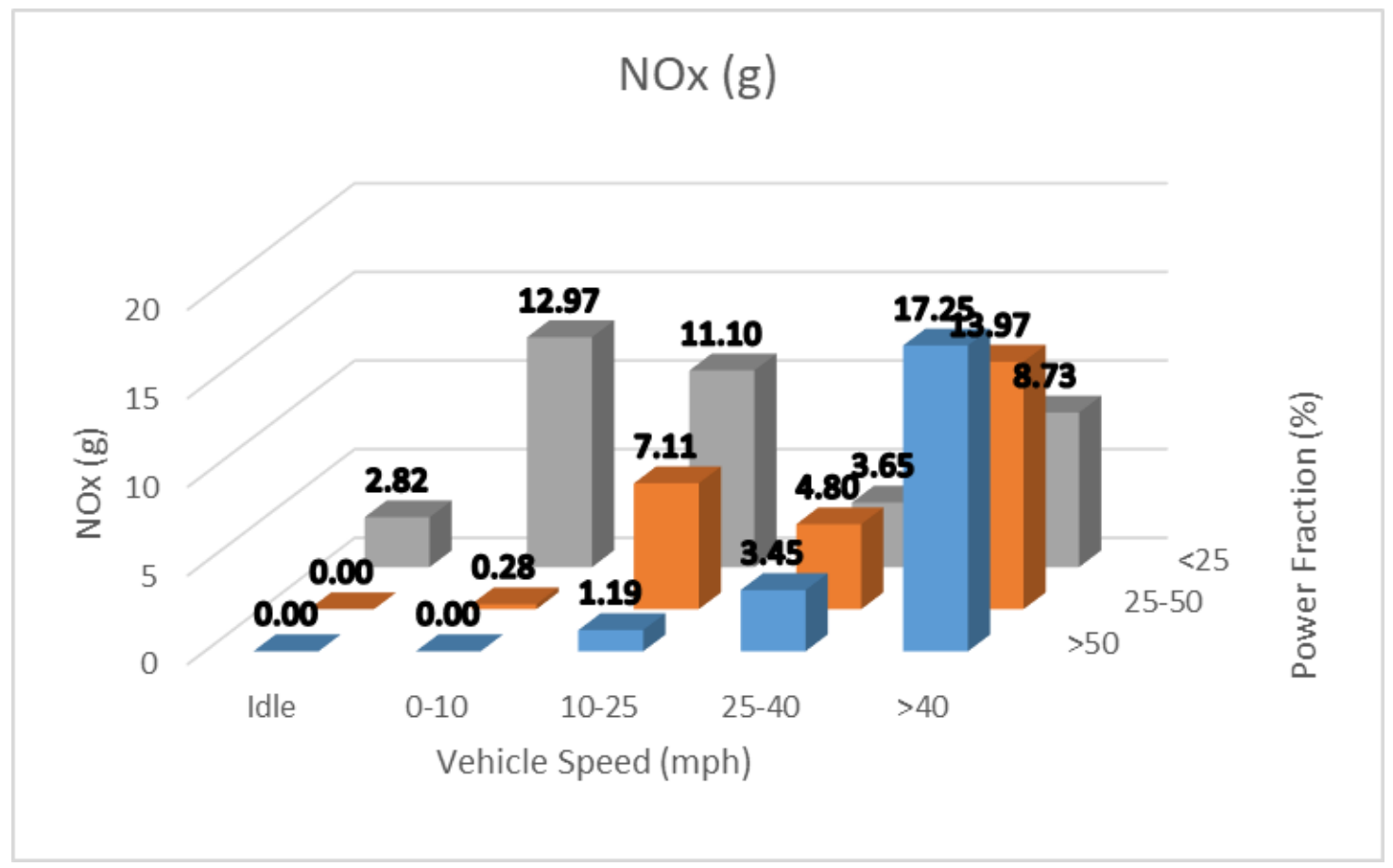

Figure 43 - Original Data NOx (g) Bin - Weekly

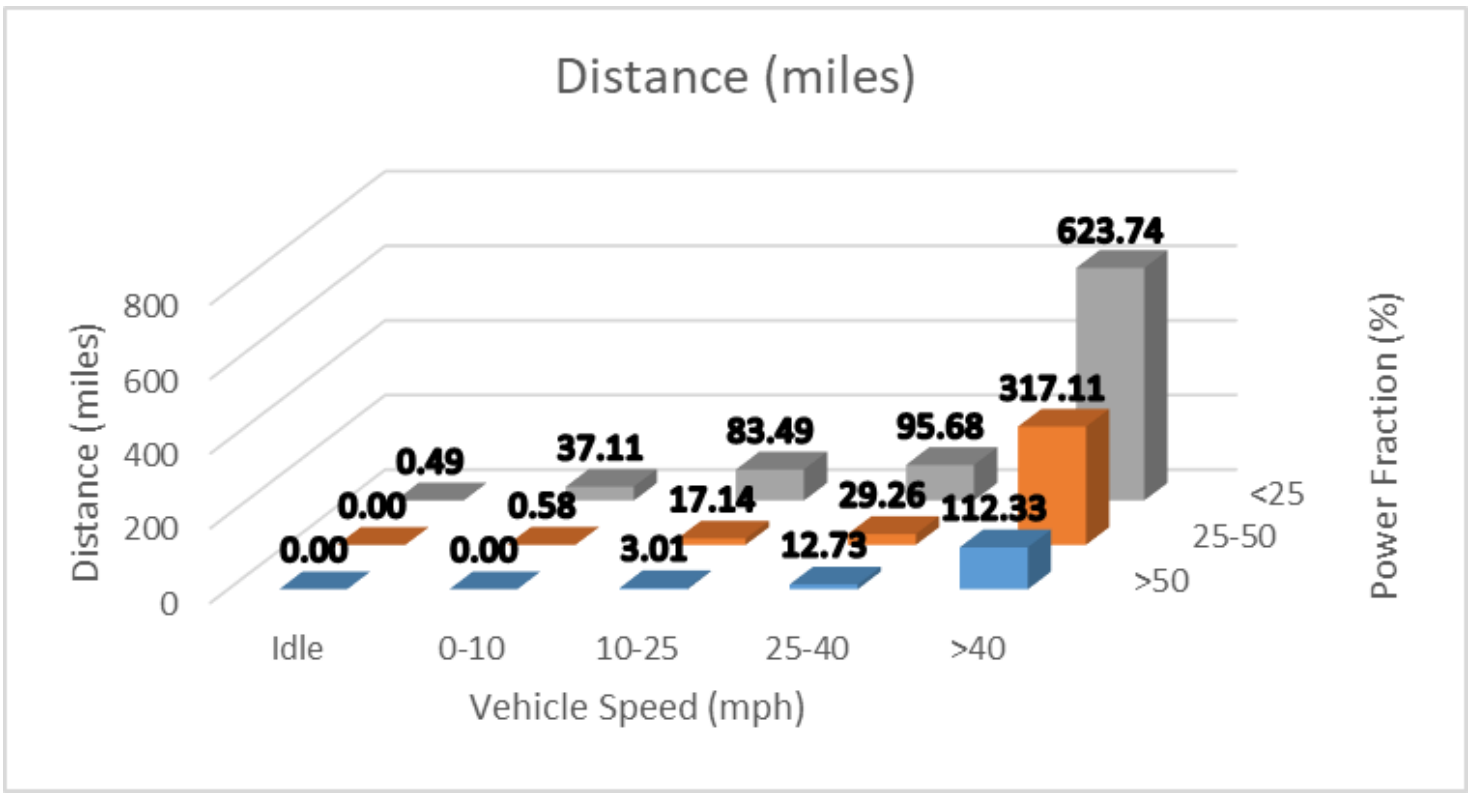

Figure 42 - Original Data Distance (miles) Bin - Weekly 


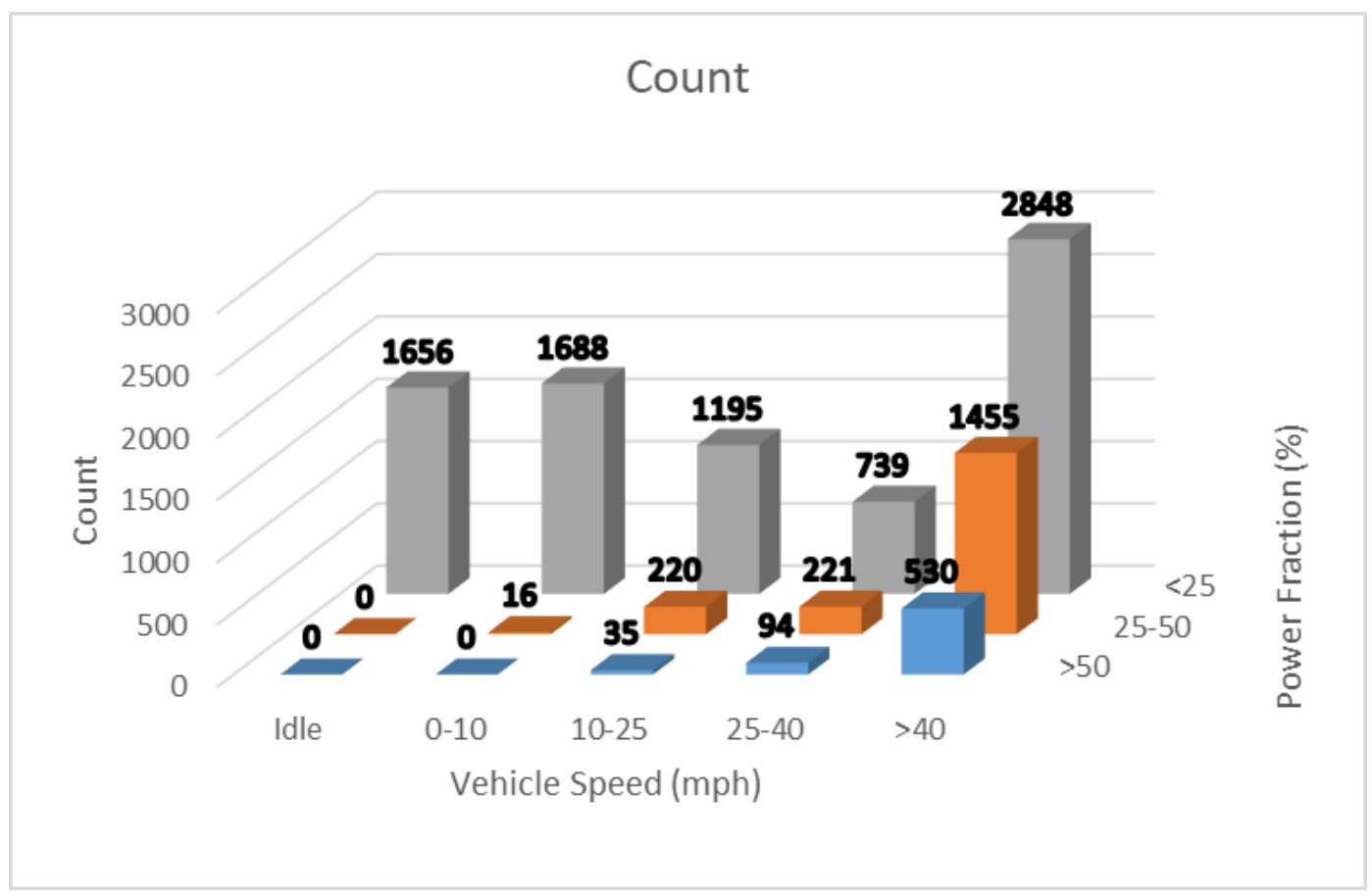

Figure 44 - Original Data Bin Count - Weekly 


\section{Appendix B: Bin Plots for Daily Dataset}

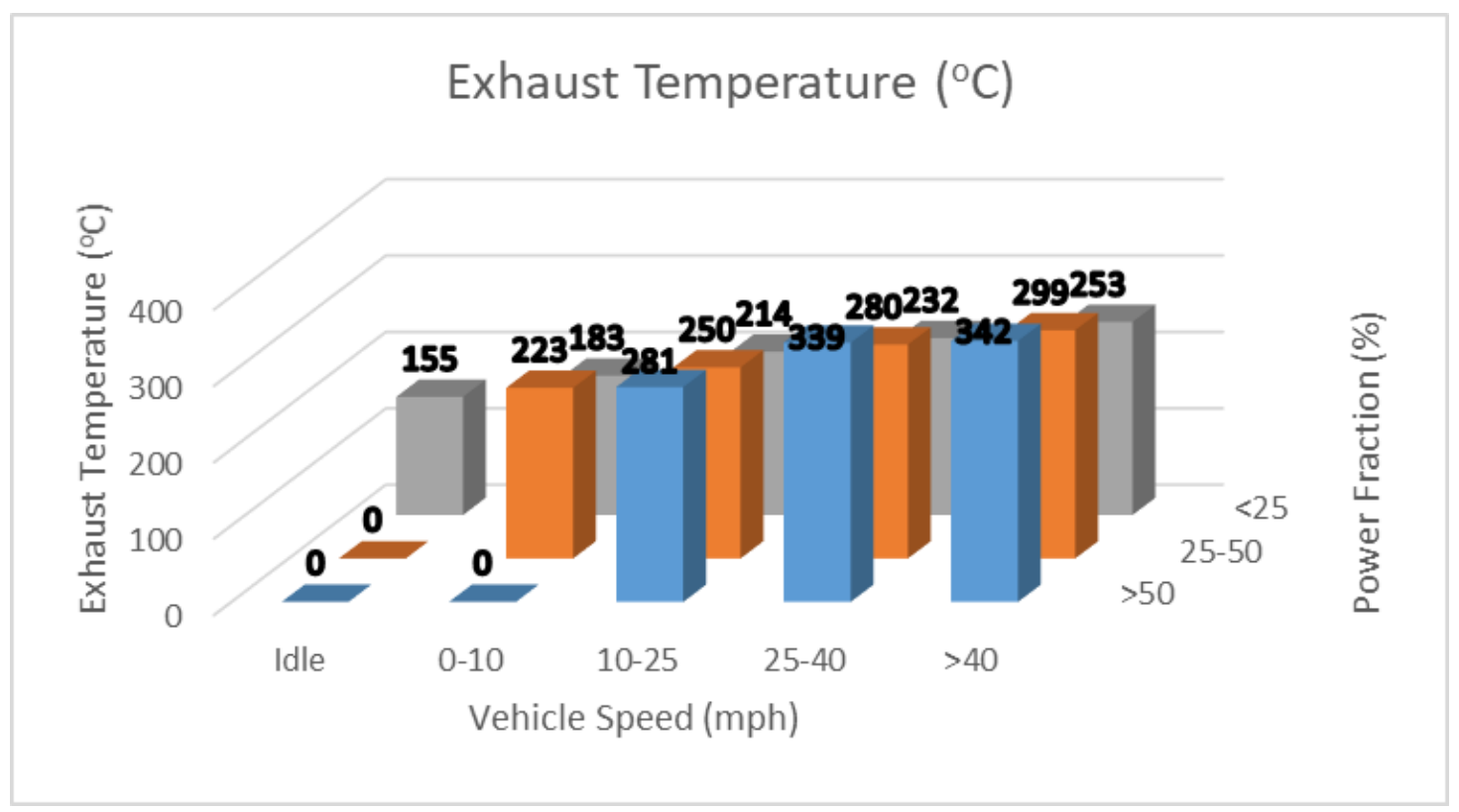

Figure 45 - Original Data Post-SCR Exhaust Temperature $\left({ }^{\circ} \mathrm{C}\right)$ Bin - Daily

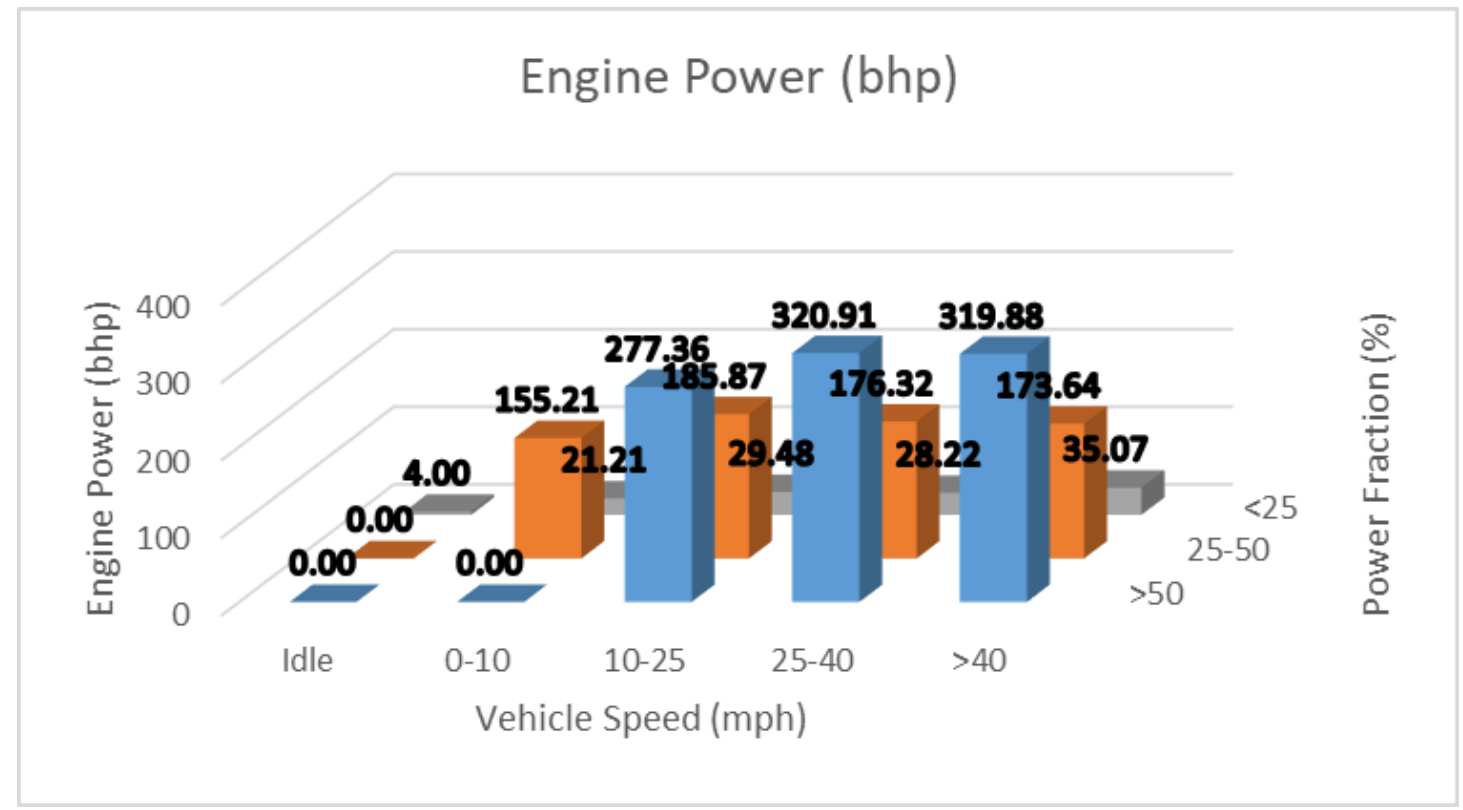

Figure 46 - Original Data Power (bhp) Bin - Daily 


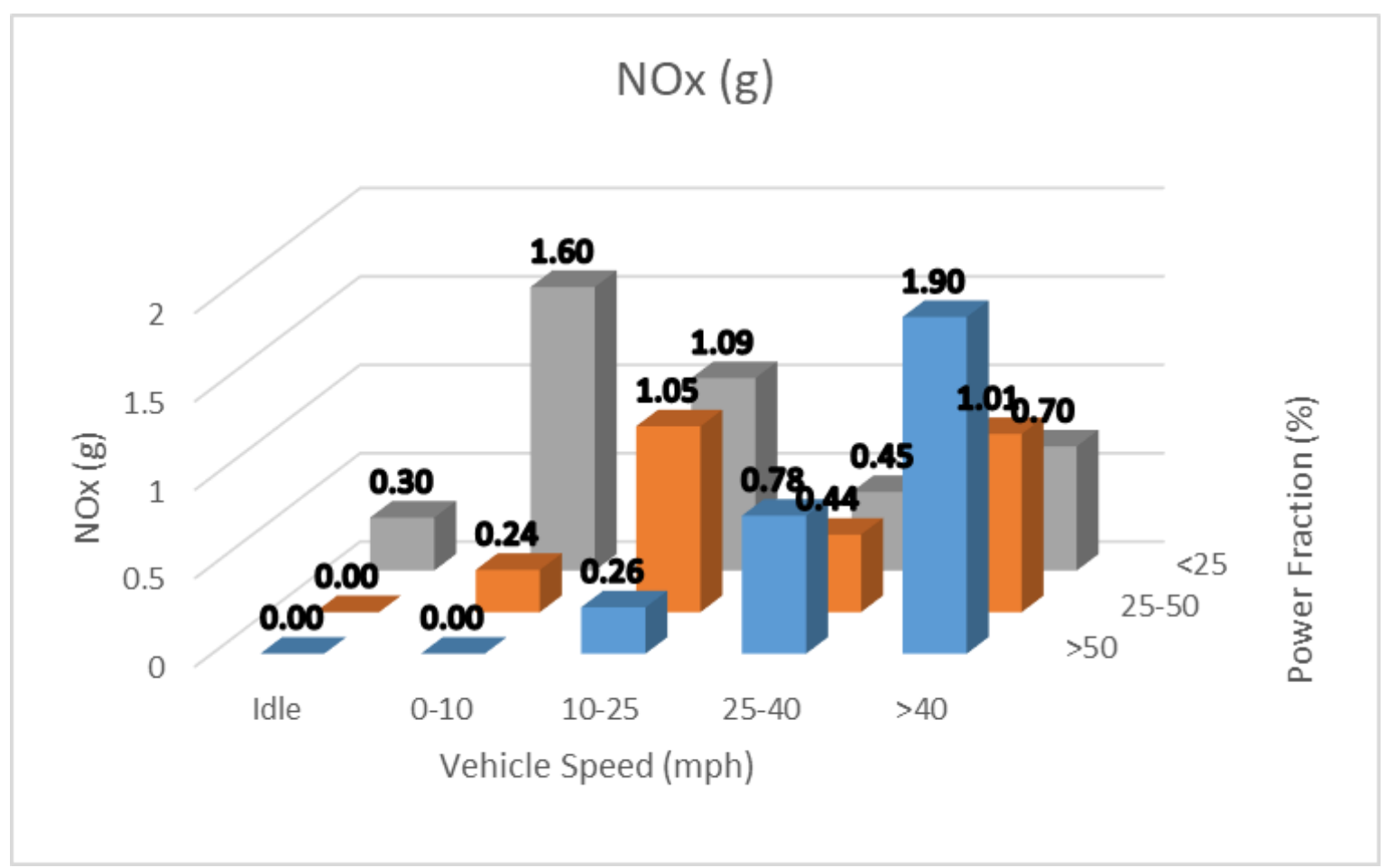

Figure 47 - Original Data NOx (g) Bin - Daily

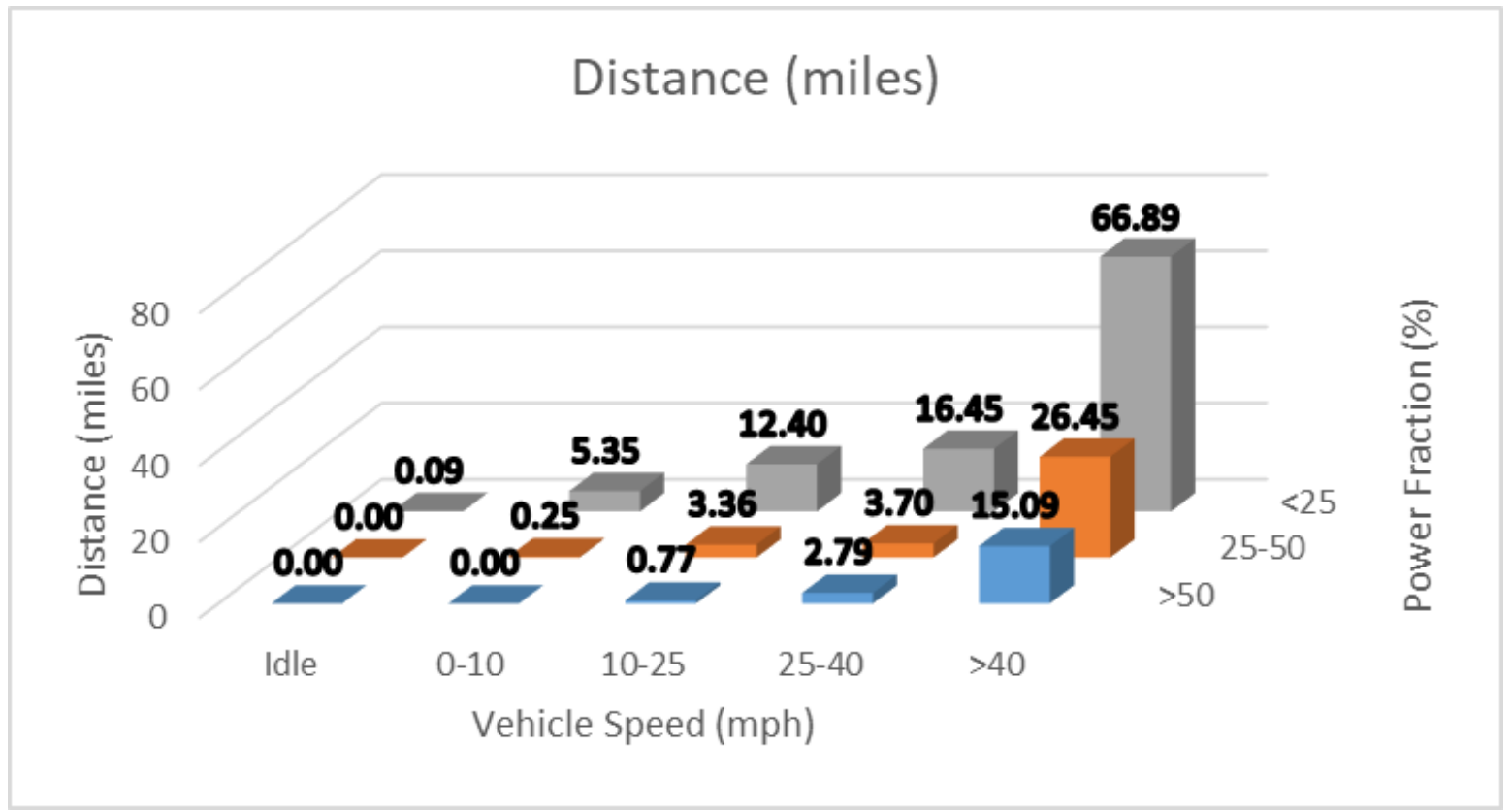

Figure 48 - Original Data Distance (miles) Bin - Daily 


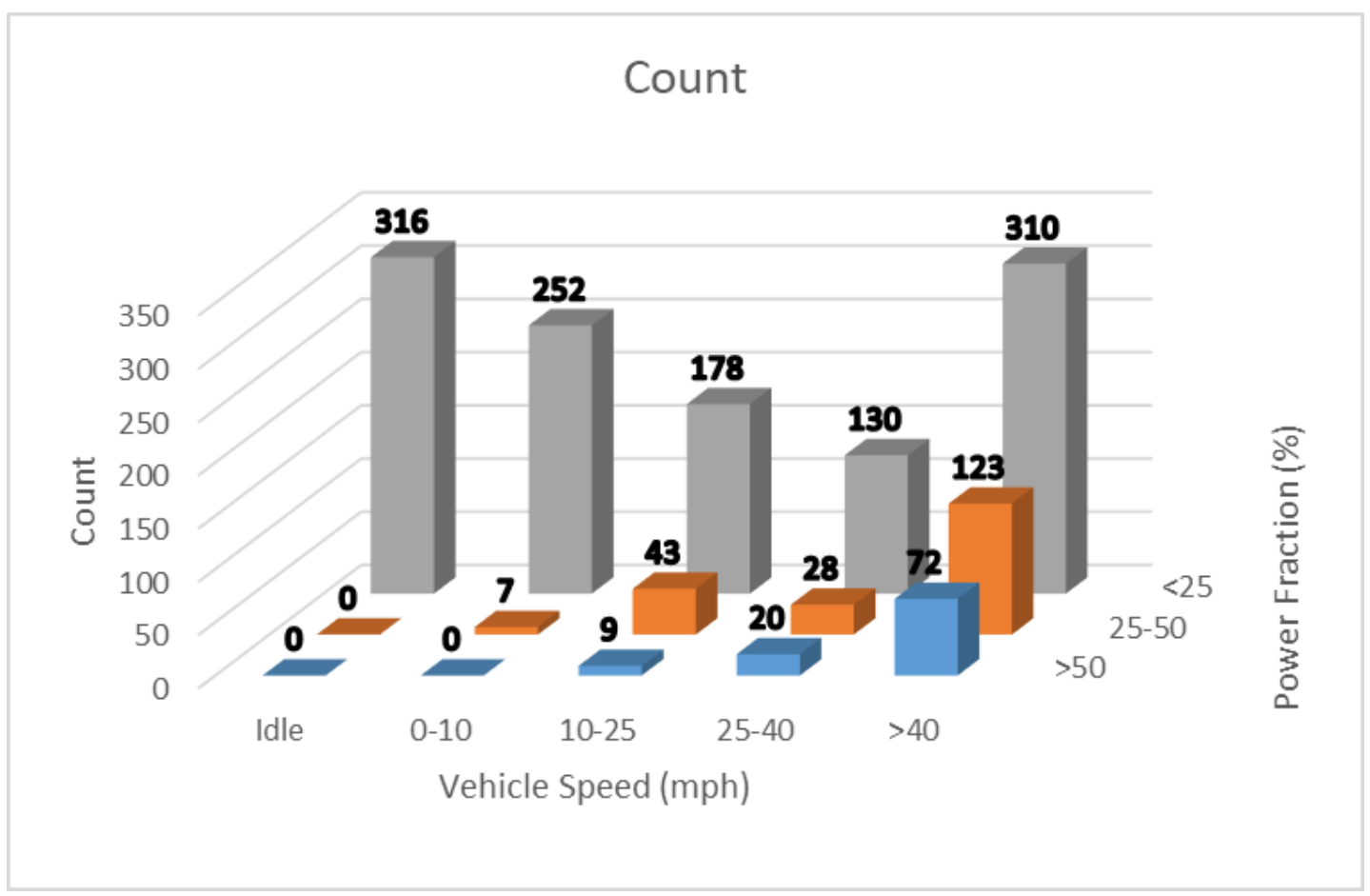

Figure 49 - Original Data Bin Count - Daily 